NBER WORKING PAPER SERIES

\title{
HOUSEHOLD RISK MANAGEMENT
}

\author{
Adriano A. Rampini \\ S. Viswanathan \\ Working Paper 22293 \\ http://www.nber.org/papers/w22293 \\ NATIONAL BUREAU OF ECONOMIC RESEARCH \\ 1050 Massachusetts Avenue \\ Cambridge, MA 02138 \\ May 2016, Revised May 2017
}

We thank Ing-Haw Cheng (WFA discussant), João Cocco (NBER discussant), Mariacristina De Nardi (NBER discussant), Emmanuel Farhi, Nobu Kiyotaki, David Laibson, David MartinezMiera (CEPR discussant), Alex Michaelides, Martin Oehmke (AFA discussant), Tomek Piskorski (AEA discussant), Alp Simsek (Wash U discussant), Jeremy Stein, Roberto Steri (FIRS discussant), George Zanjani, and seminar participants at the AEA Annual Meeting, Duke, the NBER-Oxford Sa d-CFS-EIEF Conference on Household Finance, the HBS Finance Unit Research Retreat, the Asian Meeting of the Econometric Society, MIT, UC Berkeley, Harvard, USC, the WFA Annual Conference, the SED Annual Meeting, the Bank of Canada and Queen's University Workshop on Real-Financial Linkages, Cheung Kong GSB, Cornell, DePaul, Princeton, BYU, Carnegie Mellon, Indiana, Wharton, Chicago, Amsterdam, UCL, Imperial College, Warwick, the CEPR European Summer Symposium in Financial Markets, the Washington University Conference on Corporate Finance, the AFA Annual Meeting, Houston, Minnesota, Illinois, Virginia, the Conference in Honor of Robert M. Townsend, the FIRS Conference, and the NBER SI on Capital Markets and the Economy for helpful comments. Part of this paper was written while the first author was visiting the finance area at the Stanford Graduate School of Business and the economics department at Harvard University and their hospitality is gratefully acknowledged. The views expressed herein are those of the authors and do not necessarily reflect the views of the National Bureau of Economic Research.

NBER working papers are circulated for discussion and comment purposes. They have not been peer-reviewed or been subject to the review by the NBER Board of Directors that accompanies official NBER publications.

(C) 2016 by Adriano A. Rampini and S. Viswanathan. All rights reserved. Short sections of text, not to exceed two paragraphs, may be quoted without explicit permission provided that full credit, including $\odot$ notice, is given to the source. 
Household Risk Management

Adriano A. Rampini and S. Viswanathan

NBER Working Paper No. 22293

May 2016, Revised May 2017

JEL No. D14,D91,E21,G22,I13

\section{$\underline{\text { ABSTRACT }}$}

Households' insurance against shocks to income and asset values (that is, household risk management) is limited, especially for poor households. We argue that a trade-off between intertemporal financing needs and insurance across states explains this basic insurance pattern. In a model with limited enforcement, we show that household risk management is increasing in household net worth and income, incomplete, and precautionary. These results hold in economies with income risk, durable goods and collateral constraints, and durable goods price risk, under quite general conditions and, remarkably, risk aversion is sufficient and prudence is not required. In equilibrium, collateral scarcity lowers the interest rate, reduces insurance, and increases inequality.

\section{Adriano A. Rampini}

Duke University

Fuqua School of Business

100 Fuqua Drive

Durham, NC 27708

and NBER

rampini@duke.edu

S. Viswanathan

Duke University

Fuqua School of Business

100 Fuqua Drive

Durham, NC 27708

and NBER

viswanat@duke.edu 


\section{Introduction}

In economics, insurance is typically thought of as trade across states. With limited enforcement, however, trade across states is linked to intertemporal trade. Indeed, in such an environment insurance may be better viewed as state-contingent savings as insurance premia need to be paid in advance. Since insurance is state-contingent saving, savings and insurance are intimately connected. Households with limited funds may not want to save and hence may choose to insure less or not at all. We argue that this trade-off between insurance and financing is a key factor explaining the absence of household risk management for poor households and the basic relation between insurance and household income or net worth.

We provide a standard neoclassical model in which households' ability to promise to pay is subject to limited enforcement. In our benchmark model there is no collateral and limited enforcement implies that households have access to complete markets for state-contingent claims subject to short-sale constraints. We first show that optimal household risk management of risk averse households whose income (net of expenditures for health and other non-discretionary spending needs) follows a stationary Markov chain with positive persistence is increasing in household net worth and income, and incomplete, even in the long run, that is, under the stationary distribution of household net worth. Thus, the limited ability to pledge restricts and links financing and risk management. Given this link, households limit their risk management and may completely abstain from insurance when their current funds are sufficiently low.

We extend these results to an economy with durable goods that the households can borrow against, and show that the increasing risk management result generalizes. In practice, beyond consumption needs, households' primary financing needs are two: purchases of durable goods and the accumulation of human capital. First, households consume the services of durable goods, most importantly housing, and the purchase of such goods needs to be financed. Second, investment in education requires financing, and education and learning-by-doing imply an age-income profile which is upward sloping on average. The bulk of financing actually extended to households is for purchases of durable goods. Indeed, more than $90 \%$ of household liabilities are attributable to durable goods purchases, mainly real estate (around 80\%) and vehicles (around 6\%), and less than $4 \%$ of household liabilities are attributable to education purposes. ${ }^{1}$ In our model all household

\footnotetext{
${ }^{1}$ Data from the U.S. Flow of Funds Accounts for the first quarter of 2009 shows that home mortgages are $78 \%$ of household liabilities and consumer credit is about $19 \%$ and, according to the Federal Reserve Statistical Release G.19, 12\% is non-revolving consumer credit (including automobile loans and nonrevolving loans for mobile homes, boats, trailers, education, or vacations). Data from the 2007 Survey
} 
borrowing needs to be collateralized by households' stocks of durable goods. Since most household financing is comprised of such loans, our model is plausible empirically. While households are able to borrow for education only to a limited extent, consistent with our model, education and learning-by-doing are nevertheless important as they result in ageincome profiles that are upward sloping on average which means that households have an incentive to borrow against the future using other means, namely, by financing durable goods.

Furthermore, we consider durable goods price risk, in addition to income risk, and provide conditions for increasing risk management. Under some assumptions, households partially hedge income risk but do not hedge durable goods price risk at all. When households can choose to rent durables as well as buy them, we show that households with low net worth rent and that renters may hedge high durable goods prices. Shiller (1993) has argued that markets that allow households to manage their risks would significantly improve welfare and that the absence of such markets hence presents an important puzzle. For example, Shiller (2008) writes that "[t]he near absence of derivatives markets for real estate ... is a striking anomaly that cries out for explanation and for actions to change the situation." We provide a rationale why households may not use such markets even if they exist. And given this lack of demand from households, the absence of such markets may not be so puzzling after all. The explanation we provide is simple: households' primary concern is financing, that is, shifting funds from the future to today, not risk management, that is, not transferring funds across states in the future. Risk management would require households to make promises to pay in high income states in the future, but this would reduce households' ability to promise to pay in high income states to finance durable goods purchases today, because households' total promises are limited by collateral constraints. Our dynamic model of complete markets subject to collateral constraints allows an explicit analysis of the connection between financing and risk management, and shows that the cost of risk management may be too high.

Our economy with income risk only is similar to the classic model of buffer stock savings of Bewley (1977) and Aiyagari (1994), among others. The main difference is that this class of models typically assumes that households have access only to risk-free assets subject to short-sale (or borrowing) constraints, whereas households in our model have access to state-contingent claims, albeit subject to similar short-sale constraints. The behavior of state-contingent savings in our model differs from the savings behavior in the

of Consumer Finances on the purpose of debt shows that in 2007, $83 \%$ of household debt is due to the purchase or improvement of a primary residence or other residential property, $6 \%$ to vehicle purchases, less than $4 \%$ to education, and $6 \%$ to purchases of goods or services not further broken out. 
standard incomplete markets model. Most notably, risk aversion is sufficient for statecontingent savings to be precautionary, that is, for an increase in uncertainty to lead to an increase in state-contingent savings. In contrast, with incomplete markets guaranteeing that an increase in uncertainty increases savings requires assumptions about prudence, that is, the third derivative of the utility function. Moreover, in our model net worth next period is monotone increasing in current income given current net worth, whereas this is not the case in the standard incomplete markets model.

Finally, we study the general equilibrium in the economy with durable goods in which the market for collateralized claims clears, determining the equilibrium interest rate. If durable goods are sufficiently collateralizable, collateral is abundant, the interest rate equals the rate of time preference, and households are fully insured in a stationary equilibrium. Otherwise collateral is scarce, the interest rate is below the rate of time preference, and household insurance is incomplete; the characterization of household risk management above applies. Moreover, the more scarce collateral is, the lower the interest rate, the less insurance, and the more wealth and consumption inequality there is in a stationary equilibrium. An interest rate on collateralized claims below the rate of time preference corresponds to such claims trading at a "liquidity premium," as in Holmström and Tirole $(1998,2011)$, but in our economy the premium can be positive even when risk is purely idiosyncratic unlike in their model.

Consistent with the view that financing needs may override risk management concerns, we discuss evidence on U.S. households which suggests that poor (and financially constrained) households are less well insured against many types of risks, such as health risks or flood risks, than richer (and less financially constrained) households. Most pertinently, Fang and Kung (2012) study panel data on life insurance coverage and find that income shocks are a key determinant of individuals' decisions to maintain or lapse insurance coverage; specifically, "individuals who experience negative income shocks are more likely to lapse all coverage." This within-household variation in insurance coverage is consistent with the predictions of our model. Furthermore, a similar positive relation between income and risk management has recently been documented for farmers in developing economies. In addition, there is evidence that firms' financial constraints affect corporate risk management. One important consequence of the absence of risk management by constrained households and firms is that such households and firms are then more susceptible to shocks.

We show how to derive the collateral constraints in our model from an environment with limited enforcement in the spirit of Kehoe and Levine (1993) and Kocherlakota (1996). However, while these models assume that households can be excluded from in- 
tertemporal trade if they default on their promises, in our model enforcement is more limited as households cannot be excluded from financial markets, which is similar to the limits on enforcement considered by Chien and Lustig (2010) in an endowment economy. In our environment, the optimal dynamic contract can be implemented with complete markets in one-period ahead Arrow securities subject to state-by-state collateral constraints. This rather tractable decentralization of the optimal contract is similar in spirit to the decentralization in Alvarez and Jermann (2000), but the borrowing constraints are more straightforward as borrowing is simply constrained to be no more than a fraction of the value of household's durable assets in each state next period, whereas the endogenous solvency constraints in their model are history-dependent. Our decentralization is hence very similar to the market structure in the standard incomplete markets model except of course that it allows contingent claims. Our main contribution is a general characterization of dynamic household insurance behavior. ${ }^{2}$

Much of the economics literature on insurance has focused on moral hazard (Holmström (1979)) and adverse selection (Rothschild and Stiglitz (1976)) as barriers to insurance. While these frictions are important, we consider limited enforcement as the only friction in our model in order to focus on the relation between intertemporal trade and insurance across states. This allows us to characterize the dynamic behavior of savings and insurance analytically and obtain global characterization results. We also abstract from life-cycle patterns for the sake of analytical tractability. Further, one might consider behavioral issues, such as hyperbolic discounting or optimism, and financial literacy as reasons for underinsurance. However, the challenge for all these theories is that they do not predict the relation between insurance and net worth in the cross section of households and within households over time.

We think our model applies to both aggregate shocks, such as earthquakes, floods, or house prices, and idiosyncratic shocks, such as death, health shocks, accidents, fire, or disability. In the model, all shocks are priced in a risk-neutral way, so to the extent that the shocks are aggregate, this is clearly a simplifying assumption, although our basic insight would carry over to an environment where aggregate risk is priced. Moreover, we model the shocks directly as income shocks, which should be interpreted as income net of non-discretionary expenditure shocks for health, accidents, fire, and so forth. One could argue that such expenditures and events are to a large extent observable and indeed we assume this throughout, thus abstracting away from other agency problems. This allows us to focus on the novel aspect of our model, the connection between financing

\footnotetext{
${ }^{2}$ Alvarez and Jermann (2000) and Chien and Lustig (2010) focus on the implications of limited enforcement for asset pricing.
} 
and insurance. Finally, while incomplete markets models allow for intertemporal consumption smoothing, they do not allow an analysis of insurance per se. Indeed, Kaplan and Violante (2010) find that households in the data have access to more consumption insurance against permanent earnings shocks than a calibrated life-cycle version of the standard incomplete-markets model suggests and call for alternative models of household insurance. We provide such a model based on limited enforcement.

In related work, Rampini and Viswanathan (2010, 2013) study the relation between financing and risk management for firms in an environment with risk neutral entrepreneurs and a concave production function. ${ }^{3}$ They show analytically that severely constrained firms do not hedge at all, but the fact that firms with higher net worth also invest more does not allow a more general analytical characterization. In contrast, our model with risk averse households allows us to prove much more general results. Specifically, we provide a general characterization of the relation between insurance and net worth and show that insurance is increasing in net worth globally under quite general conditions. Moreover, our global results use only risk aversion, whereas their result requires the assumption that the production function satisfies an Inada condition. In addition, we consider household insurance in general equilibrium here. Finally, our analysis of the case of an endowment economy makes the basic trade-off between savings and insurance especially stark.

Section 2 analyzes household income risk management in an economy with income risk only, derives the basic increasing household risk management result, and shows that households' state-contingent savings are precautionary. Section 3 extends the model to an economy with durable goods and shows how the increasing risk management result generalizes. Section 4 studies the general equilibrium in the market for collateralized claims in the economy with durable goods. Durable goods price risk management is analyzed in Section 5. This section also considers households' ability to rent durable goods and the interaction between the rent vs. buy decision and risk management. ${ }^{4}$ Section 6 reviews the evidence on household insurance. Section 7 concludes. All proofs are in Appendix A. An online appendix provides a comparison to the standard buffer stock savings model with incomplete markets.

\footnotetext{
${ }^{3}$ The rationale for risk management in their model is that the value function of a firm subject to financial constraints is concave in net worth, making the firm effectively risk averse.

${ }^{4}$ Two recent studies consider the asset pricing implications of housing in endowment economies with similar preferences over two goods, (nondurable) consumption and housing services with a frictionless rental market for housing: Lustig and Van Nieuwerburgh (2005) study the role of solvency constraints similar to ours and Piazzesi, Schneider, and Tuzel (2007) analyze the frictionless benchmark.
} 


\section{Household Income Risk Management}

In this section we consider household income risk management in an endowment economy. We show that optimal household income risk management is incomplete and monotone increasing in the households' net worth, that is, richer households are better insured. Moreover, we show that household risk management is precautionary, that is, increases when uncertainty is higher, and that there is a sense in which "the poor can't afford insurance." Finally, we characterize household risk management in the long run.

\subsection{Household Finance in an Endowment Economy}

Consider household income risk management in an endowment economy. Time is discrete and the horizon is infinite. Households have preferences $E\left[\sum_{t=0}^{\infty} \beta^{t} u\left(c_{t}\right)\right]$ where we assume that $\beta \in(0,1)$ and $u(c)$ is strictly increasing, strictly concave, continuously differentiable, and satisfies $\lim _{c \rightarrow 0} u_{c}(c)=\infty$ and $\lim _{c \rightarrow \infty} u_{c}(c)=0$. Households' income $y(s)$ follows a Markov chain on state space $s \in S$ with transition matrix $\Pi\left(s, s^{\prime}\right)>0$ describing the transition probability from state $s$ to state $s^{\prime}$, and $\forall s, s_{+}, s_{+}>s, y\left(s_{+}\right)>y(s)>0$. We interpret household income as net of non-discretionary spending needs for health, accidents, and other such shocks. ${ }^{5}$ We use the shorthand $y^{\prime} \equiv y\left(s^{\prime}\right)$ for income in state $s^{\prime}$ next period wherever convenient and analogously for other variables. Moreover, let $\underline{s}=$ $\min \{s: s \in S\}$ and $\bar{s}=\max \{s: s \in S\}$ and analogously for $\underline{y}$ and $\bar{y}$ and let $S$ also denote the cardinality of $S$ in a slight abuse of notation.

Lenders are risk neutral and discount the future at rate $R^{-1}>\beta$, that is, are patient relative to the households, and have deep pockets and abundant collateral in all dates and states; lenders are thus willing to provide any state-contingent claim at an expected return $R .^{6}$ Thus we take the interest rate $R$ as given for now. We endogenize the interest rate in general equilibrium in Section $4 .^{7}$

Enforcement is limited as follows: households can abscond with their income and cannot be excluded from markets for state-contingent claims in the future. Extending the results in Rampini and Viswanathan (2010, 2013) to this environment, we show in Appendix B that the optimal dynamic contract with limited enforcement can be imple-

\footnotetext{
${ }^{5} \mathrm{~A}$ significant cost of health shocks may be to force reduced labor force participation, reducing income.

${ }^{6}$ We discuss the case in which $R=\beta^{-1}$ in the online appendix. In models of buffer stock savings with idiosyncratic risk and incomplete markets, Bewley (1977), Huggett (1993), Aiyagari (1994), and others show that aggregate asset holdings are finite only if $R^{-1}>\beta$ in equilibrium.

${ }^{7}$ The general equilibrium in Section 4 applies to an economy with durable goods, which serve as collateral backing households' collateralized state-contingent claims, whereas in the endowment economy considered in this section we require outside lenders supplying claims.
} 
mented with complete markets in one-period ahead Arrow securities subject to short-sale constraints (which are a special case of collateral constraints). ${ }^{8}$

In some parts of the analysis, we consider Markov chains which exhibit the following notion of positive persistence:

Definition 1 (Monotone Markov chain). A Markov chain $\Pi\left(s, s^{\prime}\right)$ is stochastically monotone, if it displays first order stochastic dominance (FOSD), that is, if $\forall s, s_{+}, \hat{s}^{\prime}, s_{+}>s$, $\sum_{s^{\prime} \leq \hat{s}^{\prime}} \Pi\left(s_{+}, s^{\prime}\right) \leq \sum_{s^{\prime} \leq \hat{s}^{\prime}} \Pi\left(s, s^{\prime}\right)$.

This definition requires that the distribution of states next period conditional on current state $s_{+}$first order stochastically dominates the distribution conditional on current state $s$, for all $s_{+}>s$. A Markov chain which is independent over time, that is, satisfies $\Pi\left(s, s^{\prime}\right)=\pi\left(s^{\prime}\right), \forall s \in S$, is stochastically monotone. ${ }^{9}$ Arguably, such positive persistence in household income is plausible empirically.

The household solves the following recursive problem by choosing (non-negative) consumption $c$ and a portfolio of Arrow securities $h^{\prime}$ for each state $s^{\prime}$ (and associated net worth $w^{\prime}$ ) given the exogenous state $s$ and the net worth $w$ (cum current income),

$$
v(w, s) \equiv \max _{c, h^{\prime}, w^{\prime} \in \mathbb{R}_{+} \times \mathbb{R}^{2 S}} u(c)+\beta E\left[v\left(w^{\prime}, s^{\prime}\right) \mid s\right]
$$

subject to the budget constraints for the current and next period, $\forall s^{\prime} \in S$,

$$
\begin{aligned}
w & \geq c+E\left[R^{-1} h^{\prime} \mid s\right], \\
y^{\prime}+h^{\prime} & \geq w^{\prime},
\end{aligned}
$$

and the short-sale constraints, $\forall s^{\prime} \in S$,

$$
h^{\prime} \geq 0
$$

Since the return function is concave, the constraint set convex, and the operator defined by the program in (1) to (4) satisfies Blackwell's sufficient conditions, there exists

\footnotetext{
${ }^{8}$ These one-period ahead Arrow securities are akin to the cash-in-advance contracts in Bulow and Rogoff (1989). Krueger and Uhlig (2006) provide a model of competitive risk sharing and switching costs and obtain short sale constraints, a special case of the collateral constraints in our model, in the limit as switching costs go to zero. Alvarez and Jermann (2000) provide a decentralization with complete markets and endogenous solvency constraints for economies with limited enforcement as in Kehoe and Levine (1993) and Kocherlakota (1996). The outside option in their model is exclusion from intertemporal markets and implies solvency constraints that are agent and state specific, whereas our outside option without exclusion results in simple short-sale and collateral constraints with a straightforward decentralization; Chien and Lustig (2010) consider this type of outside option in an endowment economy.

${ }^{9}$ For a symmetric two-state Markov chain, stochastic monotonicity is equivalent to assuming that $\Pi(\bar{s}, \bar{s})=\Pi(\underline{s}, \underline{s}) \equiv p \geq 1 / 2$, that is, that the autocorrelation $\rho$ is positive, as $\rho=2 p-1 \geq 0$.
} 
a unique value function $v$ which solves the Bellman equation. The value function $v$ is strictly increasing, strictly concave, and differentiable everywhere. ${ }^{10}$ Denoting the multipliers on the budget constraints (2) and (3) by $\mu$ and $\beta \Pi\left(s, s^{\prime}\right) \mu^{\prime}$, respectively, and the multipliers on the short-sale constraints (4) by $\beta \Pi\left(s, s^{\prime}\right) \lambda^{\prime}$, the first order conditions are

$$
\begin{aligned}
\mu & =u_{c}(c), \\
\mu^{\prime} & =v_{w}\left(w^{\prime}, s^{\prime}\right), \\
\mu & =\beta R \mu^{\prime}+\beta R \lambda^{\prime} .
\end{aligned}
$$

We have ignored the non-negativity constraint on consumption since it is slack. The envelope condition is $v_{w}(w, s)=\mu$.

\subsection{Increasing Household Risk Management}

We first show that household risk management is increasing in household net worth. In particular, the set of states that the households hedge is increasing in net worth and richer households' net worth and consumption distribution next period dominate those of poorer households. Richer households moreover spend more on hedging.

Proposition 1 (Increasing household risk management). Let $w_{+}>w$ and denote variables associated with $w_{+}$with a subscript + . Given the current state $s, \forall s \in S$, we have: (i) The set of states that the household hedges $S_{h} \equiv\left\{s^{\prime} \in S: h\left(s^{\prime}\right)>0\right\}$ is increasing in $w$, that is, $S_{h+} \supseteq S_{h}$. (ii) Net worth and consumption next period $w_{+}^{\prime} \geq w^{\prime}$ and $c_{+}^{\prime} \geq c^{\prime}$, $\forall s^{\prime} \in S$, that is, $w_{+}^{\prime}$ and $c_{+}^{\prime}$ statewise dominate and hence FOSD $w^{\prime}$ and $c^{\prime}$, respectively; moreover, $h_{+}^{\prime} \geq h^{\prime}, \forall s^{\prime} \in S$, and $E\left[h_{+}^{\prime} \mid s\right] \geq E\left[h^{\prime} \mid s\right]$. Consumption across the hedged states $S_{h}$ is constant, that is, $c^{\prime}=c_{h}, \forall s^{\prime} \in S_{h}$, and $c_{h}$ is strictly increasing in $w$.

Note that Proposition 1 does not impose any additional structure on the Markov process for income and hence does not determine which states are hedged. If we further assume that the Markov chain is stochastically monotone, then we can show that households hedge a lower interval of income realizations. Moreover, with this assumption

\footnotetext{
${ }^{10}$ See Theorem 9.6 and 9.8 in Stokey and Lucas with Prescott (1989). To see the differentiability, following Lemma 1 in Benveniste and Scheinkman (1979) define $\hat{v}(\hat{w}, s) \equiv u\left(\hat{w}-E\left[R^{-1} h^{\prime}(w, s) \mid s\right]\right)+$ $\beta E\left[v\left(w^{\prime}(w, s), s^{\prime}\right) \mid s\right]$ where $h^{\prime}(w, s)$ and $w^{\prime}(w, s)$ are optimal at $(w, s)$. Note that $c(w, s)>0$ and hence there exists a neighborhood $N$ of $w$ such that $\hat{v}$ is a strictly concave differentiable function with the property that $\hat{v}(w, s)=v(w, s)$ and $\hat{v}(\hat{w}, s) \leq v(w, s)$ for all $\hat{w}$ in $N$. Therefore, $v$ is differentiable at $w$ with derivative $u_{c}(c(w, s))$; indeed, by the Theorem of the Maximum, $c$ is continuous in $w$ and hence $v(w, s)$ is continuously differentiable.
} 
household risk management is increasing in both net worth $w$ and the current state $s$, that is, income.

Proposition 2 (Increasing household risk management with stochastic monotonicity). Assume that $\Pi\left(s, s^{\prime}\right)$ is stochastically monotone. (i) The marginal value of net worth $v_{w}(w, s)$ is decreasing in s. (ii) The household hedges a lower interval of states, if at all, given $w$ and $s$, that $i s, S_{h}=\left\{\underline{s}^{\prime}, \ldots, s_{h}^{\prime}\right\}$; net worth next period $w^{\prime}$, hedging $h^{\prime}$, the interval of states hedged $S_{h}$, and hedged consumption next period $c_{h}$ are all increasing in $w$ and $s$, $\forall s, s^{\prime} \in S$. (iii) If moreover $\Pi\left(s, s^{\prime}\right)=\pi\left(s^{\prime}\right), \forall s, s^{\prime} \in S$, then $w\left(s^{\prime}\right)=w_{h}, \forall s^{\prime} \in S_{h}$, and $w_{h}$ is increasing in $w$, and the variance of net worth $w^{\prime}$ and consumption $c^{\prime}$ next period is decreasing in $w$.

The key to the result is the fact that the marginal value of net worth $v_{w}(w, s)$ is decreasing not just in $w$, as before, but also in the state $s .{ }^{11}$ Stochastic monotonicity means that if the household is in a higher state today, holding current net worth $w$ constant, then the household's income next period is higher in a FOSD sense. This reduces the cost of hedging to a given level for each state next period, as hedging decreases with the state, and hedging the same amount becomes less costly. The household partially consumes the resources that are thus freed up and partially uses them to buy additional Arrow securities, that is, purchase more insurance, allowing the household to consume more in the hedged states next period. ${ }^{12}$ Thus, there is a sense in which richer households are better insured.

Positive persistence in the income process means that a high income realization reduces the marginal value of net worth for two reasons: first, high current income raises current net worth, which lowers the marginal value of net worth due to concavity; and second, a high current income implies higher expected future income, further reducing the marginal value of net worth by the mechanism described above. ${ }^{13}$

\footnotetext{
${ }^{11}$ The proof is of technical interest as we prove that the marginal value of net worth is (weakly) decreasing in $s$ by showing that the Bellman operator maps functions satisfying this property into functions satisfying the property as well, and that the unique fixed point must satisfy the property, too.

${ }^{12}$ In state $s_{+}>s$, the household is therefore (weakly) better insured for all states next period, $h_{+}^{\prime} \geq h^{\prime}$, while at the same time the household's insurance expenditures are lower, $E\left[R^{-1} h_{+}^{\prime} \mid s_{+}\right] \leq E\left[R^{-1} h^{\prime} \mid s\right]$; this is possible because the household's insurance purchases are decreasing in $s^{\prime}$ and stochastic monotonicity implies that the same portfolio of Arrow securities is cheaper at $s_{+}$than at $s$.

${ }^{13}$ In contrast, in a production economy with technology shocks, positive persistence has two effects which go in opposite directions: on the one hand, high current productivity implies high cash flow and thus raises current net worth, which lowers the marginal value of net worth due to the concavity of the value function; on the other hand, high current productivity increases the expected productivity which means firms would like to invest more, and this effect in turn raises the marginal value of net worth.
} 
Under the additional assumption of independent income shocks, the household ensures a minimum level of net worth next period, which is increasing in current net worth. Moreover, the variance of both net worth and consumption next period is decreasing in current net worth, that is, there is a strong sense in which richer households are better insured. ${ }^{14}$

\subsection{Incomplete and Precautionary Household Risk Management}

Next we show that household risk management is incomplete and some households do not hedge at all.

Proposition 3 (Incomplete risk management). Assume that $\Pi\left(s, s^{\prime}\right)$ is stochastically monotone. (i) At net worth $w=y$ in state $\underline{s}$, the household does not hedge at all, i.e., $\lambda^{\prime}>0, \forall s^{\prime} \in S$, and $S_{h}=\emptyset$. (ii) At net worth $w=\bar{y}$, the household does not hedge the highest state next period, that is, $\lambda\left(\bar{s}^{\prime}\right)>0$ and $S_{h} \subsetneq S, \forall s \in S$.

At net worth $\underline{y}$ (and in state $\underline{s}$ ) the household does not insure at all, which can be interpreted as saying that "the poor can't afford insurance." We emphasize that all households could buy any state-contingent claims they want, but that households with low net worth choose not to. Thus, it is not that poor households cannot insure, but rather that they choose not to given their low net worth; it is in this sense that they cannot afford to buy insurance. Moreover, even at net worth $\bar{y}$, the household does not engage in complete risk management, and since hedging is increasing, the household does not hedge the highest state for any level of wealth $w \leq \bar{y}$.

Figure 1 illustrates Propositions 2 and 3 for an economy with an independent, symmetric two state Markov chain. The top left panel illustrates that household risk management is increasing, with the bottom left panel showing that consumption is concave in wealth and hence richer households actually spend a larger fraction of their budget on Arrow securities to hedge future income shocks.

Thus there are two competing effects when productivity shocks have positive persistence and if the second effect is sufficiently strong, firms hedge states with high productivity.

${ }^{14}$ If income is lower in downturns and risk management consequently declines, then the cross sectional variation of consumption can be countercyclical, a property that is of interest due to its asset pricing implications (see, for example, Mankiw (1986) and Constantinides and Duffie (1996)). Storesletten, Telmer, and Yaron (2004) find that the cross-sectional variation of labor income is countercyclical, and Guvenen, Ozkan, and Song (2012) find that the left-skewness of idiosyncratic income shocks is countercyclical, rather than the variance itself, in earnings data from the U.S. Social Security Administration. Rampini (2004) provides a real business cycle model with entrepreneurs subject to moral hazard in which the cross sectional variation of the optimal incentive compatible allocation is similarly countercyclical. 
In our model of income risk management without durable goods, household insurance can be interpreted as state-contingent savings. The properties of such state-contingent savings are similar to the properties of savings noted by Friedman (1957) in his famous treatise A Theory of the Consumption Function (page 39):

"These regressions show savings to be negative at low measured income levels, and to be a successively larger fraction of income, the higher the measured income. If low measured income is identified with 'poor' and high measured income with 'rich,' it follows that the 'poor' are getting poorer and the 'rich' are getting richer. The identification of low measured income with 'poor' and high measured income with 'rich' is justified only if measured income can be regarded as an estimate of expected income over a lifetime or a large fraction thereof."

In our model, all households have the same expected income in the long run, and therefore households that are currently poor hedge less, that is, have lower state-contingent savings, than households that are currently rich, and thus our model yields a "theory of the insurance function" akin to Friedman's theory of the consumption function.

How does household risk management behave in the long run, given that households can accumulate net worth? We show that the model induces a stationary distribution for household net worth. Under the unique stationary distribution, households never hedge completely. Notably, households abstain from risk management completely with positive probability under the stationary distribution. This means that even households whose current net worth is high, that are hit by a sufficiently long sequence of low income realizations, end up so constrained again that they no longer purchase any Arrow securities, that is, stop buying any insurance at all. ${ }^{15}$

Proposition 4 (Household risk management under the stationary distribution). Assume that $\Pi\left(s, s^{\prime}\right)$ is stochastically monotone. (i) There exists a unique stationary distribution of net worth. (ii) The support of the stationary distribution is a subset of $\left[\underline{w}, w_{b n d}\right]$ where $\underline{w}=\underline{y}$ and $w_{b n d} \geq \bar{y}$ with equality if $\Pi\left(s, s^{\prime}\right)=\pi\left(s^{\prime}\right), \forall s, s^{\prime} \in S$. (iii) Under the stationary distribution, household risk management is increasing, incomplete with probability 1, and completely absent with strictly positive probability.

The bottom right panel of Figure 1 illustrates Proposition 4 for an independent two state Markov chain as in the example above. This panel displays the unconditional

\footnotetext{
${ }^{15}$ In the model with incomplete markets, Schechtman and Escudero (1977) provide conditions under which households run out of buffer stock savings with positive probability.
} 
stationary distribution whose support is between the low income realization $(y=0.8$ in the example) and the high income realization $(\bar{y}=1.2)$. The household never hedges the high state next period, which means the household's net worth conditional on a high realization is always $w\left(\bar{s}^{\prime}\right)=\bar{y}$. The household does hedge low realizations of income, at least as long as net worth is sufficiently high, so starting from net worth $\bar{y}$ low income realizations decrease the household's net worth gradually over time; the probability mass decreases at a rate $\pi(\underline{s})$ in this range. Eventually, the household stops hedging, and subsequent realizations result in net worth $\underline{y}$ until a high income realization lifts the household's net worth again.

When $\beta R=1$, we show in the online appendix that households are unconstrained and fully insured in the limit, but their net worth remains finite, in contrast to the models with incomplete markets in which households accumulate infinite buffer stocks to smooth consumption in the limit. Thus, the extra flexibility that state-contingent savings in our model affords households dramatically reduces their incentives to accumulate wealth. We emphasize that household risk management is incomplete and increasing even in this case, albeit only in the transition.

Finally, we show that household risk management is precautionary in the sense that a mean preserving spread in income leads the household to increase the expenditure on risk management when income shocks are independent over time. Remarkably, risk aversion alone is sufficient for this result.

Proposition 5 (Precautionary state-contingent saving). Assume that $\Pi\left(s, s^{\prime}\right)=\pi\left(s^{\prime}\right)$, $\forall s^{\prime} \in S$, and suppose $\tilde{\pi}\left(s^{\prime}\right)$ is a mean-preserving spread of $\pi\left(s^{\prime}\right)$. Then $\tilde{E}\left[\tilde{h}^{\prime}\right] \geq E\left[h^{\prime}\right]$, where $\tilde{E}$ is the expectation operator and $\tilde{h}^{\prime}$ is optimal risk management given $\tilde{\pi}\left(s^{\prime}\right)$.

Thus, state-contingent saving is precautionary without additional assumptions about preferences, whereas saving in the Bewley (1977) economy with incomplete markets is guaranteed to be precautionary only if preferences display prudence, that is, the marginal utility of consumption is convex in consumption. We provide a more explicit comparison to the standard buffer stock savings problem in the online appendix.

Since the household increases the expenditure on risk management when risk increases, the household must consume less today. In fact, one can show that the household ends up consuming less in each date and state going forward:

Corollary 1 (Consumption implications of precautionary state-contingent saving). Given the assumptions of Proposition 5 and given net worth $w$, precautionary state-contingent saving implies for consumption that $\tilde{c} \leq c, \tilde{c}^{\prime} \leq c^{\prime}$, and indeed $\tilde{c}\left(s^{t}\right) \leq c\left(s^{t}\right)$ for any subsequent history $s^{t}$ and time $t$. 


\section{Household Risk Management with Durable Goods}

This section extends our model of household finance to include durable goods that provide consumption services. Durable goods can serve as collateral for households' promises to pay. Durable goods allow consumption smoothing to some extent, but are associated with additional financing needs at the same time. The increasing household risk management results generalize to this environment to a large extent. Moreover, we extend the model to consider the financing of education and investment in human capital.

\subsection{Household Finance with Durable Goods}

Consider an extension of the economy of Section 2 with two goods, (non-durable) consumption $c$ and durable goods $k$, which in practice comprise mainly housing. The environment, income process, and lenders are as before, but households have separable preferences $E\left[\sum_{t=0}^{\infty} \beta^{t}\left\{u\left(c_{t}\right)+g\left(k_{t}\right)\right\}\right]$ where $g(k)$ is strictly increasing, strictly concave, and satisfies $\lim _{k \rightarrow 0} g_{k}(k)=+\infty$ and $\lim _{k \rightarrow \infty} g_{k}(k)=0$.

Durable goods depreciate at rate $\delta \in(0,1)$ and the price in terms of consumption goods is assumed to be constant and normalized to $1, \forall s \in S$. Households can adjust their durable goods stock freely, but there is no rental market for durable goods and households have to purchase durable goods to consume their services. Durable goods are also used as collateral as we discuss below. We consider durable goods price risk in Section 5 and analyze the implications of households' ability to rent durables as well as purchase durables and borrow against them in Section 5.2.

Enforcement is limited as follows: households can abscond with their income and a fraction $1-\theta$ of durable goods, where $\theta \in(0,1)$, and cannot be excluded from markets for state-contingent claims or durable goods. ${ }^{16}$ As before, one can show that the optimal dynamic contract with limited enforcement can be implemented with complete markets in one-period Arrow securities subject to collateral constraints that limit the household's state-contingent promises $b^{\prime}$ in state $s^{\prime}$ next period as follows: $\theta k(1-\delta) \geq R b^{\prime}, \forall s^{\prime} \in S .{ }^{17}$

The simplest and equivalent formulation of the household's problem is to assume that the household levers durable assets fully, that is, borrows $\hat{b}^{\prime}=R^{-1} \theta k(1-\delta), \forall s^{\prime} \in S$, and purchases Arrow securities in the amount $h^{\prime}=\theta k(1-\delta)-R b^{\prime}, \forall s^{\prime} \in S$. Under this equivalent formulation, the collateral constraints on $b^{\prime}$ reduce to short-sale constraints

\footnotetext{
${ }^{16}$ One interpretation of this assumption for housing, for example, is that it takes time to foreclose on borrowers who default and hence it is as if households abscond with some fraction of housing services.

${ }^{17}$ These collateral constraints are reminiscent of the ones in Kiyotaki and Moore (1997) but allow state-contingent claims and can be explicitly derived in our model by extending the proof in Appendix B to the case with durable goods.
} 
on $h^{\prime}$. Moreover, since the household borrows as much as possible against durable assets, the household pays down $\wp \equiv 1-R^{-1} \theta(1-\delta)$ per unit of durable assets purchased only, where $\wp$ can be interpreted as the minimal down payment required from the household to purchase a unit of the durable asset.

The household solves the following recursive problem by choosing (non-negative) consumption $c$, (fully levered) durable goods $k$, and a portfolio of Arrow securities $h^{\prime}$ for each state $s^{\prime}$ (and associated net worth $w^{\prime}$ ) given the exogenous state $s$ and the net worth $w$ (cum current income and durable goods net of borrowing),

$$
v(w, s) \equiv \max _{c, k, h^{\prime}, w^{\prime} \in \mathbb{R}_{+}^{2} \times \mathbb{R}^{2 S}} u(c)+\beta g(k)+\beta E\left[v\left(w^{\prime}, s^{\prime}\right) \mid s\right]
$$

subject to the budget constraints for the current and next period, $\forall s^{\prime} \in S$,

$$
\begin{aligned}
w & \geq c+\wp k+E\left[R^{-1} h^{\prime} \mid s\right], \\
y^{\prime}+(1-\theta) k(1-\delta)+h^{\prime} & \geq w^{\prime}
\end{aligned}
$$

and the short-sale constraints (4), $\forall s^{\prime} \in S$.

The return function $u(c)+\beta g(k)$ includes the service flow of durables purchased this period for use next period, which is deterministic given purchases of durables this period. This definition of the value function and net worth allows us to formulate the problem with only one endogenous state variable, net worth $w .{ }^{18}$ Defining the multipliers as before, the first order conditions are (5) through (7) and

$$
\wp \mu=\beta g_{k}(k)+E\left[\beta \mu^{\prime}(1-\theta)(1-\delta) \mid s\right]
$$

or written as an investment Euler equation for durable goods

$$
1=\beta \frac{g_{k}(k)}{\mu} \frac{1}{\wp}+E\left[\beta \frac{\mu^{\prime}}{\mu} \frac{(1-\theta)(1-\delta)}{\wp} \mid s\right] .
$$

The first term on the right hand side is the service flow of the durable goods purchased this period and consumed next period, that is, the "dividend yield" of durables, and the second term on the right hand side is the return from the resale value of durables net of borrowing. Since durables are fully levered, $k(1-\delta)-R \hat{b}^{\prime}=(1-\theta) k(1-\delta)$. The down payment requirement $\wp=1-R^{-1} \theta(1-\delta)$ is in the denominator as this is the amount of net worth the household has to invest per unit of durable assets.

\footnotetext{
${ }^{18}$ Arguing analogously to before, there exists a unique value function which is strictly increasing, strictly concave, and everywhere differentiable. There is no need to impose non-negativity constraints on consumption and durable goods as these are slack given our preference assumptions.
} 


\subsection{Increasing Household Risk Management with Durable Goods}

A key aspect of durable goods is that purchases of durables force the household to save, as the household cannot pledge the full resale value. Indeed, if the household were able to pledge the full resale value, that is, if $\theta$ were 1 , then durable goods purchases this period would not affect net worth next period as $k$ would not appear in equation (10). The choice between non-durable consumption $c$ and durable goods $k$ reduces to a withinperiod problem given consumption expenditures $\hat{c}$ which induces an indirect utility function $\hat{u}(\hat{c}) \equiv \max _{c, k} u(c)+\beta g(k)$ subject to $\hat{c} \geq c+\wp k$, where $\hat{u}$ inherits the properties of $u$ and $g$. Therefore, Propositions 1 to 5 apply without change when $\theta=1$, that is, household risk management is increasing, incomplete, and precautionary, and is completely absent with positive probability under the stationary distribution.

With durable goods and $\theta \in(0,1)$, household risk management is increasing in net worth in the sense that the household's net worth $w^{\prime}$ next period is strictly increasing in current net worth. Unlike in the economy with income risk only in Section 2, we can no longer conclude that the household's purchases of Arrow securities necessarily increase in wealth, as the household also buys more durables which increases its net worth next period.

For a monotone Markov chain we can again show that the marginal value of net worth $v_{w}(w, s)$ decreases in state $s$. Therefore, households hedge a lower set of income realizations and, among the states they hedge, hedge worse income realizations strictly more. With independence of the income process, household risk management is incomplete under the stationary distribution.

Proposition 6 (Household risk management with durable goods and stochastic monotonicity). Assume that $\Pi\left(s, s^{\prime}\right)$ is stochastically monotone. (i) The marginal value of net worth $v_{w}(w, s)$ is decreasing in s. (ii) The household hedges a lower interval of states, if at all, given $w$ and $s$, that is, $S_{h}=\left\{\underline{s}^{\prime}, \ldots, s_{h}^{\prime}\right\}$, and $h^{\prime}$ is strictly decreasing in $s^{\prime}$ on

$S_{h}$. Consumption c, durable goods $k$, and net worth next period $w^{\prime}$ are strictly increasing in $w$, given s; consumption $c$ is also increasing in $s$, given $w$. (iii) For $w$ sufficiently low, $h^{\prime}=0, \forall s^{\prime} \in S$. (iv) If moreover $\Pi\left(s, s^{\prime}\right)=\pi\left(s^{\prime}\right), \forall s, s^{\prime} \in S$, then $w\left(s^{\prime}\right)=w_{h}$, $\forall s^{\prime} \in S_{h}$, and $w_{h}$ is strictly increasing in $w$. For $w \leq \bar{w}$, the household never hedges the highest state next period, $h\left(\bar{s}^{\prime}\right)=0$, where $\bar{w}$ is the highest wealth level attained under the stationary distribution.

Part (iii) shows that if a household's financing needs are sufficiently strong, then financing needs override hedging concerns. Since the budget constraint next period (10) binds in all states and purchases of Arrow securities are limited by short-sale con- 
straints (4), we know that net worth $w^{\prime}$ in state $s^{\prime}$ next period is bounded below, namely,

$$
w^{\prime} \geq y^{\prime}+(1-\theta) k(1-\delta)>y^{\prime}
$$

for all states $s^{\prime}$, due to households' limited ability to promise. But this means that the household must be collateral constrained against all states $s^{\prime}$ next period if the household's current net worth $w$ is sufficiently low, since the marginal value of net worth next period must be bounded above.

Households' limited ability to credibly promise repayment means that households cannot pledge future income and households' net worth has to be at least future labor income. Moreover durable goods purchases require some down payment per unit of capital from the household and hence implicitly force households to shift additional net worth to the next period. Both these aspects imply that if current household net worth is relatively low, the household shifts resources to the present to the extent possible, that is, borrows as much as possible against durable goods.

Panel A of Figure 2 illustrates Proposition 6 in the case of an independent symmetric two state Markov process for income. The consumption of both non-durables and durables are concave in household net worth, consistent with one of the basic stylized facts of the empirical consumption literature. Hedging is increasing in net worth; indeed, for low net worth the household does not hedge at all. The household hedges the low state only once net worth reaches a relatively high level, about the level of the high income in the example. This is due to the financing needs for the purchases of durable goods, which force the household to save. At the bottom of the stationary distribution (where $w\left(\underline{s}^{\prime}\right)$ intersects the 45-degree line), the household does not hedge at all. This level of net worth is also considerably above the low income. The financing needs for durable goods reduce household risk management. The behavior of the households in our model with durables is reminiscent of the "hand-to-mouth" households in Kaplan, Violante, and Weidner (2014), who find that as much as a third or more of U.S. households live effectively hand-to-mouth; two thirds of these households are "wealthy hand-to-mouth" with sizable illiquid wealth, primarily in the form of housing, but little or no liquid financial assets.

Panel B of Figure 2 illustrates the effect of collateralizability by considering the example from Panel A except with collateralizability $\theta=0.6$ instead of 0.8 . The effects are striking. The household reduces consumption of non-durables and durables for given net worth, which is intuitive as a given durable goods purchase now requires more net worth (not shown in the figure). Moreover, the household drastically reduces risk management and does not hedge at all until a much higher level of net worth is reached and even then, hedges much less. Essentially, the household is forced to save so much to finance its durable goods purchases that it chooses not to hedge. At the same time, the households' 
stationary distribution of net worth shifts to the right. This comparative statics result provides an interesting perspective on the effects of financial development, which we interpret as an increase in collateralizability. Financial development that allows households to lever durable goods more, results in lower net worth accumulation, which all else equal would leave households more susceptible to shocks. Thus, by enabling higher leverage, financial development renders households' risk management concerns more pertinent.

Panel $\mathrm{C}$ of Figure 2 illustrates the effect of persistence on household risk management by considering the same example except with a Markov process for income with autocorrelation 0.5 instead of 0 . When income is persistent, the household consumes more non-durables and durables in the high state than in the low state, holding net worth constant (not shown in the figure). Moreover, the household hedges the low state more, in particular when the current state is high. Thus an increase in persistence increases household risk management. That said, the household saves less for the high state, in particular when the current state is low.

\subsection{Financing Education}

Age-income profiles are upward sloping on average partly because of economic growth and partly presumably because of learning by doing, that is, skill accumulation with experience. These properties of the labor income process give households further incentives to borrow as much as they can against their durable goods, such as housing, and thus exhaust their debt capacity and abstain from risk management. ${ }^{19}$

Suppose moreover that households are able to invest in education or human capital $e$. An amount of education $e$ invested in the current period, which includes both foregone labor income and direct costs, results in income $A^{\prime} f(e)$ in state $s^{\prime}$ next period, where $f$ is strictly increasing and strictly concave, $\lim _{e \rightarrow 0} f_{e}(e)=+\infty$, and $\lim _{e \rightarrow \infty} f_{e}(e)=0$, and the productivity of human capital $A^{\prime}>0$, for all $s^{\prime} \in S$, is described by a Markov process also summarized by state $s$. Human capital depreciates at a rate $\delta_{e} \in(0,1)$. Note that households in our model can borrow against neither future labor income nor human capital, as education capital is inalienable, and can only borrow against durable goods. The household's problem is to choose (non-negative) consumption $c$, (fully levered) durable goods $k$, education $e$, and a portfolio of Arrow securities $h^{\prime}$ (with associated net worth $w^{\prime}$ ) for each state $s^{\prime}$ given the exogenous state $s$ and net worth $w$ (cum current income, durable goods net of borrowing, and human capital) to maximize (8) subject to

\footnotetext{
${ }^{19}$ Such age-income profiles can be captured by appropriately specifying the exogenous Markov chain for income. In this spirit, Krebs, Kuhn, and Wright (2015) study life-cycle patterns in life insurance coverage in a calibrated model with human capital accumulation and limited enforcement.
} 
the budget constraints for the current and next period, $\forall s^{\prime} \in S$,

$$
\begin{aligned}
w & \geq c+\wp k+e+E\left[R^{-1} h^{\prime} \mid s\right], \\
A^{\prime} f(e)+e\left(1-\delta_{e}\right)+(1-\theta) k(1-\delta)+h^{\prime} & \geq w^{\prime},
\end{aligned}
$$

and the short-sale constraints (4), $\forall s^{\prime} \in S$. Note that the household's problem is still well behaved, that is, the constraint set is convex.

Proposition 7. In the problem with education, that is, investment in human capital, if a household's current net worth $w$ is sufficiently low, the household is constrained against all states next period and hence does not engage in risk management.

The intuition is that if the household's net worth is sufficiently low, then the household's human capital has to be very low, too, and thus the marginal rate of transformation on investment in human capital must exceed the return on saving net worth for state $s^{\prime}$, for all states.

Investment in education is an additional reason why households are likely to have higher net worth later in life, giving them further incentives to finance as much of their durable goods purchases as they can, rather than using their limited ability to pledge to shift funds across states later on.

\section{Equilibrium and Effect of Collateral on Insurance}

We now consider the general equilibrium in the economy with durable assets and idiosyncratic risk in which the interest rate $R$ is determined to clear the market for statecontingent claims. We show that $\beta R \leq 1$ and that when collateral is scarce, that is, $\theta$ is below some threshold, $\beta R<1$, as we assume throughout the paper. The interest rate affects not just the cost of collateralized loans, that is, the supply of collateralized claims, but also the price of state-contingent claims, that is, the demand for collateralized claims. When collateral is scarce, state-contingent claims are in short supply, lowering the equilibrium interest rate, which is equivalent to collateralized assets trading at a premium as in Holmström and Tirole (1998, 2011); notably, in contrast to their model, in our model collateral may be scarce in equilibrium even if the risk in the economy is purely idiosyncratic. Collateral scarcity results in less insurance in equilibrium and more consumption and wealth inequality. When the collateralizability is sufficiently high, however, $\beta R=1$, and households are fully insured, in stark contrast to models with incomplete markets in which $\beta R<1$ always. 


\subsection{Stationary Equilibrium and Aggregation}

A stationary equilibrium is an allocation $x(z) \equiv\left\{c(z), k(z), h^{\prime}(z), w^{\prime}(z)\right\}$ for each household given $z \equiv\{w, s\}$, an interest rate $R$, and a stationary distribution $F(z)$ such that $x(z)$ solves each household's problem stated in (8)-(10) and (4), given $z$, and the market for state-contingent promises clears, that is,

$$
\int_{z} E\left[b^{\prime}(z) \mid s\right] d F(z)=0
$$

or, equivalently, the supply of collateralized claims equals the demand for state-contingent claims $h^{\prime}(z)$

$$
\int_{z} \theta k(z)(1-\delta) d F(z)=\int_{z} E\left[h^{\prime}(z) \mid s\right] d F(z) .
$$

State-contingent promises are in zero net supply which is reflected in (15) where we use the law of large numbers and the assumption that risk is idiosyncratic and independent across agents. Using the equivalent formulation in which households lever durables fully, that is, borrow $\hat{b}^{\prime}=R^{-1} \theta k(1-\delta)$, and purchase Arrow securities $h^{\prime}=\theta k(1-\delta)-R b^{\prime}$, we can rewrite (15) as (16); this equation states that the aggregate supply of fully levered claims, which equals the aggregate supply of collateralized assets, equals the aggregate demand for Arrow securities. In terms of institutions, we can interpret the market clearing condition as a competitive representative insurance firm with collateralized loans as assets and a diversified portfolio of insurance claims as liabilities. The competitive insurer makes zero profits and prices the contingent claims at their risk neutral price given the equilibrium interest rate $R$.

For simplicity, we restrict attention to the case in which households' income is independent over time. To simplify notation, we define the aggregate quantities $W \equiv$ $\int_{z} w(z) d F(z), C \equiv \int_{z} c(z) d F(z), K \equiv \int_{z} k(z) d F(z)$, and $H^{\prime} \equiv \int_{z} h^{\prime}(z) d F(z)$. In a stationary equilibrium, we can take the cross-sectional expectation of the budget constraints for the current period and the expectation of the budget constraints for the next period, $\forall s^{\prime} \in S,(9)$ and (10), and write these as

$$
\begin{aligned}
W & =C+\wp K+E\left[R^{-1} H^{\prime}\right], \\
E\left[y^{\prime}\right]+(1-\theta) K(1-\delta)+E\left[H^{\prime}\right] & =W .
\end{aligned}
$$

Using the market clearing condition (16), $\theta K(1-\delta)=E\left[H^{\prime}\right],(17)$ and (18) imply that

$$
W=C+K=E\left[y^{\prime}\right]+K(1-\delta)
$$

In a stationary equilibrium, aggregate net worth equals aggregate consumption plus the value of the aggregate durables stock and also equals the aggregate income plus the 
aggregate value of the depreciated durables stock. Rewriting the second equality we conclude that the aggregate income equals aggregate consumption plus the aggregate investment required to maintain the durables stock, that is,

$$
E\left[y^{\prime}\right]=C+\delta K
$$

This is the resource constraint of the economy.

\subsection{Full Insurance in Economy with Abundant Collateral}

When the aggregate supply of collateralized assets is sufficiently large, a stationary equilibrium obtains in which $\beta R=1$. When $\beta R=1$, the first order condition for $h^{\prime},(7)$, implies that $\mu=\mu^{\prime}+\lambda^{\prime} \geq \mu^{\prime}, \forall s^{\prime} \in S$, and thus in a stationary equilibrium $\mu=\mu^{\prime}=\mu^{*}$; the marginal value of net worth is constant and equal for all households, that is, there is full insurance. Equations (5), (6), and (11) imply that consumption $c^{*}$, net worth $w^{*}$, and durable goods $k^{*}$ are constant as well. Using the notation $R^{*} \equiv \beta^{-1}$ and $r^{*}=R^{*}-1$, the investment Euler equation (12) simplifies to

$$
r^{*}+\delta=\frac{g_{k}\left(k^{*}\right)}{u_{c}\left(c^{*}\right)},
$$

implying that the user cost of durable goods equals the marginal rate of substitution between durables and consumption. Using $\wp^{*}=1-R^{*-1} \theta(1-\delta)$, the budget constraints for the current and the next period, $\forall s^{\prime} \in S$, (9) and (10), can be written as

$$
\begin{aligned}
w^{*} & =c^{*}+\wp^{*} k^{*}+E\left[R^{*-1} h^{*}\right], \\
y^{\prime}+(1-\theta) k^{*}(1-\delta)+h^{*} & =w^{*}, \quad \forall s^{\prime} \in S .
\end{aligned}
$$

Equations (19) and (20) reduce to $w^{*}=c^{*}+k^{*}=E\left[y^{\prime}\right]+k^{*}(1-\delta)$ and $E\left[y^{\prime}\right]=c^{*}+\delta k^{*}$, respectively. This last equation and (21) determine $c^{*}$ and $k^{*}$ uniquely.

So far we have ignored the restriction that $h^{\prime *} \geq 0, \forall s^{\prime} \in S$. Using (19) to substitute for $w^{*}$ in $(23)$ we obtain $h^{\prime *}=\theta k^{*}(1-\delta)-\left(y^{\prime}-E\left[y^{\prime}\right]\right) \geq 0, \forall s^{\prime} \in S$, which is satisfied for all $s^{\prime} \in S$ as long as

$$
\theta \geq \bar{\theta} \equiv \frac{y\left(\bar{s}^{\prime}\right)-E\left[y^{\prime}\right]}{k^{*}(1-\delta)} \geq 0,
$$

where $y\left(\bar{s}^{\prime}\right)$ is the income in the highest state. As long as pledegeablity exceeds this lower bound, which is strictly positive if income is not deterministic, collateral is not scarce and there is full insurance in the steady state and $\beta R=1$. In contrast, in the analogous model with exogenously incomplete markets à la Huggett (1993) and Aiyagari (1994) the interest rate is below the rate of time preference in any equilibrium and the full-insurance allocation cannot be attained. Further, we can conclude the following in our model: 
Proposition 8. In equilibrium $\beta R \leq 1$ with equality iff $\theta \geq \bar{\theta}$.

We discuss the equilibrium when collateral is scarce below.

\subsection{Effect of Collateral Scarcity on Interest Rate and Insurance}

When the aggregate supply of collateralized assets is insufficient, that is, $\theta<\bar{\theta}$, collateral is scarce and the interest rate that clears the market for contingent claims satisfies $\beta R<1$, as Proposition 8 implies. The intuition is that if $\beta R$ equalled 1 , the households would fully insure, but then the demand for collateralized assets would strictly exceed the supply. Appendix $\mathrm{C}$ shows that there exists a unique stationary equilibrium in this case.

We demonstrate the effect of the scarcity of collateral on the equilibrium interest rate and insurance in Figure 3 by varying the collateralizability $\theta$ from 0 to values above $\bar{\theta}$. The top left of Panel A shows that the lower the collateralizability, the lower the interest rate, and that when the collateralizability exceeds $\bar{\theta}, \beta R=1$. The top right of Panel A shows that the aggregate demand for insurance claims $E\left[H^{\prime}\right]$ in equilibrium increases with the collateralizability; when $\theta=0$ the interest rate has to be sufficiently low so households do not demand insurance claims; the demand for collateralized claims increases with the collateralizability as the return on insurance claims increases. ${ }^{20}$ Since the supply of collateralized claims equals the demand in equilibrium, the supply of collateralized claims is also strictly increasing in the collateralizability. The bottom left of Panel A displays the aggregate durable goods stock; lower collateralizability reduces the interest rate and reduces the user cost of capital, increasing investment; when $\theta \geq \bar{\theta}$, investment is first-best efficient, in contrast to Aiyagari's (1994) result in a model with exogenously incomplete markets where investment is higher in any equilibrium.

The reduced equilibrium purchases of insurance claims mean that households are less well insured, resulting in a welfare loss, as the bottom right of Panel A shows. ${ }^{21}$ Reduced household insurance also implies more inequality, as Panel B illustrates. The top part shows the net worth distribution associated with various levels of collateralizability. When collateralizability exceeds $\bar{\theta}$, households are fully insured and the net worth distribution is degenerate at $w^{*}$. The lower the collateralizability, the less well insured households are and the more the wealth distribution fans out. Indeed, the standard deviation of net worth and consumption increase as collateralizability goes down, as the bottom part of

\footnotetext{
${ }^{20}$ The demand for collateralized claims is strictly increasing even when the collateralizability exceeds $\bar{\theta}$, but this is simply due to the fact that households start to purchase non-contingent claims in our implementation, effectively reducing leverage.

${ }^{21} \mathrm{We}$ measure the welfare loss as the equivalent reduction in expected income (in percent) in a deterministic economy that achieves the same welfare.
} 
Panel B illustrates. Collateral scarcity due to lower collateralizability reduces insurance and increases inequality.

Remarkably, the scarcity of collateral can lower the equilibrium interest rate so much that the frictionless Jorgensonian user cost of durable goods is negative. By rewriting the investment Euler equation (12), we define the user cost of durable goods (given net worth $w$ ) as

$$
u(w) \equiv r+\delta+E\left[\beta R \frac{\lambda^{\prime}}{\mu}\right](1-\theta)(1-\delta)=\beta R \frac{g_{k}(k)}{\mu},
$$

that is, the user cost of durable assets to a household with net worth $w$ has two components. The first is the Jorgensonian user cost that would prevail in a frictionless economy, $u \equiv r+\delta$. The second component is the premium on internal funds, which is the internal funds $(1-\theta)(1-\delta)$ that have to be put up by the household times the expectation of the scaled multiplier on the collateral or, equivalently, short-sales constraint $\lambda^{\prime}$. The marginal rate of substitution on the right hand side must be strictly positive, but the Jorgensonian user cost $r+\delta$ could be negative in equilibrium, and indeed is negative in our example for $\theta$ sufficiently low (see the top left of Panel A), because the premium on internal funds for households is positive as they are not fully insured and $\beta R<1$ in such an equilibrium.

Consider the economy with zero collateralizability, that is, $\theta=0$, and denote the equilibrium (shadow) interest rate by $R(0)$. At this interest rate, any household must choose not to buy any insurance claims, so $1 \geq \beta \frac{\mu^{\prime}}{\mu} R(0)$ with equality for at most one state $s^{\prime}$; therefore, $1>E\left[\beta \frac{\mu^{\prime}}{\mu} R(0)\right]$. Consider now households' demand for non-contingent claims; at $R(0)$ that demand is zero and there exists a (shadow) interest rate $\bar{R}>R(0)$ for which $1 \geq E\left[\beta \frac{\mu^{\prime}}{\mu} \bar{R}\right]$ with equality for some households. The interest rate that reduces the demand for insurance claims to zero for all households is therefore strictly lower than the interest rate that reduces the demand for non-contingent claims to zero. In this sense, the demand for state-contingent collateralized claims exceeds the demand for non-contingent collateralized claims at $\theta=0$. At the same time, state-contingent collateralized claims conserve collateral and a finite supply of collateralized claims, $\theta \geq \bar{\theta}$, suffices to accommodate the demand for such claims that allow households to fully insure, in contrast to incomplete markets economies.

Observe that the economy with durable goods nests the economy with income risk only which we considered in Section 2 by setting $\delta=1 .^{22}$ Further, we can characterize

\footnotetext{
${ }^{22}$ When $\delta=1$, the budget constraints for the next period (10) reduce to (3) and, since the down payment $\wp=1$ and defining $\hat{c} \equiv c+k$, using this change of notation the budget constraint for the current period (9) reduces to (2). Finally, defining $\hat{u}(\hat{c}) \equiv \max _{c, k} u(c)+\beta g(k)$ subject to $\hat{c} \geq c+k$ as before, where $\hat{c}$ is the consumption expenditure, the objective (8) is identical to (1) except for the change of notation. The indirect utility function $\hat{u}(\cdot)$ inherits the properties of $u(\cdot)$ and $g(\cdot)$.
} 
the equilibrium interest rate in the economy with income risk only as the limit of the economy with durable goods when $\delta \rightarrow 1 .^{23}$

In sum, the general equilibrium version of our model provides several novel insights in addition to endogenizing the assumption that $\beta R<1$ in the rest of the paper: collateral can be scarce even with purely idiosyncratic risk; collateral scarcity reduces the interest rate and insurance, increasing inequality; and a finite amount of collateral is sufficient to achieve the first best, with $\beta R=1$, when markets are complete except for collateral constraints.

\section{Durable Goods Price Risk Management}

In this section we consider households' hedging of durable goods price risk in addition to income risk. Moreover, we study households' choice between owning and renting durable goods and its interaction with the hedging of price risk. We show that financially constrained households choose not to hedge durable goods price risk. Moreover, households' ability to rent durables leads them to hedge due to the high implied leverage and indeed can affect the sign of the hedging demand.

\subsection{Risk Management and Durable Goods Price Risk}

We now consider an economy with durable goods price risk. Suppose the price of durable goods $q(s)$ is stochastic, where the state $s$ describes the joint evolution of income $y(s)$ and $q(s)$, and the economy is otherwise the same as in Section $3 .{ }^{24}$ For simplicity, we take the price process $q(s)$ and the interest rate $R$ as exogenously given here. As before, we assume without loss of generality that the household levers durable assets fully, that is, borrows $\hat{b}^{\prime}=R^{-1} \theta q^{\prime} k(1-\delta)$ against state $s^{\prime}, \forall s^{\prime} \in S$, and purchases Arrow securities in the amount $h^{\prime}, \forall s^{\prime} \in S$. The collateral constraints again reduce to short-sale constraints. Moreover, since the household borrows as much as possible against durable assets, the household pays down $\wp(s) \equiv q(s)-R^{-1} \theta E\left[q^{\prime} \mid s\right](1-\delta)$ per unit of durable assets purchased only.

\footnotetext{
${ }^{23}$ When $\delta \rightarrow 1$, the supply of collateralized assets is zero and there is no insurance. The equilibrium interest rate therefore has to be such that the first order condition for $h^{\prime},(7)$, is satisfied $\forall s^{\prime} \in S$ without insurance, and has to be just satisfied for a household with current income $\bar{y}$ who considers buying claims for the worst state next period, $\underline{y}$, that is, $\hat{u}_{c}(\bar{y})=\beta R \hat{u}_{c}(\underline{y})$, implying that the equilibrium interest rate is $R=\left(\beta \frac{\hat{u}_{c}(y)}{\hat{u}_{c}(\bar{y})}\right)^{-1}=\beta^{-1} \frac{\hat{u}_{c}(\bar{y})}{\hat{u}_{c}(y)}<\beta^{-1}$. In our example, $u(c)=\frac{c^{1-\gamma}}{1-\gamma}, g(k)=g \frac{k^{1-\gamma}}{1-\gamma}$, and the indirect utility function takes the form $\hat{u}(\hat{c})=\kappa \frac{\hat{c}^{1-\gamma}}{1-\gamma}$ where $\kappa$ is a constant; given the parameters in the numerical illustration, $R \approx-88 \%$.

${ }^{24}$ In Section 3, the price of durable goods is constant and normalized to 1.
} 
We assume that $q(s)$ and $\wp(s)$ are increasing in $s$, although some of our results obtain more generally.

The household's problem, formulated recursively, is to choose (non-negative) consumption $c$, (fully levered) durable goods $k$, and a portfolio of Arrow securities $h^{\prime}$ for each state $s^{\prime}$ (and associated net worth $w^{\prime}$ ) given the exogenous state $s$ and the net worth $w$ (cum current income and durable goods net of borrowing), to maximize (8) subject to the budget constraints for the current and next period, $\forall s^{\prime} \in S$,

$$
\begin{aligned}
w & \geq c+\wp(s) k+E\left[R^{-1} h^{\prime} \mid s\right], \\
y^{\prime}+(1-\theta) q^{\prime} k(1-\delta)+h^{\prime} & \geq w^{\prime}
\end{aligned}
$$

and the short-sale constraints (4), $\forall s^{\prime} \in S$.

Defining the multipliers as before, the first order conditions are (5) through (7) and

$$
\wp(s) \mu=\beta g_{k}(k)+E\left[\beta \mu^{\prime}(1-\theta) q^{\prime}(1-\delta) \mid s\right]
$$

The durable goods price affects the down payment $\wp(s)$ in the current period and the resale value of durable goods next period. If the household cannot pledge the full resale value of durables, that is, if $\theta<1$, then durable goods purchases force the household to implicitly save. Moreover, the household is then exposed to the price risk of durables in two ways: first, the resale value of durable goods affects the household's net worth next period, and second, the durable goods price affects the down payment which in turn affects the marginal value of net worth. If the household can pledge the full resale value of durables, that is, if $\theta=1$, the second term on the right hand side of (26) is zero, and the first order condition simplifies to $\wp(s) \mu=\beta g_{k}(k)$. In this case, the durable goods price only affects the household's problem through the down payment. We are able to characterize the solution explicitly in the case of isoelastic preferences with coefficient of relative risk aversion $\gamma \leq 1$ : household risk management is increasing. Specifically, we show that the economy is equivalent to an economy with income risk and preference shocks. Remarkably, with logarithmic preferences, households do not hedge the durable goods price risk at all, but may partially hedge income risk. With $\gamma<1$, higher durable goods prices, and hence higher down payments, reduce the marginal value of net worth as the substitution effect dominates the income effect. And vice versa, lower house prices amount to investment opportunities and raise the marginal value of net worth.

Proposition 9. Suppose $\theta=1$ and preferences satisfy $u(c)=c^{1-\gamma} /(1-\gamma)$ and $g(k)=$ $g k^{1-\gamma} /(1-\gamma)$ where $\gamma>0$ and $g>0$. (i) If $\gamma=1$ (logarithmic preferences), then $v(w, s)=(1+\beta g) \hat{v}(w, s)+v_{\varphi}(s)$, where $\hat{v}(w, s)$ solves the income risk management 
problem (without durable goods) in equations (1) through (4) and $v_{\varphi}(s)$ is an exogenous function defined in the proof. Household risk management is increasing in the sense of Propositions 1 and 2 and the household does not hedge durable goods price risk at all. (ii) For $\gamma \neq 1$, the problem is equivalent to an income risk management problem in an economy with preference shocks where $\hat{u}(\hat{c}, s)=\phi(s) u(\hat{c})$ with $\hat{c}$ and $\phi(s)$ defined in the proof. Household risk management is increasing in the sense of Proposition 1. Moreover, if $\Pi\left(s, s^{\prime}\right)$ is stochastically monotone, $\wp(s)$ is increasing in $s$, and $\gamma<1$, then the marginal value of net worth $v_{w}(w, s)$ is decreasing in $s$, the household hedges a lower set of states, and $w^{\prime}, h^{\prime}$, and $S_{h}$ are all increasing in $w$ and $s, \forall s, s^{\prime} \in S$.

More generally, when $\theta<1$, a drop in the durable goods price lowers the household's net worth and hence raises the marginal utility of net worth, and, when $\gamma<1$, the low durable goods price may further raise the marginal utility of net worth. Thus, households likely hedge low durable goods prices in this case. In contrast, when $\gamma>1$, a drop in the durable goods price has two opposing effects, on the one hand lowering net worth and on the other hand raising the marginal utility of net worth due to the price effect. This additional effect reduces the household's hedging demand. Under plausible parameterizations, the direct effect on net worth arguably dominates nonetheless, but this is of course a quantitative question. ${ }^{25}$

Figure 4 illustrates the effect of durable goods price risk on the household's consumption and insurance problem. We consider an example in which income and the price of durables are perfectly correlated, that is, there are two states only, one with high income and a high durable goods price and one with low income and a low durable goods price, ${ }^{26}$ and assume that the Markov process is independent across time. ${ }^{27}$ For given net worth, when the durable goods price is currently low, the household consumes more non-durables and durables and hedges less. The household hedges less because the higher durable goods purchases force the household to save more resulting in a higher level of net worth next period. At the bottom of the stationary distribution, and for levels of net worth below that, the household does not hedge at all. This implies that the household chooses not to hedge the price risk of durable goods when the household is sufficiently

\footnotetext{
${ }^{25}$ This result is reminiscent of the results in the consumption based asset pricing literature that show that investors' hedging demand in the presence of expected return variation depends in a similar way on the coefficient of relative risk aversion; investors hedge states with low expected returns when the coefficient of relative risk aversion exceeds 1 and otherwise hedge high expected returns (see, for example, Campbell (1996)).

${ }^{26} \mathrm{We}$ analyze the case where income and durable goods price processes are independent of each other in the next subsection.

${ }^{27}$ Persistence of the Markov process has quantitative but not qualitative effects on the solution.
} 
constrained.

\subsection{Risk Management and the Rent vs. Buy Decision}

In the analysis so far we have not considered households' ability to rent durable goods. If there were a frictionless rental market, ownership of a durable good and the use of its services would be separable. The need to collateralize claims might still limit risk sharing, but tenure choice would not affect households' portfolio choice. Moreover, households' demand for housing services would not induce a substantial financing need in that case.

We consider a rental market that is not frictionless. Renting durable goods is possible, albeit costly, but relaxes collateral constraints as landlords or lessors can more easily repossess rented durables. ${ }^{28}$ Sufficiently constrained households choose to rent, which affects their risk management or portfolio choice. Because renting housing is costly, households will continue to have a strong incentive to own housing and hence face considerable financing needs for housing. We are able to characterize the interaction between risk management and home ownership since in our model markets are complete, although subject to collateral constraints. In contrast the literature typically studies the interaction of the risk of home ownership and portfolio choice under the assumption that markets are incomplete. Sinai and Souleles (2005) argue that both home ownership and renting are risky when households do not have access to complete markets. ${ }^{29}$

The household can purchase durable goods as before as well as rent them. We denote the total amount of durable goods of the household by $k$, owned durables by $k_{o}$ and rented durables by $k_{l}$, where $k=k_{o}+k_{l}$. Given the current price of durables $q(s)$ in state $s$, the user cost of rented capital is $u_{l}(s) \equiv r q(s)-\left(E\left[q^{\prime} \mid s\right]-q(s)\right)+E\left[q^{\prime} \mid s\right](\delta+m)$ where $m$ is the landlord's or lessor's monitoring cost per unit of durable asset, which we assume is paid in terms of durable goods at the end of the period. ${ }^{30}$ Because of limited enforcement, the household has to pay the rental fee up front, in present value terms, that is, $R^{-1} u_{l}(s)$.

The household's problem with renting, formulated recursively, is to choose (nonnegative) consumption $c$, (fully levered) owned and rented durable goods $k_{o}$ and $k_{l}$ and a portfolio of Arrow securities $h^{\prime}$ for each state $s^{\prime}$ (and associated net worth $w^{\prime}$ ) given the

\footnotetext{
${ }^{28}$ Eisfeldt and Rampini (2009) and Rampini and Viswanathan (2013) analyze a similar market for rented capital in a corporate finance context.

${ }^{29}$ Our model may also provide a useful framework to study household interest rate risk management, which Campbell and Cocco (2003) model as the choice of mortgage type, specifically the choice between adjustable rate mortgages (ARMs) and fixed rate mortgages.

${ }^{30}$ Note that if the price of durable goods were constant and normalized to 1 , then $u_{l}=r+\delta+m$ which is the sum of Jorgenson's (1963) frictionless user cost $r+\delta$ plus the monitoring cost $m$. The additional term adjusts the user cost for the expected capital gain or loss $E\left[q^{\prime} \mid s\right]-q(s)$.
} 
exogenous state $s$ and the net worth $w$ (cum current income and owned durable goods net of borrowing), to maximize (8) subject to the budget constraints for the current and next period, $\forall s^{\prime} \in S$,

$$
\begin{aligned}
w & \geq c+\wp(s) k_{o}+R^{-1} u_{l}(s) k_{l}+E\left[R^{-1} h^{\prime} \mid s\right], \\
y^{\prime}+(1-\theta) q^{\prime} k_{o}(1-\delta)+h^{\prime} & \geq w^{\prime}
\end{aligned}
$$

the non-negativity constraints on owned and rented durables,

$$
k_{o}, k_{l} \geq 0
$$

and the short-sale constraints (4), $\forall s^{\prime} \in S$.

Defining the multipliers as before, the first order conditions are (5) through (7) and

$$
\begin{aligned}
\wp(s) \mu & \geq \beta g_{k}(k)+E\left[\beta \mu^{\prime}(1-\theta) q^{\prime}(1-\delta) \mid s\right], \\
R^{-1} u_{l}(s) \mu & \geq \beta g_{k}(k) .
\end{aligned}
$$

Using (30) and (31) one can show that a necessary condition for the household to rent some durables is that the down payment required to purchase durables exceeds the rental cost, that is, $\wp(s)-R^{-1} u_{l}(s)>0$, as renting is otherwise dominated. Moreover, when the household is severely constrained, the household rents all its durable assets; the intuition is that renting durables allows the household to borrow more. Such households also typically do not hedge as noted throughout. There is an interesting interaction between the rent vs. buy decision and hedging. Since renting allows higher leverage, renters' net worth becomes rather volatile, and hence renters with sufficient net worth may partially hedge until they reach net worth levels where they start to own their durables. Households with higher net worth on the other hand own some or all of their durables, and may hedge income and durable goods price risk. This implies that household risk management may no longer be monotone in household net worth.

Interestingly, renters' hedging demand for durable goods price risk may have the opposite sign from that of households who own most of their durables. That said, since renting is endogenous and more constrained households rent, the demand from renters for hedging claims which pay off in high durable goods price states may be low.

Figure 5 illustrates risk management when households can rent and buy durables, say housing. We assume that the income and price processes are independent of each other and independent across time. This allows us to separate hedging of income and price risk. The bottom right panel shows that households rent when their net worth is low but substitute to owning houses as net worth increases. Rented houses are smaller than owned houses because renters are low net worth households. Households rent and 
buy smaller houses, and consume fewer non-durables, when the price of housing is high. Moreover, households start to own housing at higher levels of net worth, so rent longer, when the price of housing is high, as high house prices imply larger downpayments and hence households are more constrained all else equal, that is, for given net worth.

The top left panel shows households' risk management which displays the by now familiar properties with two noteworthy changes: since renting allows higher leverage, households are more inclined to hedge when they rent; indeed, for moderate levels of net worth households are hedging but switch back to not hedging at all at higher levels of net worth. Thus, hedging is no longer monotone increasing in net worth. Moreover, the housing price affects the level of hedging as households purchase larger houses when the price is low forcing them to save more and in turn reducing their incentives to save, and hedge, using financial assets.

The other main additional insight regards the sign of the hedging demand: households, in particular renters, hedge the high house price state. Note that when income and the price of housing are independent, there are four states next period that households could hedge. As before, households primarily hedge the low income state, except for households with very high net worth. More interestingly, households hedge the high price state, that is, buy more claims for the state with low income and high house prices than for the state with low income and low house prices; to see this in the figure, note that the dashed lines (associated with high house prices) are above the corresponding solid lines (associated with low house prices). Here it is important to keep in mind that the example features isoelastic preferences with $\gamma=2$. Renting has implied collateralization one and hence the fact that renters hedge the high house price state is related to the results in Proposition 9 for $\gamma>1$; high house prices increase the marginal value of net worth, all else equal. For owners there is an additional effect, that is, all else is not equal: owners' home equity $(1-\theta) q^{\prime} k(1-\delta)$ is worth more when house prices are high. This effect reduces the marginal utility of net worth when prices are high, but in the example the first effect dominates and even home owners hedge the high price state somewhat more.

Our results on durable goods price risk management lead to two important conclusions. First, financial constraints may be at the heart of the absence of hedging of house prices. Second, the sign of the hedging demand depends on households' preferences, their ability to borrow, and on whether households rent or buy. 


\section{Evidence on Household Insurance}

In this section we briefly survey evidence of what we consider a stylized fact, namely that poor (and more financially constrained) households are less well insured than richer (and less financially constrained) households. Indeed, we think this is part of a much broader pattern applying to entrepreneurial households and firms as well, and we briefly discuss evidence on risk management by Indian farmers suggesting that financial constraints reduce risk management substantially. ${ }^{31}$

Among U.S. households, health insurance coverage varies considerably with income and age according to data from the U.S. Census Bureau. ${ }^{32}$ The percentage of people without health insurance in the U.S. decreases from $25 \%$ of people with income less than $\$ 25,000$ to $21 \%$ for people with income between $\$ 25,000$ and $\$ 50,000$, and further decreases to $15 \%$ of people with income between $\$ 50,000$ and $\$ 75,000$ and finally decreases to $8 \%$ of people with income exceeding $\$ 75,000$. Similarly, by age, the fraction of adults without health insurance decreases from $28 \%$ and $26 \%$ for age groups 18-24 and 25-34, respectively, to $18 \%$ and $14 \%$ for age groups 35-44 and 45-64, respectively, and to less than $2 \%$ for age group 65 and up. Krebs, Kuhn, and Wright (2015) find that the median young married household with children insures only between $10 \%$ and $40 \%$ of the net present value loss associated with the death of an adult family member, whereas older households are close to fully insured. Brown and Finkelstein (2007) report that participation in longterm care insurance by individuals aged 60 and over also varies substantially by wealth in U.S. data, increasing from about $3 \%$ for the bottom wealth quartile to about $6 \%, 11 \%$, and $20 \%$ for the second, third, and top quartile, respectively. ${ }^{33}$ Inkmann, Lopes, and Michaelides (2011) find that annuity market participation among U.K. households with at least one retired person increases substantially with financial wealth, from less than $1 \%$ in the bottom $5 \%$ to almost $20 \%$ in the top $5 \%$ of the wealth distribution. Browne and Hoyt (2000) find that flood insurance coverage, both in terms of the number of policies

\footnotetext{
${ }^{31}$ For firms, Rampini, Sufi, and Viswanathan (2014) find a strong positive correlation between net worth and risk management both in the cross section and within firms over time in data on fuel price risk management by U.S. airlines. Moreover, fuel price hedging drops remarkably as airlines approach distress and recovers only slowly after distress. Relatedly, the corporate finance literature documents a strong size pattern in risk management, when measured by participation of firms in derivatives markets, among U.S. corporations overall. Thus, the basic pattern for corporate insurance seems to be the same as for households: better financed firms are better hedged than poorly financed firms.

${ }^{32}$ Table 6 of the U.S. Census Bureau's Report on Income, Poverty, and Health Insurance Coverage in the United States: 2007 provides data on people without health insurance coverage by income and age.

${ }^{33}$ See their Table 1 which provides data on private long-term care insurance ownership rates among individuals aged 60 and over from the 2000 Health and Retirement Survey.
} 
per capita and the amount of coverage per capita, is positively correlated with disposable personal income per capita using U.S. state level data.

Clearly, the extent to which households are insured varies substantially with households' income and, assuming that younger individuals and households are more financially constrained, also seems to vary with financial constraints. This cross-sectional evidence is consistent with the view that there is an important connection between household risk management and households' financial constraints. That said, there are certainly other reasons why insurance participation varies with income, such as crowding out of private insurance by public programs, as stressed, for example, by Brown and Finkelstein (2008), financial literacy that varies with income, or fixed costs of obtaining insurance. We now turn to data documenting the relation between insurance coverage and income using within-household variation, which is consistent with our theory and challenges explanations based on financial literacy or fixed costs.

Fang and Kung (2012) use panel data for males from the Health and Retirement Survey, a representative longitudinal survey of older Americans conducted every two years. They find that income shocks are one of the important determinants of whether individuals maintain or lapse life insurance coverage, along with changes in health and marital status. The probability of buying life insurance increases with income and importantly the probability of lapsing coverage decreases with income; "individuals who experience negative income shocks are more likely to lapse all coverage." Therefore, the within-household variation in insurance coverage is consistent with the predictions of our model.

Among farmers in rural India, Giné, Townsend, and Vickery (2008) find that participation in rainfall insurance programs increases in wealth and decreases with measures of borrowing constraints. Cole, Giné, Tobacman, Topalova, Townsend, and Vickery (2013) provide evidence on the importance of credit constraints for the adoption of rainfall insurance using randomized field experiments in rural India. Farmers who are randomly surprised with a positive liquidity shock are much more likely to buy insurance. Moreover, the authors report that the most frequently stated reason for not purchasing insurance is "insufficient funds to buy insurance." Farmers might of course use other risk sharing mechanisms, including informal ones. To overcome the limitation of analyzing specific risk sharing mechanisms in isolation, Townsend (1994) studies data on Indian farmers' household consumption directly in a seminal paper, and finds that, while the full insurance model provides a remarkably good benchmark, "[t]here is evidence that the landless are less well insured than their village neighbors in one of the three villages." That is, there is "a hint of a pattern by land class. Specifically, the landless and small farmers in Aurepalle and the small and medium farmers in Shirapur seem more vulnerable." 
In the spirit of Townsend (1994), Blundell, Pistaferri, and Preston (2008) study the extent of insurance by analyzing the income and consumption distribution for U.S. households jointly. They find "some partial insurance of permanent shocks, especially for the college educated and those near retirement. [They] find full insurance of transitory shocks except among poor households." Overall, we conclude that there is a basic pattern in household insurance: richer households are better insured than poorer households.

That said, much of the existing evidence is on the extensive margin of insurance that is, whether households do or do not have a particular type of coverage - and mostly cross-sectional in nature with limited panel dimension. The main empirical prediction of our theory is that household insurance increases in net worth not just at the extensive margin, but also importantly at the intensive margin, both across and within households. To date, evidence on the intensive margin of household insurance is limited. Our model provides a guide for empirical work on within-household variation of the intensive margin of insurance in household panel data going forward.

\section{Conclusion}

An explicit analysis of household risk management is provided in which households have access to complete markets subject to collateral constraints. With limited enforcement, insurance may be better viewed as state-contingent savings and hence insurance and financing are fundamentally connected. We show the optimality of increasing household risk management, that is, risk management that increases in household net worth and income, under quite general conditions. Moreover, household risk management is precautionary in the sense that an increase in uncertainty increases risk management. Remarkably, risk aversion alone is sufficient for this result and assumptions on prudence, that is, the third derivative of the utility function, are not required to guarantee this result, in contrast to the classic results on precautionary savings using risk-free assets.

Durable goods, most importantly housing, are used as collateral. In the absence of a frictionless rental market, households' demand for the services of consumer durables results in substantial financing needs. We show that if these financing needs are sufficiently strong, they override hedging concerns, which explains the limited extent, or lack, of household risk management. In our view, proposals to introduce new markets providing household risk management tools are hence unlikely to be successful, as many households may not use such markets even if they exist.

The fact that household risk management may require collateral in the form of margins has been recognized in the literature, but not explicitly analyzed. For example, 
Athanasoulis and Shiller (2000) write that "[m]argin requirements might deal with this [collection] problem, but only for people who have sufficient assets as margin. We will disregard these kinds of ... problems." Our work, in contrast, suggests that collateral constraints, together with households' intertemporal financing needs, are at the heart of the explanation why household risk management is limited and key to understanding the basic patterns in household insurance.

The main empirical prediction of our theory - that household insurance increases in net worth at both the intensive and extensive margin, across and within households - is consistent with the basic patterns documented in the existing literature. That said, the theory provides a guide for empirical work on the within-household dynamics of insurance at both the intensive and extensive margin, on which there is limited evidence to date. 


\section{Appendix A: Proofs}

Proof of Proposition 1. Part (i): Suppose $\exists \hat{s}^{\prime} \in S_{h}$ such that $\hat{s}^{\prime} \notin S_{h+}$. Using (7), (6), the envelope condition, and strict concavity of the value function we have

$$
\beta R v_{w}\left(w\left(\hat{s}^{\prime}\right), \hat{s}^{\prime}\right)=v_{w}(w, s)>v_{w}\left(w_{+}, s\right) \geq \beta R v_{w}\left(w_{+}\left(\hat{s}^{\prime}\right), \hat{s}^{\prime}\right),
$$

implying, again by strict concavity of the value function, that $w\left(\hat{s}^{\prime}\right)<w_{+}\left(\hat{s}^{\prime}\right)$. But $w\left(\hat{s}^{\prime}\right)=$ $y\left(\hat{s}^{\prime}\right)+h\left(\hat{s}^{\prime}\right)>y\left(\hat{s}^{\prime}\right)=w_{+}\left(\hat{s}^{\prime}\right)$, a contradiction.

Part (ii): Note that $w_{+}^{\prime} \geq w^{\prime}, \forall s^{\prime} \in S$, implies that $y^{\prime}+h_{+}^{\prime}=w_{+}^{\prime} \geq w^{\prime}=y^{\prime}+h^{\prime}$, that is, $h_{+}^{\prime} \geq h^{\prime}, \forall s^{\prime} \in S$, and hence $E\left[h_{+}^{\prime} \mid s\right] \geq E\left[h^{\prime} \mid s\right]$, and, using the envelope condition, $u_{c}\left(c_{+}^{\prime}\right)=v_{w}\left(w_{+}^{\prime}, s^{\prime}\right) \leq v_{w}\left(w^{\prime}, s^{\prime}\right)=u_{c}\left(c^{\prime}\right)$, implying that $c_{+}^{\prime} \geq c^{\prime}$. To see that $w_{+}^{\prime} \geq w^{\prime}, \forall s^{\prime} \in S$, suppose not, that is, suppose $\exists \hat{s}^{\prime} \in S$, such that $w_{+}\left(\hat{s}^{\prime}\right)<w\left(\hat{s}^{\prime}\right)$, i.e., $h_{+}\left(\hat{s}^{\prime}\right)<h\left(\hat{s}^{\prime}\right)$. Proceeding as in part (i), since $h\left(\hat{s}^{\prime}\right)>0, \beta R v_{w}\left(w\left(\hat{s}^{\prime}\right), \hat{s}^{\prime}\right)=v_{w}(w, s)>$ $v_{w}\left(w_{+}, s\right) \geq \beta R v_{w}\left(w_{+}\left(\hat{s}^{\prime}\right), \hat{s}^{\prime}\right)$, implying that $w_{+}\left(\hat{s}^{\prime}\right)>w\left(\hat{s}^{\prime}\right)$, a contradiction. Finally, for $s^{\prime}, \hat{s}^{\prime} \in S_{h}$, using (7), (6), and the envelope condition for next period, we have $\beta R u_{c}\left(c\left(s^{\prime}\right)\right)=v_{w}(w, s)=\beta R u_{c}\left(c\left(\hat{s}^{\prime}\right)\right)$, that is, $c\left(s^{\prime}\right)=c\left(\hat{s}^{\prime}\right) \equiv c_{h}$. By strict concavity of the value and utility function, $c_{h}$ is strictly increasing in $w$ when $S_{h}$ is non-empty.

Proof of Proposition 2. Part (i) \& (ii) Define the operator $T$ as

$$
T v(w, s) \equiv \max _{c, h^{\prime}, w^{\prime} \in \mathbb{R}_{+} \times \mathbb{R}^{2 S}} u(c)+\beta E\left[v\left(w^{\prime}, s^{\prime}\right) \mid s\right]
$$

subject to equations (2) through (4). We show that if $v$ is a weakly concave function in $w$ and has the property that $\forall s, s_{+}, s_{+}>s$,

$$
\frac{v\left(\hat{w}, s_{+}\right)-v\left(w, s_{+}\right)}{\hat{w}-w} \leq \frac{v(\hat{w}, s)-v(w, s)}{\hat{w}-w}, \quad \forall \hat{w}, w
$$

then $T v$ inherits this property. Since the set $\mathcal{S}$ of bounded, continuous, and weakly concave functions which satisfy the property is closed under the sup norm, the fixed point has the property, too.

Recall that for any concave function, the left and right derivatives exist and denote these by $v_{w}^{-}(w, s)$ and $v_{w}^{+}(w, s)$, respectively; by concavity, $v_{w}^{-}(w, s) \geq v_{w}^{+}(w, s)$. For $v \in \mathcal{S}, v_{w}^{-}\left(w, s_{+}^{\prime}\right) \leq v_{w}^{-}\left(w, s^{\prime}\right)$ and $v_{w}^{+}\left(w, s_{+}^{\prime}\right) \leq v_{w}^{+}\left(w, s^{\prime}\right)$. Let the set $\mathcal{S}^{o}$ of bounded, continuous, strictly concave, and differentiable functions which satisfy the property that $\forall s^{\prime}, s_{+}^{\prime}, s_{+}^{\prime}>s^{\prime}, v_{w}\left(w, s_{+}^{\prime}\right) \leq v_{w}\left(w, s^{\prime}\right), \forall w$. The set $\mathcal{S}^{o}$ is not a closed set under the sup norm, but $\mathcal{S}^{o} \subset \mathcal{S}$. We show that $T(\mathcal{S}) \subset \mathcal{S}^{o} \subset \mathcal{S}$ and use Corollary 1 to Theorem 3.2 of Stokey, Lucas with Prescott (1989) to conclude that $v=T v \in \mathcal{S}^{o}$.

Using an argument similar to the proof of Theorem 9.8 in Stokey, Lucas with Prescott (1989), one can show that $T v(w, s)$ is strictly concave and using Benveniste and Scheinkman $(1979) T v(w, s)$ is differentiable (see footnote 10). Suppose $v \in \mathcal{S}$. For given $w$ and $s$, suppose $\exists s_{+}^{\prime}>s^{\prime}$ such that $h\left(s_{+}^{\prime}\right)>h\left(s^{\prime}\right)$. Note that the first order condition with respect to $h^{\prime}$ can be written as $T v_{w}(w, s) \geq \beta R v_{w}^{-}\left(w^{\prime}, s^{\prime}\right)$ if $h^{\prime}=0$ and $T v_{w}(w, s) \in$ $\left[\beta R v_{w}^{+}\left(w^{\prime}, s^{\prime}\right), \beta R v_{w}^{-}\left(w^{\prime}, s^{\prime}\right)\right]$ if $h^{\prime}>0$. Then $\beta R v_{w}^{-}\left(w\left(s_{+}^{\prime}\right), s_{+}^{\prime}\right) \geq v_{w}(w, s) \geq \beta R v_{w}^{-}\left(w\left(s^{\prime}\right), s^{\prime}\right)$, 
implying, given the assumed property, that $w\left(s_{+}^{\prime}\right) \leq w\left(s^{\prime}\right)$. But $w\left(s_{+}^{\prime}\right)=y\left(s_{+}^{\prime}\right)+h\left(s_{+}^{\prime}\right)>$ $y\left(s^{\prime}\right)+h\left(s^{\prime}\right)=w\left(s^{\prime}\right)$, a contradiction. Therefore, $h\left(s_{+}^{\prime}\right) \leq h\left(s^{\prime}\right), \forall s_{+}^{\prime}>s^{\prime}$, that is, the household hedges lower income realizations (weakly) more. Hence, the household hedges a lower set of states, if at all.

Denote the set of states that the household hedges by $S_{h} \equiv\left\{s^{\prime} \in S: h\left(s^{\prime}\right)>0\right\}$. Take $s_{+}>s$ and let $S_{h+}$ be associated with $s_{+}$(and similarly for other variables). Suppose $\exists s_{+}>s$, such that $T v_{w}\left(w, s_{+}\right)>T v_{w}(w, s)$ and, using the envelope condition, $c_{+}<c$. Since $h^{\prime}$ is decreasing in $s^{\prime}$, stochastic monotonicity implies that $E\left[h^{\prime} \mid s\right] \geq E\left[h^{\prime} \mid s_{+}\right]$and hence (2) implies that the solution at $s,\left\{c, h^{\prime}, w^{\prime}\right\}$, is feasible at $s_{+}$. Since we assumed that $c_{+}<c$, there must exist an $\hat{s}^{\prime} \in S$ such that $h_{+}\left(\hat{s}^{\prime}\right)>h\left(\hat{s}^{\prime}\right)$ since otherwise the household would not spend all its net worth. Using the first order condition stated above and the envelope condition, we have

$$
T v_{w}\left(w, s_{+}\right) \leq \beta R v_{w}^{-}\left(w_{+}\left(\hat{s}^{\prime}\right), \hat{s}^{\prime}\right) \leq \beta R v_{w}^{+}\left(w\left(\hat{s}^{\prime}\right), \hat{s}^{\prime}\right) \leq \beta R v_{w}^{+}\left(w\left(\hat{s}^{\prime}\right), s^{\prime}\right) \leq T v_{w}(w, s),
$$

a contradiction. Thus $T v$ inherits the property that $\forall s, s_{+}, s_{+}>s, T v_{w}\left(w, s_{+}\right) \leq$ $T v_{w}(w, s)$; moreover, $\operatorname{Tv}(w, s)$ is a strictly concave differentiable function, and hence $T(\mathcal{S}) \subset \mathcal{S}^{o} \subset \mathcal{S}$.

As a corollary of Proposition $1, w^{\prime}, h^{\prime}, S_{h}$, and $c_{h}$ are increasing in $w$ given $s, \forall s^{\prime} \in S$. To see that $S_{h}$ is increasing in $s$ given $w$, take $s_{+}>s$ and suppose instead that $\exists \hat{s}^{\prime}$ such that $h\left(\hat{s}^{\prime}\right)>0$ but $h_{+}\left(\hat{s}^{\prime}\right)=0$. Then $\beta R v_{w}\left(y\left(\hat{s}^{\prime}\right), \hat{s}^{\prime}\right) \leq v_{w}\left(w, s_{+}\right) \leq v_{w}(w, s)=$ $\beta R v_{w}\left(w\left(\hat{s}^{\prime}\right), \hat{s}^{\prime}\right)$ which implies $w\left(\hat{s}^{\prime}\right) \leq y\left(\hat{s}^{\prime}\right)$, contradicting $w\left(\hat{s}^{\prime}\right)=y\left(\hat{s}^{\prime}\right)+h\left(\hat{s}^{\prime}\right)>y\left(\hat{s}^{\prime}\right)$. Thus, any state that the household hedges at $s$, the household hedges at $s_{+}>s$, that is, $S_{h}$ is increasing in $s$. If the household hedges $s^{\prime}$ at $s_{+}$but not at $s$, then clearly $w_{+}^{\prime}>w^{\prime}$ and $h_{+}^{\prime}>h^{\prime}$. If the household hedges $s^{\prime}$ at both $s_{+}$and $s$, then $\beta R v_{w}\left(w_{+}^{\prime}, s^{\prime}\right)=$ $v_{w}\left(w, s_{+}\right) \leq v_{w}(w, s)=\beta R v_{w}\left(w^{\prime}, s^{\prime}\right)$ and hence $w_{+}^{\prime} \geq w^{\prime}$ and $h_{+}^{\prime} \geq h^{\prime}$. Thus, $w^{\prime}$ and $h^{\prime}$ are increasing in $s$. Moreover, since $w^{\prime}$ is increasing in $s$, the envelope condition for next period $v_{w}\left(w^{\prime}, s^{\prime}\right)=u_{c}\left(c^{\prime}\right)$ implies that $c^{\prime}$, and $c_{h}$, are increasing in $s$ as well.

Part (iii): Take $w_{+}>w$ and denote with a subscript + the optimal policy associated with $w_{+}$. Let $\tilde{w}^{\prime} \equiv w^{\prime}-E\left[w^{\prime}\right], \tilde{w}_{h} \equiv w_{h}-E\left[w^{\prime}\right]$, (and $\tilde{y}^{\prime}=y^{\prime}-E\left[w^{\prime}\right]$, ) and analogously for $\tilde{w}_{+}^{\prime}, \tilde{w}_{h+}$, and $\tilde{y}_{+}^{\prime}$. We need to show that $\operatorname{var}\left(\tilde{w}_{+}^{\prime}\right) \leq \operatorname{var}\left(\tilde{w}^{\prime}\right)$. Note that $\tilde{w}^{\prime}=\max \left\{\tilde{w}_{h}, \tilde{y}^{\prime}\right\}$ and analogously for $\tilde{w}_{+}^{\prime}$. If $\tilde{w}_{h+}=\tilde{w}_{h}$, then $\tilde{w}_{+}^{\prime}=\tilde{w}^{\prime}$ and the result is obvious. Otherwise, noting that $E\left[w_{+}^{\prime}\right]-E\left[w^{\prime}\right] \leq w_{h+}-w_{h}$, we have $\tilde{w}_{h+}>\tilde{w}_{h}$, and hence $E\left[w_{+}^{\prime}\right]>E\left[w^{\prime}\right]$. Moreover, $\tilde{w}_{+}^{\prime}<\tilde{w}^{\prime}, \forall s^{\prime} \in S$ such that $\tilde{w}^{\prime}>0$ and $E\left[\tilde{w}_{+}^{\prime} \mid \tilde{w}_{+}^{\prime}>0\right]<E\left[\tilde{w}^{\prime} \mid \tilde{w}^{\prime}>0\right]$. We construct a random variable $\hat{\tilde{w}}_{+}^{\prime}$ such that $\tilde{w}^{\prime}$ is a mean preserving spread of $\hat{\tilde{w}}_{+}^{\prime}$ and $\hat{\tilde{w}}_{+}^{\prime}$ is in turn a mean preserving spread of $\tilde{w}_{+}^{\prime}$. Let $\hat{\tilde{w}}_{+}^{\prime} \equiv \max \left\{\tilde{w}_{+}^{\prime}, 0\right\}, \forall s^{\prime} \in S$ such that $\tilde{w}^{\prime}>0$ and $\hat{\tilde{w}}_{+}^{\prime} \equiv \max \left\{\hat{\tilde{w}}_{h}, \tilde{y}^{\prime}\right\}$ otherwise, where $\hat{\tilde{w}}_{h}$ such that $E\left[\hat{\tilde{w}}_{+}^{\prime}\right]=0$. Note that $\exists \hat{\tilde{w}}_{h} \in\left(\tilde{w}_{h}, \tilde{w}_{h+}\right]$ since $E\left[\tilde{w}^{\prime} \mid \tilde{w}^{\prime}>0\right]>E\left[\tilde{w}_{+}^{\prime} \mid \tilde{w}_{+}^{\prime}>0\right]=E\left[\tilde{\tilde{w}}^{\prime} \mid \tilde{w}^{\prime}>0\right]$ and thus $E\left[\tilde{w}_{+}^{\prime} \mid \tilde{w}_{+}^{\prime} \leq 0\right]=E\left[\hat{\tilde{w}}_{+}^{\prime} \mid \tilde{w}^{\prime} \leq 0\right]>E\left[\tilde{w}^{\prime} \mid \tilde{w}^{\prime} \leq 0\right]$. Since $\left|\hat{\tilde{w}}_{+}^{\prime}\right| \leq\left|\tilde{w}^{\prime}\right|, \forall s^{\prime} \in S$, with strict inequality for some $s^{\prime} \in S, \operatorname{var}\left(\hat{\tilde{w}}_{+}^{\prime}\right)<\operatorname{var}\left(\tilde{w}^{\prime}\right)$. Moreover, $E\left[\hat{\tilde{w}}_{+}^{\prime}-\tilde{w}_{+}^{\prime}\right]=0$ and $\hat{\tilde{w}}_{+}^{\prime}$ is a mean preserving spread of $\tilde{w}_{+}^{\prime}$, that is, $\operatorname{var}\left(\tilde{w}_{+}^{\prime}\right)<\operatorname{var}\left(\hat{\tilde{w}}_{+}^{\prime}\right)<\operatorname{var}\left(\tilde{w}^{\prime}\right)$. Moreover, consumption $c$ is monotone and strictly increasing in net worth $w$ and, defining $\tilde{c}^{\prime}, \tilde{c}_{h}, \tilde{c}_{+}^{\prime}$, and $\tilde{c}_{h+}$ analogously, we can proceed in a similar fashion for consumption. 
Proof of Proposition 3. Part (i): Using (6) and the envelope condition, equation (7) evaluated at $w=y$ and $s=\underline{s}$ implies that $\beta R \lambda\left(\underline{s}^{\prime}\right)=v_{w}(y, \underline{s})-\beta R v_{w}\left(w\left(\underline{s}^{\prime}\right), \underline{s}^{\prime}\right) \geq$ $(1-\beta R) v_{w}(\underline{y}, \underline{s})>0$ where we used the fact that $w\left(\underline{s}^{\prime}\right) \geq \underline{y}$. But then Part (ii) of Proposition 2 implies that $S_{h}=\emptyset$.

Part (ii): At net worth $w=\bar{y}$, using (7) and the envelope condition, we have $v_{w}(\bar{y}, s)=\beta R v_{w}\left(w\left(\bar{s}^{\prime}\right), \bar{s}^{\prime}\right)+\beta R \lambda\left(\bar{s}^{\prime}\right)$ which implies that $\lambda\left(\bar{s}^{\prime}\right)>0$ since $w\left(\bar{s}^{\prime}\right) \geq \bar{y}$ and hence, by strict concavity of $v$ and the fact that $v_{w}(w, s)$ is decreasing in $s$ (see Part (i) of Proposition 2), $\beta R \lambda\left(\bar{s}^{\prime}\right)=v_{w}(\bar{y}, s)-\beta R v_{w}\left(w\left(\bar{s}^{\prime}\right), \bar{s}^{\prime}\right) \geq(1-\beta R) v_{w}(\bar{y}, s)>0$.

Proof of Proposition 4. Part (i): We first argue that levels of net worth below $y$ and above $w_{b n d}(s), \forall s \in S$, defined below, are transient. Using (3) which holds with equality and (4) we have $w^{\prime} \geq y^{\prime} \geq y$ and hence levels of net worth below $y$ are transient, $\forall s \in S$. Using part (ii) of Proposition $3, \forall w \leq \bar{y}, \lambda\left(\bar{s}^{\prime}\right)>0, \forall s \in S$. Suppose $S_{h}=\emptyset$ at $(\bar{y}, \bar{s})$, then since hedging is increasing, $S_{h}=\emptyset, \forall(w, s)$ with $w \leq \bar{y}$. Therefore, once $w \leq \bar{y}$, net worth never exceeds $\bar{y}$ again. Suppose $S_{h} \neq \emptyset$ at $(\bar{w}, \bar{s})$; then $v_{w}(\bar{y}, \bar{s})=\beta R v_{w}\left(w^{\prime}, s^{\prime}\right)$, $\forall s^{\prime} \in S_{h}$, and let $w_{b n d}\left(s^{\prime}\right)$ solve this equation $\forall s^{\prime} \in S_{h}$. Moreover, define $w_{b n d}\left(s^{\prime}\right)=y\left(s^{\prime}\right)$, $\forall s^{\prime} \in S \backslash S_{h}$. By part (i) of Proposition 2, $v_{w}\left(w^{\prime}, s^{\prime}\right)$ is decreasing in $s^{\prime}$ and hence $w_{b n d}\left(s^{\prime}\right)$ is decreasing in $s^{\prime}, \forall s^{\prime} \in S_{h}$, and $w_{b n d}\left(\underline{s}^{\prime}\right)=\max _{s^{\prime} \in S_{h}} w_{b n d}\left(s^{\prime}\right)$. Note that for any $s \in S$, $\forall w \leq w_{\text {bnd }}(s), w^{\prime} \leq w_{\text {bnd }}\left(s^{\prime}\right), \forall s^{\prime} \in S$. To see this, suppose instead that $\exists \hat{s}^{\prime}$ such that $w^{\prime}>w_{b n d}\left(\hat{s}^{\prime}\right)$. If $w \leq \bar{y}$, both $w$ and $s$ are smaller than or equal $\bar{y}$ and $\bar{s}$, respectively, and the fact that $w^{\prime}$ is increasing in $w$ and $s$ (see part (ii) of Proposition 2) implies $w^{\prime} \leq w_{b n d}\left(\hat{s}^{\prime}\right)$, a contradiction. Therefore, $w>\bar{y}$ and $w_{b n d}(s)>y(s)$; moreover,

$$
\begin{aligned}
v_{w}\left(w_{b n d}(s), s\right) & \leq v_{w}(w, s)=\beta R v_{w}\left(w^{\prime}, \hat{s}^{\prime}\right)+\beta R \lambda\left(\hat{s}^{\prime}\right)<\beta R v_{w}\left(w_{b n d}\left(\hat{s}^{\prime}\right), \hat{s}^{\prime}\right) \\
& \leq v_{w}(\bar{y}, \bar{s})=\beta R v_{w}\left(w_{b n d}(s), s\right)<v_{w}\left(w_{b n d}(s), s\right)
\end{aligned}
$$

a contradiction. Thus, for any $s \in S$, once $w \leq w_{b n d}(s), w^{\prime} \leq w_{b n d}\left(s^{\prime}\right), \forall s^{\prime} \in S$, and let $w_{\text {bnd }}=\max \left\{\bar{y}, w_{\text {bnd }}\left(\underline{s}^{\prime}\right)\right\}$.

To show that net worth levels above $w_{\text {bnd }}$ are transient, suppose net worth $w\left(s_{t}\right)$ at time $t$ in state $s_{t}$ is such that $w\left(s_{t}\right)>w_{b n d}$. Any path which reaches a state $s_{t+n}$ against which the household is constrained at time $t+n$ results in a household net worth $w\left(s_{t+n}\right)=$ $y\left(s_{t+n}\right) \leq \bar{y}$ and indeed net worth is bounded above by $w_{b n d}$ from then onwards. Consider a path along which the household is never constrained; since $v_{w}(w, s)=\beta R v_{w}\left(w^{\prime}, s^{\prime}\right)$ along such a path, $\exists n<\infty$, such that $v_{w}\left(w_{t+n}, s_{t+n}\right)=(\beta R)^{-n} v_{w}\left(w_{t}, s_{t}\right)>v_{w}\left(\bar{y}, s_{t+n}\right)$ and hence again $w_{t+n}<\bar{y}$ at time $t+n$ and net worth is less than $w_{b n d}$ thereafter.

To prove that the existence of a unique stationary distribution, define $Z^{*}$ as the set of $(w, s)$ such that either $(w, s)=(y(s), s)$, any $s \in S$, or for any $\hat{s} \in S, s \in S,(w, s)$ solves $v_{w}(y(\hat{s}), \hat{s})=(\beta R)^{n} v_{w}(w, s)$, for $n \geq 1$, and $w \geq y(s)$. Let $Z \equiv \cup_{s \in S}\left(\left[y, w_{b n d}(s)\right] \times\{s\}\right)$. For any $z=(w, s) \in Z, v_{w}(w, s) \geq \beta R v_{w}(y(\bar{s})=\bar{y}, \bar{s})$, as the household does not hedge the highest state. So $\forall z \in Z, P(z,(\bar{y}, \bar{s}))>0$, where $P\left(z, z^{\prime}\right)$ is the induced transition function, and hence $(\bar{y}, \bar{s})$ is a consequent $\forall z \in Z$. Next we show that $(\bar{y}, \bar{s})$ is recurrent, and indeed that all $z \in Z^{*}$ are recurrent, whereas all $z \in Z \backslash Z^{*}$ are transient. For $(\bar{y}, \bar{s})$ pick $s \in S$ and solve for $v_{w}(\bar{y}, \bar{s})=(\beta R)^{n} v_{w}(w, s)$ for each $n \geq 1$ such that $w \geq y(s)$. Each $\operatorname{such}(w, s) \in Z^{*}$ is a consequent of $(\bar{y}, \bar{s})$ and so is $(y(s), s), \forall s \in S$, 
since the household stops hedging state $s$ in state $s$ after a finite $n$. Hence for each $\hat{s}$, $(y(\hat{s}), \hat{s}), \forall s \leq \hat{s}$, solve for $v_{w}(\hat{y}, \hat{s})=(\beta R)^{n} v_{w}(w, s)$, for each $n \geq 1$, such that $w \geq$ $y(s)$. Each such $(w, s) \in Z^{*}$ is a consequent of $(y(s), s)$ and hence of $(\bar{y}, \bar{s})$. Hence, $\forall z \in Z^{*}, P((\bar{y}, \bar{s}), z)>0$, that is, all $z \in Z^{*}$ are consequent for $(\bar{y}, \bar{s})$. Therefore, $(\bar{y}, \bar{s})$ is recurrent and so are all $z \in Z^{*}$. In contrast, for any $z \in Z \backslash Z^{*},(\bar{y}, \bar{s})$ is a consequent of $z$ but not vice versa, that is, $P((\bar{y}, \bar{s}), z)=0$ for $z \in Z \backslash Z^{*}$, and such $z$ are transient. Since $P(z,(\bar{y}, \bar{s})) \geq \min _{s \in S} \Pi(s, \bar{s})>0$, Theorem 11.2 in Stokey and Lucas with Prescott (1989) implies that there exists a unique invariant distribution. For each $z \in Z^{*}$, define $\varepsilon_{z}=\min _{\hat{z} \in Z^{*}} P(\hat{z}, z)$ and note that $\varepsilon_{(\bar{y}, \bar{s})}=\min _{s \in S} \Pi(s, \bar{s})>0$. Hence, let $\varepsilon=\sum_{z \in Z^{*}} \varepsilon_{z} \geq \varepsilon_{(\bar{y}, \bar{s})}>0$. Theorem 11.4 in Stokey and Lucas with Prescott (1989) implies that there exists a unique ergodic set with no cyclically moving subsets and the rate of convergence is geometric.

Part (ii): See the proof of part (i) for a proof that net worth levels below $y$ and above $w_{\text {bnd }}$ are transient. When $\Pi\left(s, s^{\prime}\right)=\pi\left(s^{\prime}\right), \forall s, s^{\prime} \in S$, denote the net worth at the upper bound of the stationary distribution by $w_{b n d}$ and using (7) and the envelope condition, we have $v_{w}\left(w_{b n d}\right)=\beta R v_{w}\left(w_{b n d}\right)+\beta R \lambda\left(\bar{s}^{\prime}\right)$, implying that $\lambda\left(\bar{s}^{\prime}\right)>0$ and hence since $w^{\prime}$ is weakly increasing in $w$ and $s^{\prime}, w_{b n d}=w\left(\bar{s}^{\prime}\right)=\bar{y}$.

Part (iii): Household risk management is increasing by Proposition 1. Household risk management is incomplete with probability 1 since the stationary distribution of net worth is bounded above by $w_{b n d}$ and at $w_{b n d}(s)$ for $s \in S_{h}$ we have $w_{b n d}(s)>y(s)$ and

$$
\begin{aligned}
v_{w}\left(w_{b n d}(s), s\right) & =\beta R v_{w}\left(w\left(\bar{s}^{\prime}\right), \bar{s}^{\prime}\right)+\beta R \lambda\left(\bar{s}^{\prime}\right) \\
& \leq \beta R v_{w}\left(\bar{y}, \bar{s}^{\prime}\right)+\beta R \lambda\left(\bar{s}^{\prime}\right)=(\beta R)^{2} v_{w}\left(w_{b n d}(s), s\right)+\beta R \lambda\left(\bar{s}^{\prime}\right)
\end{aligned}
$$

implying that $\lambda\left(\bar{s}^{\prime}\right)>0$, and at $w_{b n d}(s)$ for $s \in S \backslash S_{h}$ we have $w_{b n d}(s)=y(s)$ and

$$
v_{w}(\bar{y}, \bar{s}) \leq v_{w}\left(w_{b n d}(s), s\right)=\beta R v_{w}\left(w\left(\bar{s}^{\prime}\right), \bar{s}^{\prime}\right)+\beta R \lambda\left(\bar{s}^{\prime}\right) \leq \beta R v_{w}\left(\bar{y}, \bar{s}^{\prime}\right)+\beta R \lambda\left(\bar{s}^{\prime}\right)
$$

and again $\lambda\left(\bar{s}^{\prime}\right)>0$. Therefore, since risk management is increasing, $\lambda\left(\bar{s}^{\prime}\right)>0$ for all $w \leq w_{\text {bnd }}(s), \forall s \in S$. By Part (i) of Proposition 3, risk management is completely absent at $\underline{w}=y$ and $\underline{s}$; by continuity, $\exists \varepsilon>0$ such that for $w>\underline{w}$ with $|w-\underline{w}|<\varepsilon, v_{w}(w, \underline{s})>$ $\beta R v_{w}(\underline{y}, \underline{s})$, which means that the household does not hedge at all in this neighborhood. Clearly, $w=\bar{y}$ has positive probability under the stationary distribution since household income $\bar{y}$ has positive probability under the stationary distribution of income. If the household does not hedge $\underline{s}^{\prime}$ at $\bar{y}$, then $\underline{w}$ has strictly positive probability. Consider instead a path along which the household continues to hedge the lowest income realization the following period, then $\exists n<\infty$ such that $v_{w}\left(w_{t+n}, s_{t+n}\right)=(\beta R)^{-n} v_{w}(\bar{y}, \bar{s})>v_{w}\left(y, s_{t+n}\right)$ and hence $w_{t+n}<y$, which is not possible. So the household must stop hedging the lowest state after a finite sequence of lowest income realizations, that is, the household does not hedge at all with positive probability under the stationary distribution.

Proof of Proposition 5. Let $\overline{\mathcal{S}}$ be the set of bounded, continuous, and weakly concave functions and $\overline{\mathcal{S}}^{\circ}$ be the set of bounded, continuous, strictly concave, and differentiable functions. Using a proof similar to that in Proposition 2 and defining the operator $T$ 
analogously, we conclude that $T(\overline{\mathcal{S}}) \subset \overline{\mathcal{S}}^{o} \subset \overline{\mathcal{S}}$ so $v \in \overline{\mathcal{S}}^{o}$, and similarly for $\tilde{v}$ (using $\tilde{T}$ ), which denotes the value function (and operator, respectively) associated with $\tilde{\pi}\left(s^{\prime}\right)$.

Consider some $\hat{v} \in \overline{\mathcal{S}}^{o}$. We show that if $\tilde{T}^{n} \hat{v}_{w}(w) \geq T^{n} \hat{v}_{w}(w)$, then $\tilde{T}^{n+1} \hat{v}_{w}(w) \geq$ $T^{n+1} \hat{v}_{w}(w)$, which in turn implies that the value functions $v$ and $\tilde{v}$ satisfy $\tilde{v}_{w}(w) \geq v_{w}(w)$, $\forall w$, too. Suppose that $\tilde{T}^{n} \hat{v}_{w}(w) \geq T^{n} \hat{v}_{w}(w)$, but that $\tilde{E}\left[\tilde{h}^{\prime}\right]<E\left[h^{\prime}\right]$, which, from the budget constraint, implies that $\tilde{c}>c$. Moreover, $S_{h} \neq \emptyset$ and using the first order condition with respect to $h$ and the envelope condition we have

$$
\begin{aligned}
\beta R u_{c}\left(c_{h}\right)=\beta R T^{n} \hat{v}_{w}\left(w_{h}\right) & =T^{n+1} \hat{v}_{w}(w)=u_{c}(c) \\
& >u_{c}(\tilde{c})=\tilde{T}^{n+1} \hat{v}_{w}(w) \geq \beta R \tilde{T}^{n} \hat{v}_{w}\left(\tilde{w}_{h}\right)=\beta R u_{c}\left(\tilde{c}_{h}\right),
\end{aligned}
$$

and therefore $\tilde{c}_{h}>c_{h}$. Further, $\tilde{T}^{n} \hat{v}_{w}\left(\tilde{w}_{h}\right)=u_{c}\left(\tilde{c}_{h}\right)<u_{c}\left(c_{h}\right)=T^{n} \hat{v}_{w}\left(w_{h}\right)$, which in turns implies that $\tilde{w}_{h}>w_{h}$. Then, since $\max \{\cdot, 0\}$ is convex,

$$
E\left[h^{\prime}\right]=E\left[\max \left\{w_{h}-y^{\prime}, 0\right\}\right]<E\left[\max \left\{\tilde{w}_{h}-y^{\prime}, 0\right\}\right] \leq \tilde{E}\left[\max \left\{\tilde{w}_{h}-y^{\prime}, 0\right\}\right]=\tilde{E}\left[\tilde{h}^{\prime}\right],
$$

a contradiction. Hence, $\tilde{E}\left[\tilde{h}^{\prime}\right] \geq E\left[h^{\prime}\right]$, which implies that $\tilde{c} \leq c$ and $\left(\tilde{T}^{n+1} \hat{v}\right)_{w}(w)=$ $u_{c}(\tilde{c}) \geq u_{c}(c)=\left(T^{n+1} \hat{v}\right)_{w}(w)$, so the value function $\tilde{T}^{n+1} \hat{v}$ and $T^{n+1} \hat{v}$ satisfy the property, too.

Proof of Corollary 1. The fact that $\tilde{c} \leq c$ is an immediate consequence of Proposition 5 . To see that $\tilde{c}^{\prime} \leq c^{\prime}$, suppose not, that is, suppose $\exists \hat{s}^{\prime}$ such that $\tilde{c}\left(\hat{s}^{\prime}\right)>c\left(\hat{s}^{\prime}\right)$, which can only be true if $\tilde{w}\left(\hat{s}^{\prime}\right)>w\left(\hat{s}^{\prime}\right)$ and therefore $\tilde{h}\left(\hat{s}^{\prime}\right)>0$. But then

$$
\beta R u_{c}\left(\tilde{c}\left(\hat{s}^{\prime}\right)\right)=u_{c}(\tilde{c}) \geq u_{c}(c) \geq \beta R u_{c}\left(c\left(\hat{s}^{\prime}\right)\right)
$$

which in turn implies that $\tilde{c}\left(\hat{s}^{\prime}\right) \leq c\left(\hat{s}^{\prime}\right)$, a contradiction.

Proceeding analogously, suppose $\exists \hat{s}^{\prime \prime}$ such that $\tilde{c}\left(\hat{s}^{\prime \prime}\right)>c\left(\hat{s}^{\prime \prime}\right)$, which can only be true if $\tilde{w}\left(\hat{s}^{\prime \prime}\right)>w\left(\hat{s}^{\prime \prime}\right)$ and therefore $\tilde{h}\left(\hat{s}^{\prime \prime}\right)>0$. But then

$$
\beta R u_{c}\left(\tilde{c}\left(\hat{s}^{\prime \prime}\right)\right)=u_{c}\left(\tilde{c}\left(s^{\prime}\right)\right) \geq u_{c}\left(c\left(s^{\prime}\right)\right) \geq \beta R u_{c}\left(c\left(\hat{s}^{\prime \prime}\right)\right)
$$

where $s^{\prime}$ is the state preceding $\hat{s}^{\prime \prime}$ and where we used the fact that $\tilde{c}^{\prime} \leq c^{\prime}, \forall s^{\prime} \in S$. This in turn implies that $\tilde{c}\left(\hat{s}^{\prime \prime}\right) \leq c\left(\hat{s}^{\prime \prime}\right)$, a contradiction. By induction, $\tilde{c}\left(s^{t}\right) \leq c\left(s^{t}\right)$ for any subsequent history $s^{t}$ and time $t$.

Proof of Proposition 6. Part (i): The proof is in a similar spirit to the Proof of Part (i) of Proposition 2. We show that if the properties that $v(w, s)$ is increasing in $s$ and $v_{w}(w, s)$ is decreasing in $s$ are satisfied by $v$ next period, then $T v$ satisfies these same properties this period, and conclude that the fixed point satisfies these properties as well. Moreover, as before, we observe that if the properties are satisfied next period, then the household hedges a lower set of states and $h^{\prime}$ is decreasing in $s^{\prime}$.

Now suppose that $\exists s_{+}>s$, such that $T v_{w}\left(w, s_{+}\right)>T v_{w}(w, s)$, implying by the envelope condition that $c_{+}<c$. From the budget constraint(2) we have

$$
c_{+}+\wp k_{+}+\sum_{s^{\prime} \in S} \Pi\left(s_{+}, s^{\prime}\right) h_{+}^{\prime}=w=c+\wp k+\sum_{s^{\prime} \in S} \Pi\left(s, s^{\prime}\right) h^{\prime},
$$


and given stochastic monotonicity and the fact that $h^{\prime}$ is decreasing in $s^{\prime}$ we have $\sum_{s^{\prime} \in S} \Pi\left(s_{+}, s^{\prime}\right) h^{\prime} \leq \sum_{s^{\prime} \in S} \Pi\left(s, s^{\prime}\right) h^{\prime}$, which implies that $x=\left\{c, k, h^{\prime}\right\}$ is feasible at $s_{+}$ and, since $v(w, s)$ is increasing in $w$ and $s, T v\left(w, s_{+}\right) \geq T v(w, s)$.

Suppose $k_{+} \leq k$. There must exist an $\hat{s}^{\prime}$ such that $w_{+}\left(\hat{s}^{\prime}\right)>w\left(\hat{s}^{\prime}\right)$, since otherwise consumption of goods and durables and the net worth next period are all lower at $s_{+}$ than $s$, contradicting the optimality of $x_{+}$since $x$ is feasible. But then $h(\hat{s})>0$ and therefore $\beta R \mu_{+}\left(\hat{s}^{\prime}\right)=\mu_{+}>\mu \geq \beta R \mu\left(\hat{s}^{\prime}\right)$ implying $w_{+}\left(\hat{s}^{\prime}\right)<w\left(\hat{s}^{\prime}\right)$, a contradiction.

Now suppose $k_{+}>k$. For $s^{\prime} \in S_{h} \cap S_{h+}, \beta \mu^{\prime} / \mu=R^{-1}=\beta \mu_{+}^{\prime} / \mu_{+}$. For $s^{\prime} \in S \backslash$ $S_{h} \cap S \backslash S_{h+}, \beta \mu^{\prime} / \mu>\beta \mu_{+}^{\prime} / \mu_{+}$. For $s^{\prime} \in S_{h} \cap S \backslash S_{h+}, \beta \mu^{\prime} / \mu=R^{-1} \geq \beta \mu_{+}^{\prime} / \mu_{+}$. Finally $S_{h} \cap S \backslash S_{h+}=\emptyset$, since for such $s^{\prime}$ we would have $\beta R \mu_{+}^{\prime}=\mu_{+}>\mu \geq \beta R \mu^{\prime}$, implying $w_{+}^{\prime}<w^{\prime}$, whereas $w_{+}^{\prime}=y^{\prime}+(1-\theta) k_{+}(1-\delta)+h_{+}^{\prime}>y^{\prime}+(1-\theta) k(1-\delta)=w^{\prime}$, a contradiction. Recalling that $R^{-1} \geq \beta \mu^{\prime} / \mu$ and that the right hand side is decreasing in $s^{\prime}$, the Euler equation for durables (12) implies

$$
\begin{aligned}
1 & =\beta \frac{g_{k}\left(k_{+}\right)}{\mu_{+}} \frac{1}{\wp}+\left[\sum_{s^{\prime} \in S_{h+}} \Pi\left(s_{+}, s^{\prime}\right) R^{-1}+\sum_{s^{\prime} \in S \backslash S_{h+}} \Pi\left(s_{+}, s^{\prime}\right) \beta \frac{\mu_{+}^{\prime}}{\mu_{+}}\right] \frac{(1-\theta)(1-\delta)}{\wp} \\
& <\beta \frac{g_{k}(k)}{\mu} \frac{1}{\wp}+\left[\sum_{s^{\prime} \in S_{h}} \Pi\left(s_{+}, s^{\prime}\right) R^{-1}+\sum_{s^{\prime} \in S \backslash S_{h}} \Pi\left(s_{+}, s^{\prime}\right) \beta \frac{\mu^{\prime}}{\mu}\right] \frac{(1-\theta)(1-\delta)}{\wp} \\
& \leq \beta \frac{g_{k}(k)}{\mu} \frac{1}{\wp}+\left[\sum_{s^{\prime} \in S_{h}} \Pi\left(s, s^{\prime}\right) R^{-1}+\sum_{s^{\prime} \in S \backslash S_{h}} \Pi\left(s, s^{\prime}\right) \beta \frac{\mu^{\prime}}{\mu}\right] \frac{(1-\theta)(1-\delta)}{\wp}=1,
\end{aligned}
$$

a contradiction.

Part (ii): Arguing analogously to Part (i) of Proposition 2, since the property in Part (i) above is satisfied, the household hedges a lower set of states and $w^{\prime}$ and $h^{\prime}$ is decreasing in $s^{\prime}$ since for two states $s_{+}^{\prime}>s^{\prime}$ which are hedged we have $v_{w}\left(w_{+}^{\prime}, s_{+}^{\prime}\right)=$ $v_{w}\left(w^{\prime}, s^{\prime}\right) \geq v_{w}\left(w^{\prime}, s_{+}^{\prime}\right)$, that is, $w^{\prime} \geq w_{+}^{\prime}$, and $h^{\prime}>h_{+}^{\prime}$ as $y^{\prime}<y_{+}^{\prime}$.

Using the envelope condition and (5) we have $v_{w}(w, s)=u_{c}(c)$, and given the strict concavity of the value function, if $w_{+}>w, v_{w}\left(w_{+}, s\right)<v_{w}(w, s)$ and hence $c_{+}>c$, that is, $c$ is strictly increasing in $w$, given $s$, and since $v_{w}(w, s)$ is decreasing in $s, c$ is increasing in $s$.

To see that $k$ is strictly increasing in $w$ given $s$, take $w_{+}>w$ and note that by strict concavity of $v, \mu_{+}<\mu$. Suppose that $k_{+} \leq k$, then $g_{k}(k) \leq g_{k}\left(k_{+}\right)$. Rewriting the Euler equation for durable goods purchases (12) we have

$$
1=\beta \frac{g_{k}(k)}{\mu} \frac{1}{\wp}+\sum_{s^{\prime} \in S_{h}} \Pi\left(s, s^{\prime}\right) R^{-1} \frac{(1-\theta)(1-\delta)}{\wp}+\sum_{s^{\prime} \in S \backslash S_{h}} \Pi\left(s, s^{\prime}\right) \beta \frac{\mu^{\prime}}{\mu} \frac{(1-\theta)(1-\delta)}{\wp} .
$$

Assume, without loss of generality, that $S_{h}=S_{h+}$. Since $g_{k}\left(k_{+}\right) / \mu_{+}>g_{k}(k) / \mu$, it must be the case that $\exists \hat{s}^{\prime} \in S \backslash S_{h}$ such that $\mu_{+}\left(\hat{s}^{\prime}\right) / \mu_{+}<\mu\left(\hat{s}^{\prime}\right) / \mu$ and hence $\mu_{+}\left(\hat{s}^{\prime}\right)<\mu\left(\hat{s}^{\prime}\right)$, that is, $w_{+}\left(\hat{s}^{\prime}\right)>w\left(\hat{s}^{\prime}\right)$. But since $\hat{s}^{\prime} \in S \backslash S_{h}, w_{+}\left(\hat{s}^{\prime}\right)=y\left(\hat{s}^{\prime}\right)+(1-\theta) k_{+}(1-\delta) \leq$ $y\left(\hat{s}^{\prime}\right)+(1-\theta) k(1-\delta)=w\left(\hat{s}^{\prime}\right)$, we have a contradiction.

To see that $w^{\prime}$ is strictly increasing in $w$ given $s, \forall s^{\prime} \in S$, assume again w.l.o.g. that $S_{h}=S_{h+}$. On $S_{h}, v_{w}(w, s)=\beta R v_{w}\left(w^{\prime}, s^{\prime}\right)$ and hence $w_{+}^{\prime}>w^{\prime}$. On $S \backslash S_{h}, w_{+}^{\prime}=$ $y^{\prime}+(1-\theta) k_{+}(1-\delta)>y^{\prime}+(1-\theta) k(1-\delta)=w^{\prime}$. 
Part (iii): The budget constraint (9) implies that $w \geq c$; thus, as $w$ goes to 0 , $c$ goes to 0 and using the envelope condition $v_{w}(w, s)=u_{c}(c)$ goes to $+\infty$. Since $w^{\prime} \geq$ $y^{\prime}+(1-\theta) k(1-\delta)>y^{\prime} \geq \underline{y}$ and $v_{w}\left(\underline{y}, s^{\prime}\right)$ is bounded for all $s^{\prime}, v_{w}\left(w^{\prime}, s^{\prime}\right)<v_{w}\left(\underline{y}, s^{\prime}\right)<+\infty$, and hence for sufficiently low $w, \lambda^{\prime}>0, \forall s^{\prime} \in S$.

Part (iv): If $\Pi\left(s, s^{\prime}\right)=\pi\left(s^{\prime}\right), \forall s, s^{\prime}$, then for any two states $s_{+}^{\prime}>s^{\prime}$ that are hedged we have $v_{w}\left(w_{+}^{\prime}\right)=v_{w}\left(w^{\prime}\right)$, that is, $w^{\prime}=w_{+}^{\prime} \equiv w_{h}$.

Since $\bar{w}$ is the highest wealth level that is attained under the (unique) stationary distribution, we have at $\bar{w}$ that $v_{w}(\bar{w})=\beta R v_{w}\left(\bar{w}^{\prime}\right)+\beta R \lambda\left(\bar{s}^{\prime}\right)$, so $\lambda\left(\bar{s}^{\prime}\right)>0$. Now suppose $\exists \hat{w}<\bar{w}$ such that the household hedges all states at $\hat{w}$ implying that $v_{w}(\hat{w})=$ $\beta R v_{w}\left(\hat{w}\left(s^{\prime}\right)\right), \forall s^{\prime} \in S$, that is, net worth next period must be lower than net worth this period in all states. But then there would have to exist a $w_{-}<\hat{w}$ such that $w_{-}\left(\bar{s}^{\prime}\right)>\hat{w}\left(\bar{s}^{\prime}\right)$ (since otherwise $\bar{w}$ could not be attained from below $\hat{w}$ ), which implies that $\hat{w}\left(\bar{s}^{\prime}\right)<w_{-}\left(\bar{s}^{\prime}\right)=y\left(\bar{s}^{\prime}\right)+(1-\theta) k_{-}(1-\delta)+h_{-}\left(\bar{s}^{\prime}\right)$, so $h_{-}\left(\bar{s}^{\prime}\right)>0$. This in turn implies that $v_{w}\left(w_{-}\right)=\beta R v_{w}\left(w_{-}\left(\bar{s}^{\prime}\right)\right)$, that is, $v_{w}\left(w_{-}\right)<v_{w}(\hat{w})$, a contradiction.

Proof of Proposition 7. The household's Euler equation for education, that is, investment in human capital, can be written as

$$
\begin{aligned}
1 & =E\left[\beta \frac{v_{w}\left(w^{\prime}, s^{\prime}\right)}{v_{w}(w, s)}\left(A^{\prime} f_{e}(e)+\left(1-\delta_{e}\right)\right) \mid s\right] \\
& \geq \Pi\left(s, s^{\prime}\right) \beta \frac{v_{w}\left(w^{\prime}, s^{\prime}\right)}{v_{w}(w, s)}\left(A\left(s^{\prime}\right) f_{e}(e)+\left(1-\delta_{e}\right)\right), \quad \forall s, s^{\prime} \in S .
\end{aligned}
$$

The budget constraint (13) implies that $w \geq e$ and hence as $w$ goes to zero, so does $e$ implying that $f_{e}(e)$ goes to $+\infty$. But then $\beta v_{w}\left(w^{\prime}, s^{\prime}\right) / v_{w}(w, s)$ must go to zero, $\forall s^{\prime} \in S$, using the Euler equation for investment in education, and, using equation (7), $\beta \lambda^{\prime} / \mu$ must go to $R^{-1}$ implying that the multipliers on the short-sale constraints $\lambda^{\prime}>0, \forall s^{\prime} \in S$.

Proof of Proposition 8. If $\beta R>1$, then $\mu>\mu^{\prime}$ by (7). Hence $\mu>E\left[\mu^{\prime}\right]$ and the supermartingale theorem (see Chamberlain and Rothschild (1984) for example) implies that there is a limit $\mu^{\infty}$ with $E\left[\mu^{\infty}\right]=0$ and since $\mu^{\infty}$ must be weakly positive, $\mu^{\infty}=0$. From the envelope condition $\mu^{\infty}=u_{c}\left(c^{\infty}\right)=0$ and thus consumption is infinite, which violates the resource constraint (20).

If $\beta R=1$, the argument above implies that we have full insurance but then in general equilibrium there must be sufficient collateralizability to ensure that these insurance claims can be issued, that is, $\theta \geq \bar{\theta}$.

Suppose that $\theta<\bar{\theta}$ but nevertheless $\beta R=1$. Then households are fully insured and (21) holds. Using (22) and the expectation of (23) we obtain

$$
E\left[y^{\prime}\right]=c^{*}+\delta k^{*}+\left(1-R^{*-1}\right)\left(\theta k^{*}(1-\delta)-E\left[h^{\prime *}\right]\right) .
$$

Subtracting (23) at $\bar{s}^{\prime}$ from (23) at $s^{\prime}$ yields $h^{*}\left(s^{\prime}\right)=y\left(\bar{s}^{\prime}\right)-y\left(s^{\prime}\right)+h^{*}\left(\bar{s}^{\prime}\right)$ and $E\left[h^{\prime *}\right]=$ $y\left(\bar{s}^{\prime}\right)-E\left[y^{\prime}\right]+h^{*}\left(\bar{s}^{\prime}\right) \geq y\left(\bar{s}^{\prime}\right)-E\left[y^{\prime}\right]$. At $\theta=\bar{\theta}, h^{*}\left(\bar{s}^{\prime}\right)=0$, so indexing variables associated with $\theta$ and $\bar{\theta}$ we conclude $E\left[h^{\prime *}(\theta)\right] \geq E\left[h^{\prime *}(\bar{\theta})\right]$. Moreover, market clearing at $\bar{\theta}$ implies 
that $\bar{\theta} k^{*}(\bar{\theta})(1-\delta)=E\left[h^{\prime *}(\bar{\theta})\right]$. Suppose there is (weakly) positive excess supply of collateralized claims at $\theta$, that is, $\theta k^{*}(\theta)(1-\delta) \geq E\left[h^{\prime *}(\theta)\right]$; combined with market clearing at $\bar{\theta}$, this implies that $k^{*}(\theta)>k^{*}(\bar{\theta})$, and, using $(21), c^{*}(\theta)>c^{*}(\bar{\theta})$. But substituting into (32) yields a contradiction. Thus, if $\theta<\bar{\theta}$, then $\beta R=1$ implies strictly positive excess demand.

Proof of Proposition 9. Part (i): When $\theta=1$, the investment Euler equation for durable goods (26) simplifies to

$$
\wp(s) \mu=\beta g_{k}(k),
$$

which in the case of logarithmic utility further simplifies to $k=(\beta g / \wp(s)) c$. Define the total expenditure on consumption and durable goods as $\hat{c}=c+\wp(s) k=(1+\beta g) c$. Substituting for $c$ and $k$ in the return function we have

$$
\hat{u}(\hat{c}, s)=u(c)+\beta g(k)=(1+\beta g) u(\hat{c})+\varphi(s),
$$

where $\varphi(s)=-(1+\beta g) \log (1+\beta g)+\beta g \log (\beta g)-\beta g \log (\wp(s))$. The problem with durable goods can then be written as an income risk management problem with preference shocks

$$
v(w, s)=\max _{\hat{c}, h^{\prime}, w^{\prime} \in \mathbb{R}_{+} \times \mathbb{R}^{2 S}} \hat{u}(\hat{c}, s)+\beta E\left[v\left(w^{\prime}, s^{\prime}\right) \mid s\right]
$$

subject to

$$
w \geq \hat{c}+E\left[R^{-1} h^{\prime} \mid s\right],
$$

(3), and (4).

Let $\hat{v}(w, s)$ solve the following income risk management problem without preference shocks

$$
\hat{v}(w, s)=\max _{\hat{c}, h^{\prime}, w^{\prime} \in \mathbb{R}_{+} \times \mathbb{R}^{2 S}} u(\hat{c})+\beta E\left[\hat{v}\left(w^{\prime}, s^{\prime}\right) \mid s\right]
$$

subject to (35), (3), and (4). This is in fact the problem considered in Section 3. Noting that the preference shock component of utility $\varphi(s)$ is separable and defining $v_{\varphi}(s)$ recursively as

$$
v_{\varphi}(s) \equiv \varphi(s)+\beta E\left[v_{\varphi}\left(s^{\prime}\right) \mid s\right],
$$

we have $v(w, s)=(1+\beta g) \hat{v}(w, s)+v_{\varphi}(s)$ as can be verified by substituting into equation (34).

Part (ii): With isoelastic preferences, (33) simplifies to $k=(\beta g / \wp(s))^{1 / \gamma} c$. Define the total expenditure on consumption and durable goods as $\hat{c}=c+\wp(s) k=$ $\left(1+\wp(s)(\beta g / \wp(s))^{1 / \gamma}\right) c$. Substituting for $c$ and $k$ in the return function we have

$$
\hat{u}(\hat{c}, s)=u(c)+\beta g(k)=\phi(s) u(\hat{c}),
$$

where $\phi(s)=\left(1+(\beta g)^{1 / \gamma} \wp(s)^{(\gamma-1) / \gamma}\right)^{\gamma}$. The proof of Proposition 1 applies without change.

Suppose $\Pi\left(s, s^{\prime}\right)$ is stochastically monotone and $\wp(s)$ is increasing in $s$. To prove that $v_{w}(w, s)$ is decreasing in $s$ when $\gamma<1$, first observe that $\phi(s)$ is decreasing in $s$ in that case (whereas it is increasing in $s$ if $\gamma>1$ ). We can now proceed as in the proof of the 
first part of Part (ii) of Proposition 2, that is, we assume that the property is satisfied by $v(\cdot)$ next period and then show that it has to be satisfied by $T v(\cdot)$ in the current period as well. As before, note that if the property is satisfied next period, the household hedges a lower set of states and $h^{\prime}$ decreases in $s^{\prime}$. Suppose the opposite, that is, suppose $\exists s_{+}>s$, such that $T v_{w}\left(w, s_{+}\right)>T v_{w}(w, s)$, implying by the envelope condition that $\phi\left(s_{+}\right) u\left(\hat{c}_{+}\right)=\mu_{+}>\mu=\phi(s) u(\hat{c})$ and therefore $u\left(\hat{c}_{+}\right)>\phi(s) / \phi\left(s_{+}\right) u(\hat{c}) \geq u(\hat{c})$, which further implies that $\hat{c}_{+}<\hat{c}$. Since $h^{\prime}$ is decreasing in $s^{\prime}, E\left[R^{-1} h^{\prime} \mid s\right] \leq E\left[R^{-1} h^{\prime} \mid s_{+}\right]$and $\left\{\hat{c}, h^{\prime}, w^{\prime}\right\}$ is feasible at $s_{+}$. Since $\hat{c}_{+}<\hat{c}, \exists \hat{s}^{\prime}$ such that $w_{+}\left(\hat{s}^{\prime}\right)>w\left(\hat{s}^{\prime}\right)$ since otherwise $\left\{\hat{c}_{+}, h_{+}^{\prime}, w_{+}^{\prime}\right\}$ would achieve lower utility than switching to $\left\{\hat{c}, h^{\prime}, w^{\prime}\right\}$, contradicting optimality. But then $y\left(\hat{s}^{\prime}\right)+h_{+}\left(\hat{s}^{\prime}\right)=w_{+}\left(\hat{s}^{\prime}\right)>w\left(\hat{s}^{\prime}\right)=y\left(\hat{s}^{\prime}\right)+h\left(\hat{s}^{\prime}\right)$ and $h_{+}\left(\hat{s}^{\prime}\right)>h\left(\hat{s}^{\prime}\right) \geq 0$, so $\beta R \mu_{+}\left(w_{+}\left(\hat{s}^{\prime}\right), \hat{s}^{\prime}\right)=\mu_{+}>\mu \geq \beta R\left(w\left(\hat{s}^{\prime}\right), \hat{s}^{\prime}\right)$, implying $w_{+}\left(\hat{s}^{\prime}\right)<w\left(\hat{s}^{\prime}\right)$, a contradiction. Therefore $v_{w}(w, s)$ is decreasing in $s$, and the rest of the proposition obtains from the proof of Part (ii) of Proposition 2 without change. 


\section{Appendix B: Equivalence of Economies with Limited Enforcement and Collateral Constraints}

This appendix shows the equivalence of the optimal dynamic contract with limited enforcement without exclusion and an economy with one-period state-contingent claims subject to collateral constraints. For simplicity we consider the case without durable goods. The household's problem with limited enforcement at time $\tau \geq 0$ given net worth $w\left(s^{\tau}\right)$, which we denote $\mathcal{P}_{\tau}\left(w\left(s^{\tau}\right)\right)$, is to choose a sequence of consumption choices and net payments $\left\{c\left(s^{t}\right), p\left(s^{t}\right)\right\}_{t \geq \tau}$ where $s^{t} \equiv\left\{s_{0}, \ldots, s_{t}\right\}$, to maximize

$$
E_{\tau}\left[\sum_{t=\tau}^{\infty} \beta^{(t-\tau)} u\left(c_{t}\right)\right]
$$

subject to

$$
\begin{aligned}
w\left(s^{\tau}\right) & \geq c\left(s^{\tau}\right)+p\left(s^{\tau}\right), \\
y\left(s^{t}\right) & \geq c\left(s^{t}\right)+p\left(s^{t}\right), \quad \forall t>\tau,
\end{aligned}
$$

the lender's participation constraint

$$
E_{\tau}\left[\sum_{t=\tau}^{\infty} R^{-(t-\tau)} p_{t}\right] \geq 0
$$

the limited enforcement constraint

$$
E_{\tau^{\prime}}\left[\sum_{t=\tau^{\prime}}^{\infty} \beta^{\left(t-\tau^{\prime}\right)} u\left(c_{t}\right)\right] \geq E_{\tau^{\prime}}\left[\sum_{t=\tau^{\prime}}^{\infty} \beta^{\left(t-\tau^{\prime}\right)} u\left(\hat{c}_{t}\right)\right], \quad \forall \tau^{\prime} \geq \tau, \forall\left\{\hat{c}\left(s^{t}\right)\right\}_{t=\tau^{\prime}}^{\infty},
$$

where $\left\{\hat{c}\left(s^{t}\right)\right\}_{t=\tau^{\prime}}^{\infty}$ together with $\left\{\hat{p}\left(s^{t}\right)\right\}_{t=\tau^{\prime}}^{\infty}$ solve $\mathcal{P}_{\tau^{\prime}}\left(\hat{w}\left(s^{\tau^{\prime}}\right)\right)$ with $\hat{w}\left(s^{\tau^{\prime}}\right)=y\left(s^{\tau^{\prime}}\right)$. We say a sequence of net payments is implementable if it satisfies the lender's participation constraint and the limited enforcement constraints.

Proposition 10 (Equivalence of limited enforcement and collateral constraints). (i) Any sequence of net payments $\left\{p\left(s^{t}\right)\right\}_{t=\tau}^{\infty}$ is implementable in problem $\mathcal{P}_{\tau}\left(w\left(s^{\tau}\right)\right)$ iff

$$
0 \geq E_{\tau^{\prime}}\left[\sum_{t=\tau^{\prime}}^{\infty} R^{-\left(t-\tau^{\prime}\right)} p_{t}\right], \quad \forall \tau^{\prime}>\tau
$$

that is, the present value of the remaining payments is never positive. (ii) The set of sequences of net payments satisfying (41) is equivalent to the set of sequences of one-period state-contingent claims $\left\{h\left(s^{t}\right)\right\}_{t=\tau}^{\infty}$ that satisfy the short-sale constraints

$$
h\left(s^{t}\right) \geq 0, \quad \forall t>\tau .
$$


Proof of Proposition 10. Part (i): $(\Rightarrow)$ Suppose not, that is, suppose that $\left\{p\left(s^{t}\right)\right\}_{t=\tau}^{\infty}$ is such that (41) is violated for some $s^{\tau^{\prime}}, \tau^{\prime}>\tau$, that is

$$
E_{\tau^{\prime}}\left[\sum_{t=\tau^{\prime}}^{\infty} R^{-\left(t-\tau^{\prime}\right)} p_{t}\right]>0 .
$$

W.l.o.g. let $\tau^{\prime}=\tau+1$. The household could default in state $s^{\tau+1}$ at time $\tau+1$ and issue new payments $\left\{\hat{p}\left(s^{t}\right)\right\}_{t=\tau+1}^{\infty}$ such that $\hat{p}\left(s^{t}\right)=p\left(s^{t}\right), t>\tau+1$, and $\hat{p}\left(s^{\tau+1}\right)=$ $-E_{\tau+1}\left[\sum_{t=\tau+2}^{\infty} R^{-(t-(\tau+1))} \hat{p}_{t}\right]$, and hence by construction $\left.E_{\tau+1}\left[\sum_{t=\tau+1}^{\infty} R^{-(t-(\tau+1))} \hat{p}_{t}\right)\right]=$ 0 . Clearly, $\hat{p}\left(s^{\tau+1}\right)<p\left(s^{\tau+1}\right)$ and $\hat{c}\left(s^{t}\right)=c\left(s^{t}\right)$, for all $t \geq \tau+2$, but

$$
\hat{c}\left(s^{\tau+1}\right)=c\left(s^{\tau+1}\right)+p\left(s^{\tau+1}\right)-\hat{p}\left(s^{\tau+1}\right)=c\left(s^{\tau+1}\right)+E_{\tau+1}\left[\sum_{t=\tau+1}^{\infty} R^{-(t-(\tau+1))} p_{t}\right]>c\left(s^{\tau+1}\right),
$$

which would be an improvement and hence a contradiction. We prove the other direction after proving part (ii).

Part (ii): Take any sequence of net payments $\left\{p\left(s^{t}\right)\right\}_{t=\tau}^{\infty}$ that satisfies (41) and define

$$
h\left(s^{\tau^{\prime}}\right) \equiv-E_{\tau^{\prime}}\left[\sum_{t=\tau^{\prime}}^{\infty} R^{-\left(t-\tau^{\prime}\right)} p_{t}\right] \geq 0, \quad \forall \tau^{\prime}>\tau
$$

then $h\left(s^{\tau^{\prime}}\right)=-p\left(s^{\tau^{\prime}}\right)+R^{-1} E_{\tau^{\prime}}\left[h_{\tau^{\prime}+1}\right]$ or $p\left(s^{\tau^{\prime}}\right)=-h\left(s^{\tau^{\prime}}\right)+R^{-1} E_{\tau^{\prime}}\left[h_{\tau^{\prime}+1}\right]$. We can therefore rewrite $(38)$ as

$$
y\left(s^{t}\right)+h\left(s^{t}\right) \geq c\left(s^{t}\right)+R^{-1} E_{t}\left[h_{t+1}\right], \quad \forall t \geq \tau+1,
$$

and (37) as

$$
w\left(s^{\tau}\right) \geq c\left(s^{\tau}\right)+R^{-1} E_{\tau}\left[h_{\tau+1}\right],
$$

where $h\left(s^{\tau}\right)=0$ as (39) holds with equality.

Moreover, any sequence $\left\{h\left(s^{t}\right)\right\}_{t=\tau+1}^{\infty}$ with $h\left(s^{t}\right) \geq 0, \forall t>\tau$, satisfies (41) as

$$
\begin{aligned}
E_{\tau^{\prime}}\left[\sum_{t=\tau^{\prime}}^{\infty} R^{-\left(t-\tau^{\prime}\right)} p_{t}\right] & =E_{\tau^{\prime}}\left[\sum_{t=\tau^{\prime}}^{\infty} R^{-\left(t-\tau^{\prime}\right)}\left\{-h_{t}+R^{-1} E_{t}\left[h_{t+1}\right]\right\}\right] \\
& =-E_{\tau^{\prime}}\left[\sum_{t=\tau^{\prime}}^{\infty} R^{-\left(t-\tau^{\prime}\right)} h_{t}\right]+E_{\tau^{\prime}}\left[\sum_{t=\tau^{\prime}+1}^{\infty} R^{-\left(t-\tau^{\prime}\right)} h_{t}\right]=-h\left(s^{\tau^{\prime}}\right) \leq 0 .
\end{aligned}
$$

Finally, to complete part $(\mathrm{i}),(\Leftarrow)$, the household would never default on a sequence $\left\{h\left(s^{t}\right)\right\}_{t=\tau+1}^{\infty}$ with $h\left(s^{t}\right) \geq 0, \forall t>\tau$, establishing that if (41) is satisfied, the sequence $\left\{p\left(s^{t}\right)\right\}_{t=\tau}^{\infty}$ is implementable.

The problem with limited enforcement $\mathcal{P}_{\tau}\left(w\left(s^{\tau}\right)\right)$ in equations (36) to (40) is therefore equivalent to maximizing (36) subject to (44), (43), and (42), which can be written recursively as in equations (1) to (4). Moreover, the proof can be extended to the case with durable goods by adapting the proof in Rampini and Viswanathan (2013). 


\section{Appendix C: Existence of a Stationary Equilibrium}

This appendix shows first that, for given $R$ such that $\beta R<1$, a unique bounded stationary distribution of net worth exists, and second that when $\theta<\bar{\theta}$, an equilibrium with an interest rate satisfying $\beta R<1$ exists. Proposition 11 provides a sufficient condition for the existence of a bounded stationary distribution, in particular a unique lower bound $\underline{w}$ for the stationary distribution via a restriction on the slope of the growth of wealth in the lowest state next period. ${ }^{34}$

Proposition 11. Assume that $\beta R<1$. If $\frac{(1-\theta)(1-\delta)}{\wp}\left(1-c_{w}(w)\right)<1$ for all $w$, then there is an unique stationary distribution on $[\underline{w}, \bar{w}]$ where $\underline{w}$ is the unique solution to $y\left(\underline{s}^{\prime}\right)+\frac{(1-\theta)(1-\delta)}{\wp}(\underline{w}-c(\underline{w}))=\underline{w}$ and $\bar{w}$ is the lowest solution to $y\left(\bar{s}^{\prime}\right)+(1-\theta)(1-\delta) k(\bar{w})=$ $\bar{w}$.

Proof of Proposition 11. Consider the function $\underline{G}(w)=y\left(\underline{s}^{\prime}\right)+\frac{(1-\theta)(1-\delta)}{\wp}(w-c(w))$ which gives the wealth next period in the lowest state assuming that $h\left(\underline{s}^{\prime}\right)=0$ (and hence $h\left(s^{\prime}\right)=0$ for all $\left.s^{\prime} \in S\right)$. Since $\underline{G}(0)>0$ and the function $\underline{G}(w)$ has a slope less than one, it must intersect the 45-degree line from above. Further since $\frac{(1-\theta)(1-\delta)}{\wp}\left(1-c_{w}(w)\right)$ $<1$, the function $G(w)$ does not have any more intersections with the 45-degree line. Thus a unique intersection $\underline{w}$ exists. Consider now the wealth next period in the low state $w\left(\underline{s}^{\prime}\right)(w)$. At any intersection where $w\left(\underline{s}^{\prime}\right)(w)=w$, we must have $h\left(\underline{s}^{\prime}\right)=0$ from $\mu(\underline{w})>\beta R \mu(\underline{w})=\beta R \mu^{\prime}\left(w\left(\underline{s}^{\prime}\right)(\underline{w})\right)$, thus $h\left(s^{\prime}\right)=0, \forall s^{\prime} \in S$ (no state is hedged). Thus at such an intersection, we must have $w\left(\underline{s}^{\prime}\right)(w)=\underline{G}(w)$, which implies that $w\left(\underline{s}^{\prime}\right)(w)$ intersects the 45-degree line only once at $\underline{w}$. Further $w\left(\underline{s}^{\prime}\right)(0)>0$, hence for $w<\underline{w}$, $w\left(\underline{s}^{\prime}\right)(w)>w$ and for $w>\underline{w}, w\left(\underline{s}^{\prime}\right)(w)<w$.

Consider the function $\overline{\bar{G}}(w)=y\left(\bar{s}^{\prime}\right)+\frac{(1-\theta)(1-\delta)}{\wp}(w-c(w))$. Since $\bar{G}(w)$ only differs from $\underline{G}(w)$ by the constant $y\left(\bar{s}^{\prime}\right)-y\left(\underline{s}^{\prime}\right)$, there is a unique intersection point with 45 degree line at $\hat{w}$. Now consider the wealth in the highest state $w\left(\bar{s}^{\prime}\right)(w)$. At $w=0$, $w\left(\bar{s}^{\prime}\right)(0) \geq w\left(\underline{s}^{\prime}\right)(0)>0$. Further at any intersection point $w$ where $w\left(\bar{s}^{\prime}\right)(w)=w$ (if such a point exists), $\mu(w)>\beta R \mu(w)=\beta R \mu^{\prime}\left(w\left(\bar{s}^{\prime}\right)(w)\right)$ and thus $h\left(\bar{s}^{\prime}\right)=0$, the high state cannot be hedged. But then at such an intersection $w$,

$$
\bar{G}(w)=y\left(\bar{s}^{\prime}\right)+\frac{(1-\theta)(1-\delta)}{\wp}(w-c(w)) \geq y\left(\bar{s}^{\prime}\right)+(1-\theta)(1-\delta) k(w)=w\left(\bar{s}^{\prime}\right)(w)=w
$$

which implies that any intersection $w$ must have $w \leq \hat{w}$. If there are multiple intersections, we pick the lowest one and call this $\bar{w}$ (at this intersection as we have already argued the high state is not hedged). It follows by construction that $w\left(\bar{s}^{\prime}\right)(w)>w$ for all $w<\bar{w}$. Immediately, for $w<\bar{w}, \mu(w)>\mu^{\prime}\left(w\left(\bar{s}^{\prime}\right)(w)\right)$ and hence the highest state is not hedged. Hence insurance is incomplete on $[\underline{w}, \bar{w}]$.

Any $w \notin[\underline{w}, \bar{w}]$ is transient. For any $w<\underline{w}$, create the sequence, $w_{0}^{u}=w, w_{1}^{u}=$ $w\left(\bar{s}^{\prime}\right)\left(w_{0}^{u}\right), w_{2}^{u}=w\left(\bar{s}^{\prime}\right)\left(w_{1}^{u}\right), \ldots, w_{n}^{u}=w\left(\bar{s}^{\prime}\right)\left(w_{n-1}^{u}\right), \ldots$, and $w_{n}^{u}<\bar{w}$. This is a strictly

\footnotetext{
${ }^{34}$ For $R>\frac{\theta(1-\delta)}{\delta+\theta(1-\delta)}$, this slope condition automatically obtains. The bound of the proposition allows verification of a unique intersection at interest rates lower than $\frac{\theta(1-\delta)}{\delta+\theta(1-\delta)}$, though these interest rates are far from the equilibrium interest rate in our numerical illustration.
} 
increasing bounded sequence that must converge to a limit that is less than or equal to $\bar{w}$; in fact the limit is $\bar{w}$. But then $\exists N_{u}>0$ such that for $n \geq N_{u}, w_{n}^{u}>\underline{w}$ and we never go below $\underline{w}$ once we cross $\underline{w}$ as for $n \geq N_{u} w\left(\underline{s}^{\prime}\right)\left(w_{n}^{u}\right)>w\left(\underline{s}^{\prime}\right)(\underline{w})=\underline{w}$ as $w\left(s^{\prime}\right)$ is strictly increasing in $w$. Similarly, if $w>\bar{w}$, create the sequence $w_{0}^{d}=w, w_{1}^{d}=w\left(\underline{s}^{\prime}\right)\left(w_{0}^{d}\right)$, $w_{2}^{d}=w\left(\underline{s}^{\prime}\right)\left(w_{1}^{d}\right), \ldots, w_{n}^{d}=w\left(\underline{s}^{\prime}\right)\left(w_{n-1}^{d}\right), \ldots$ By construction this is a decreasing bounded sequence as $w\left(\underline{s}^{\prime}\right)<w$ for $w>\underline{w}$; hence it must converge to a limit. But this sequence lives between the 45-degree line and the function $\underline{G}(w)=y\left(\underline{s}^{\prime}\right)+\frac{(1-\theta)(1-\delta)}{\wp}(w-c(w))$ (which assumes no hedging of the lowest state). Hence it must converge to $\underline{w}$ (since at any intersection with the 45-degree line, there is no hedging of the lowest state). But then $\exists N_{d}>0$ such that for $n \geq N_{d}, w_{n}^{d}<\bar{w}$ and we never go above $\bar{w}$ once we cross $\bar{w}$ as for $n \geq N_{d}, w\left(\bar{s}^{\prime}\right)\left(w_{n}^{d}\right)<w\left(\bar{s}^{\prime}\right)(\bar{w})=\bar{w}$ since $w\left(s^{\prime}\right)$ is strictly increasing in $w^{35}$

We show existence of a unique stationary distribution as follows. We consider all right continuous distribution functions on the interval $[\underline{w}, \bar{w}]$. Given two distribution functions $F_{1}(w)$ and $F_{2}(w)$ we say that $F_{1} \succeq F_{2}$ if $F_{1}(w) \leq F_{2}(w)$ for all $w$ (and $F_{1} \succ F_{2}$ if $F_{1}(w) \leq F_{2}(w)$ for all $w$ with strict inequality for a positive interval of $\left.w\right)$. Given this partial order, $\min \left\{F_{1}(w), F_{2}(w)\right\}$ and $\max \left\{F_{1}(w), F_{2}(w)\right\}$ are also distribution functions and are the greatest lower bound and least upper bound for the pair $\left\{F_{1}(w), F_{2}(w)\right\}$. Thus the set $\mathcal{F}=\{F \mid F$ is a distribution on $[\underline{w}, \bar{w}]\}$ has as its least upper bound the distribution $\bar{F}(w), \bar{F}(w)=0$ for $w<\bar{w}$ and $\bar{F}(\bar{w})=1$ and as its greatest lower bound the distribution $\underline{F}(w), \underline{F}(w)=1$ for $w \in[\underline{w}, \bar{w}]$; hence the set $\mathcal{F}$ is a complete lattice.

Further the equilibrium mapping $w\left(s^{\prime}\right)(w)$ implies the adjoint map $T^{*}: \mathcal{F} \rightarrow \mathcal{F}$ by $T^{*}(F(w))=\sum_{s^{\prime}=1}^{S} \pi\left(s^{\prime}\right) F\left(w\left(s^{\prime}\right)^{-1}(w)\right)$; this is a monotone map in the following sense: if $F_{1} \succeq F_{2}$, then $T^{*}\left(F_{1}\right) \succeq T^{*}\left(F_{2}\right)$ as

$$
T^{*}\left(F_{1}(w)\right)=\sum_{s^{\prime}=1}^{S} \pi\left(s^{\prime}\right) F_{1}\left(w\left(s^{\prime}\right)^{-1}(w)\right) \leq \sum_{s^{\prime}=1}^{S} \pi\left(s^{\prime}\right) F_{2}\left(w\left(s^{\prime}\right)^{-1}(w)\right)=T^{*}\left(F_{2}(w)\right) .
$$

By Knaster-Tarski's theorem, there exists a fixed point in the space of distribution functions. We show next that this fixed point is unique. Start with the least upper bound $\bar{F}(w)$, then $T^{* n}(\bar{F})$ converges downwards to the highest fixed point. Similarly start with the greatest lower bound $\underline{F}(w)$, then $T^{* n}(\underline{F})$ converges upwards to the lowest fixed point. Since these two limiting distributions are identical, the stationary distribution is unique.

Define $w\left(s^{\prime n}\right)(w)$ as the random wealth that occurs starting with wealth $w$ where $s^{\prime n}$ is the subsequent history of states for the next $n$ periods. Let $w_{o} \in(\underline{w}, \bar{w})$ and create the strictly increasing sequence $w_{n}^{u}$ starting at $\underline{w}$ and the strictly decreasing sequence $w_{n}^{d}$ starting at $\bar{w}$ (as before in this proof). Since $w_{n}^{u} \rightarrow \bar{w}$ and $w_{n}^{d} \rightarrow \underline{w}$, there exists $N_{u}$ and $N_{d}$ such that for $n \geq N_{u}, w_{n}^{u}>w_{o}$ and for $n \geq N_{d}, w_{n}^{d}<w_{o}$. Take $N=\max \left\{N_{u}, N_{d}\right\}$ and $\varepsilon=\min \left\{\left(\pi\left(\bar{s}^{\prime}\right)\right)^{N_{u}},\left(\pi\left(\underline{s}^{\prime}\right)\right)^{N_{d}}\right\}$. Since $w\left(s^{\prime}\right)$ is increasing in $w$, it follows that $\forall n \geq N$ and $\forall w \in[\underline{w}, \bar{w}], P^{n}\left(w, w\left(\underline{s}^{\prime n}\right)(w)<w_{o}\right)>\varepsilon$ and $P^{n}\left(w, w\left(\bar{s}^{\prime n}\right)(w)>w_{o}\right)>\varepsilon$, where $\underline{s}^{\prime n}$ $\left(\bar{s}^{\prime n}\right)$ corresponds to the lowest (highest) state occurring $n$ times. Hence the monotone mixing condition in Theorem 2 in Hopenhayn and Prescott (1992) and in Theorem 2.1 in

\footnotetext{
${ }^{35}$ This proves that even though there may be multiple intersections of net worth in the highest state next period $w\left(\bar{s}^{\prime}\right)(w)$ with the 45-degree line, only the first intersection $\bar{w}$ is relevant as any $w>\bar{w}$ is transient. The uniqueness of the intersection of $\underline{G}(w)$ with the 45 -degree line is critical here.
} 
Bhattacharya and Lee (1988) is satisfied and a unique invariant distribution exists; further starting from any initial distribution, the convergence to the invariant distribution is exponential.

For $\theta<\bar{\theta}$, we now prove the existence of an equilibrium interest rate $R$, with $\beta R<1$, such that the excess demand for collateralized claims equals zero, that is, rewriting (16),

$$
\int_{\underline{w}(R)}^{\bar{w}(R)} E\left[h^{\prime}(w \mid R)\right] d F(w \mid R)-\int_{\underline{w}(R)}^{\bar{w}(R)} \theta k(w \mid R)(1-\delta) d F(w \mid R)=0 .
$$

From the proof of Proposition 8, we know that at $\beta R=1$ there must be strict excess demand for collateralized claims, that is, the left-hand side of (45) is strictly positive.

Suppose $\pi_{h}=\sum_{s^{\prime} \in S_{h}} \pi\left(s^{\prime}\right)$ where $S_{h}$ is a potential set of states to be hedged. Then if $\frac{(1-\theta)(1-\delta)}{\wp} \geq \frac{1}{R^{-1} \pi_{h}}$, households do not hedge this set of states. This follows from the fact that the return to hedging these states is less than the marginal return in terms of net resale value of investing in the durable good in these states and purchasing the durable good yields additional positive marginal utility in terms of housing services as well as a payoff in the other states. Hence if $\frac{(1-\theta)(1-\delta)}{\wp} \geq \frac{1}{R^{-1} \pi\left(\underline{s}^{\prime}\right)}$, no household hedges any state. We can rewrite this inequality as $R \leq\left[\pi\left(\underline{s}^{\prime}\right)+\theta\left(1-\pi\left(\underline{s}^{\prime}\right)\right)\right](1-\delta)$; at such interest rates, the left-hand side of (45) must be strictly less than zero.

Proposition 12. Assume that $\theta<\bar{\theta}$. If for $R \in\left[\theta(1-\delta)+\pi\left(\underline{s}^{\prime}\right)(1-\theta)(1-\delta), \beta^{-1}\right]$, $\frac{(1-\theta)(1-\delta)}{\wp}\left(1-c_{w}(w)\right)<1$ for all $w$, then there exists an $R$ such that $\beta R<1$ that solves (45), that is, clears the market for collateralized claims.

Proof of Proposition 12. We have already shown that at $R=\theta(1-\delta)+\pi\left(\underline{s}^{\prime}\right)(1-\theta)(1-$ $\delta$ ), the left-hand side of (45) is strictly greater than zero and at $R=\beta^{-1}$ (45) is strictly less than zero. Also from Proposition 11, for all $R \in\left[\theta(1-\delta)+\pi\left(\underline{s}^{\prime}\right)(1-\theta)(1-\delta), \beta^{-1}\right]$, a unique stationary distribution $F(w \mid R)$ on $[\underline{w}(R), \bar{w}(R)]$ exists. It is immediately clear that both $\underline{w}(R)$ and $\bar{w}(R)$ are continuous in $R$ since $c(w \mid R)$ is continuous in $w$ and $R$ by the theorem of the maximum. Further the net worth next period $w\left(s^{\prime} \mid R\right)(w)$ is continuous in $w$ and $R$. Hence, we take $w_{l}=\min \underline{w}(R)$ and $w_{u}=\max \bar{w}(R)$ for $R \in[\theta(1-\delta)+$ $\left.\pi\left(\underline{s}^{\prime}\right)(1-\theta)(1-\delta), \beta^{-1}\right]$ (these exist since $\underline{w}(R)$ and $\bar{w}(R)$ are continuous functions on a compact set), and for each $R, P\left(w, W^{\prime} \mid R\right)$ is induced by the function $w\left(s^{\prime} \mid R\right)(w)$ where $W^{\prime} \subset\left[w_{l}, w_{u}\right]$. Then if $\left(w_{n}, R_{n}\right) \rightarrow(w, R)$, the sequence $P\left(w_{n}, W^{\prime} \mid R_{n}\right) \rightarrow P\left(w, W^{\prime} \mid R\right)$ using the continuity of $\underline{w}(R), \bar{w}(R)$ and $w\left(s^{\prime} \mid R\right)(w)$. Further for each $R$, there is an unique stationary distribution, and hence following the argument in Theorem 12.13 in Stokey and Lucas with Prescott (1989), the stationary distribution is continuous in the parameter $R$. Integrating against this stationary distribution we conclude that the left-hand side of (45) must be continuous in $R$. Hence by the intermediate value theorem, there exists an $R$ for which (45) is zero, that is, an interest rate at which the market for collateralized claims clears. 


\section{References}

Aguiar, M., M. Amador, and G. Gopinath, "Investment Cycles and Sovereign Debt Overhang," Review of Economic Studies 76 (2009) 1-31.

Aiyagari, S.R., "Uninsured Idiosyncratic Risk and Aggregate Saving," Quarterly Journal of Economics 109 (1994) 659-684.

Alvarez, F., and U.J. Jermann, "Efficiency, Equilibrium and Asset Pricing with Risk of Default," Econometrica 68 (2000) 775-797.

Athanasoulis, S.G., and R.J. Shiller, "The Significance of the Market Portfolio," Review of Financial Studies 13 (2000) 301-329.

Benveniste, L.M., and J.A. Scheinkman, "On the Differentiability of the Value Function in Dynamic Models of Economics," Econometrica 47 (1979) 727-732.

Bewley, T., "The Permanent Income Hypothesis: A Theoretical Formulation," Journal of Economic Theory 16 (1977) 252-292.

Bewley, T., "The Optimum Quantity of Money," in Models of Monetary Economies, eds. John H. Kareken and Neil Wallace. (Minneapolis, MN: Federal Reserve Bank, 1980).

Bhattacharya, R.N., and O. Lee, "Asymptotics of a Class of Markov Processes which Are Not in General Irreducible," Annals of Probability 16 (1988) 1333-1347.

Blundell, R., L. Pistaferri, and I. Preston, "Consumption Inequality and Partial Insurance," American Economic Review 98 (2008) 1887-1921.

Brown, J.R., and A. Finkelstein, "Why is the Market for Long-term Care Insurance so Small?" Journal of Public Economics 91 (2007) 1967-1991.

Brown, J.R., and A. Finkelstein, "The Interaction of Public and Private Insurance: Medicaid and the Long-term Care Insurance Market," American Economic Review 98 (2008) 1083-1102.

Browne, M.J., and R.E. Hoyt, "The Demand for Flood Insurance: Empirical Evidence," Journal of Risk and Uncertainty 20 (2000) 291-306.

Bulow, J., and K. Rogoff, "Sovereign Debt: Is to Forgive to Forget?" American Economic Review 79 (1989) 43-50.

Campbell, J.Y., "Understanding Risk and Return," Journal of Political Economy 104 (1996) 298-345.

Campbell, J.Y., and João F. Cocco, "Household Risk Management and Optimal Mortgage Choice," Quarterly Journal of Economics 118 (2003) 1449-1494. 
Castañeda, A., J. Díaz-Giménez, and J.-V. Ríos-Rull, “Accounting for the U.S. Earnings and Wealth Inequality," Journal of Political Economy 111 (2003) 818-857.

Chamberlain, G., and C.A. Wilson, "Optimal Intertemporal Consumption under Uncertainty," Review of Economic Dynamics 3 (2000) 365-395.

Chien, Y., and H. Lustig, "The Market Price of Aggregate Risk and the Wealth Distribution," Review of Financial Studies 23 (2010) 1596-1650.

Cole, S., X. Giné, J. Tobacman, P. Topalova, R. Townsend, and J. Vickery, "Barriers to Household Risk Management: Evidence from India," American Economic Journal: Applied Economics 5 (2013) 104-135.

Constantinides, G.M., and D. Duffie, "Asset Pricing with Heterogeneous Consumers," Journal of Political Economy 104 (1996) 219-240.

Deaton, A., "Saving and Liquidity Constraints," Econometrica 59 (1991) 1221-1248.

Eisfeldt, A.L., and A.A. Rampini, "Leasing, Ability to Repossess, and Debt Capacity," Review of Financial Studies 22 (2009) 1621-1657.

Fang, H., and E. Kung, "Why Do Life Insurance Policyholders Lapse? The Roles of Income, Health and Bequest Motive Shocks," University of Pennsylvania and Duke University Working Paper, 2012.

Friedman, M., A Theory of the Consumption Function (Princeton, NJ: Princeton University Press, 1957).

Froot, K.A., D.S. Scharfstein, and J.C. Stein, "Risk Management: Coordinating Corporate Investment and Financing Policies," Journal of Finance 48 (1993) 1629-1658.

Fuster, A., and P.S. Willen, "Insuring Consumption Using Income-Linked Assets," Review of Finance 15 (2011) 835-873.

Giné, X., R. Townsend, and J. Vickery, "Patterns of Rainfall Insurance Participation in Rural India," World Bank Economic Review 22 (2008) 539-566.

Guvenen, F., S. Ozkan, and J. Song, "The Nature of Countercyclical Income Risk," University of Minnesota Working Paper, 2012.

Harris, M., and B. Holmström, "A Theory of Wage Dynamics," Review of Economic Studies 49 (1982) 315-333.

Holmström, B., "Moral Hazard and Observability," Bell Journal of Economics 10 (1979) $74-91$.

Holmström, B., and J. Tirole, "Private and Public Supply of Liquidity," Journal of Political Economy 106 (1998) 1-40.

Holmström, B., and J. Tirole, Inside and Outside Liquidity (Cambridge, MA: MIT Press, 2011). 
Hopenhayn, H.A., and E.C. Prescott, "Stochastic Monotonicity and Stationary Distributions for Dynamic Economies," Econometrica 60 (1992) 1387-1406.

Huggett, M., "The Risk Free Rate in Heterogeneous-Agent, Incomplete-Insurance Economies," Journal of Economic Dynamics and Control 17 (1993) 953-969.

Inkmannn, J., P. Lopes, and A. Michaelides, "How Deep is the Annuity Market Participation Puzzle?" Review of Financial Studies 24 (2011) 279-319.

Jorgenson, D.W., "Capital Theory and Investment Behavior," American Economic Review Papers and Proceedings 53 (1963) 247-259.

Kaplan, G., and G.L. Violante, "How Much Consumption Insurance Beyond Self-Insurance?" American Economic Journals: Macroeconomics 2 (2010) 53-87.

Kaplan, G., G.L. Violante, and Justin Weidner, "The Wealthy Hand-to-Mouth," Brookings Papers on Economic Activity Spring (2014) 77-138.

Kehoe, T.J., and D.K. Levine, "Debt-constrained Asset Markets," Review of Economic Studies 60 (1993) 865-888.

Kimball, M.S., "Precautionary Saving in the Small and in the Large," Econometrica 58 (1990) 53-73.

Kiyotaki, N., and J. Moore, "Credit Cycles," Journal of Political Economy 105 (1997) 211-248.

Kocherlakota, N.R., "Implications of Efficient Risk Sharing Without Commitment," Review of Economic Studies 63 (1996) 595-609.

Krebs, T., M. Kuhn, and M.L.J. Wright, "Human Capital Risk, Contract Enforcement, and the Macroeconomy," American Economic Review 105 (2015) 3223-3272.

Krueger, D., and H. Uhlig, "Competitive Risk Sharing Contracts with One-sided Commitment," Journal of Monetary Economics 53 (2006) 1661-1691.

Leland, H.E., "Saving and Uncertainty: The Precautionary Demand for Saving," Quarterly Journal of Economics 82 (1968) 465-473.

Ljungqvist, L., and T.J. Sargent, Recursive Macroeconomic Theory (Cambridge, MA: MIT Press, 2012).

Lustig, H.N., and S.G. Van Nieuwerburgh, "Housing Collateral, Consumption Insurance, and Risk Premia: An Empirical Perspective," Journal of Finance 60 (2005) 11671219.

Mankiw, N.G., "The Equity Premium and the Concentration of Aggregate Shocks," Journal of Financial Economics 17 (1986) 211-219.

Modigliani, F., and M.H. Miller, "The Cost of Capital, Corporation Finance and the Theory of Investment," American Economic Review 48 (1958) 261-297. 
Piazzesi, M., M. Schneider, and S. Tuzel, "Housing, Consumption and Asset Pricing," Journal of Financial Economics 83 (2007) 531-569.

Rampini, A.A., "Entrepreneurial Activity, Risk, and the Business Cycle, Journal of Monetary Economics 51 (2004) 555-573.

Rampini, A.A., A. Sufi, and S. Viswanathan, "Dynamic Risk Management," Journal of Financial Economics 111 (2014) 271-296.

Rampini, A.A., and S. Viswanathan, "Collateral, Risk Management, and the Distribution of Debt Capacity," Journal of Finance 65 (2010) 2293-2322.

Rampini, A.A., and S. Viswanathan, "Collateral and Capital Structure," Journal of Financial Economics, 109 (2013), 466-492.

Rothschild, M., and J. Stiglitz, "Equilibrium in Competitive Insurance Markets: An Essay on the Economics of Imperfect Information," Quarterly Journal of Economics 90 (1976) 629-649.

Sandmo, A., "The Effect of Uncertainty on Saving Decisions," Review of Economic Studies 37 (1970) 353-360.

Schechtman, J., "An Income Fluctuation Problem," Journal of Economic Theory 12 (1976) 218-241.

Schechtman, J., and V.L.S. Escudero, "Some Results on 'An Income Fluctuation Problem'," Journal of Economic Theory 16 (1977) 151-166.

Shiller, R.J., Macro Markets: Creating Institutions for Managing Society's Largest Economic Risks (New York, NY: Oxford University Press, 1993).

Shiller, R.J., "Derivatives Markets for Home Prices," NBER Working Paper 13962, 2008.

Sibley, D.S., "Permanent and Transitory Income Effects in a Model of Optimal Consumption with Wage Income Uncertainty," Journal of Economic Theory 11 (1975) 68-82.

Sinai, T., and N.S. Souleles, "Owner-occupied Housing as a Hedge Against Rent Risk," Quarterly Journal of Economics 120 (2005) 763-789.

Stokey, N.L., and R.E. Lucas, with E.C. Prescott, Recursive Methods in Economic Dynamics (Cambridge, MA: Harvard University Press, 1989).

Storesletten, K., C.I. Telmer, and A. Yaron, "Cyclical Dynamics in Idiosyncratic LaborMarket Risk," Journal of Political Economy 112 (2004) 695-717.

Townsend, R.M., "Risk and Insurance in Village India," Econometrica 65 (1994) 539592.

Yaari, M.E., "A Law of Large Numbers in the Theory of Consumer's Choice under Uncertainty," Journal of Economic Theory 12 (1976) 202-217. 


\section{Figure 1: Increasing Household Risk Management}

This figure displays household income risk management when household income follows an independent two state Markov process. The solid (dashed) lines plot the policies for the low (high) state next period. Top left: hedging $h^{\prime}$; top right: net worth next period $w^{\prime}$ and 45-degree line (dotted); bottom left: consumption $c$; and bottom right: stationary distribution of net worth. The parameter values are: $\beta=0.90, R=1.05, \Pi(\underline{s}, \underline{s})=\Pi(\bar{s}, \bar{s})=0.50, y(\underline{s})=0.80, y(\bar{s})=1.20$, and preferences $u(c)=c^{1-\gamma} /(1-\gamma)$ with $\gamma=2$.
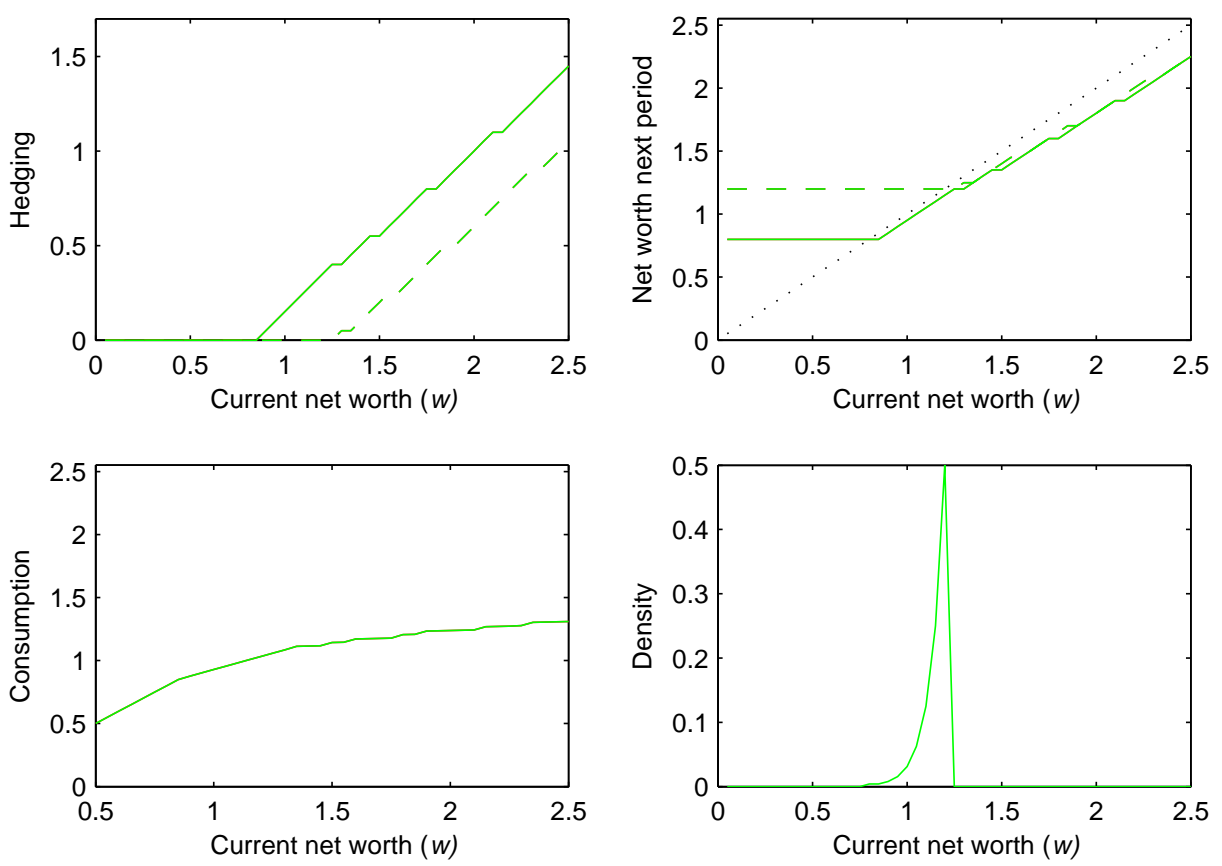


\section{Figure 2: Household Risk Management with Durable Goods}

This figure displays household income risk management with durable goods when income follows a two state Markov process with independence (Panel A and B) and persistence (Panel C). The solid (dashed) lines plot the policies for the low (high) state next period. In Panel C, the darker (and red) lines are associated with $\underline{s}$ and the lighter (and green) lines with $\bar{s}$. Top left: hedging $h^{\prime}$; top right: net worth next period $w^{\prime}$ and 45-degree line (dotted); bottom left (Panel A): consumption $c$; and bottom right (Panel A): durable goods consumption $k$. Parameters are as in Figure 1 except that $\theta=0.80$ in Panel A and $\mathrm{C}$ and $\theta=0.6$ in Panel $\mathrm{B}$ and utility from durable goods $g(k)=g k^{1-\gamma} /(1-\gamma)$ with $\gamma=2$ and $g=2$. In Panel A and B $(\mathrm{C}), \Pi(\underline{s}, \underline{s})=\Pi(\bar{s}, \bar{s})=0.50(0.75)$.

\section{Panel A: Independent income}
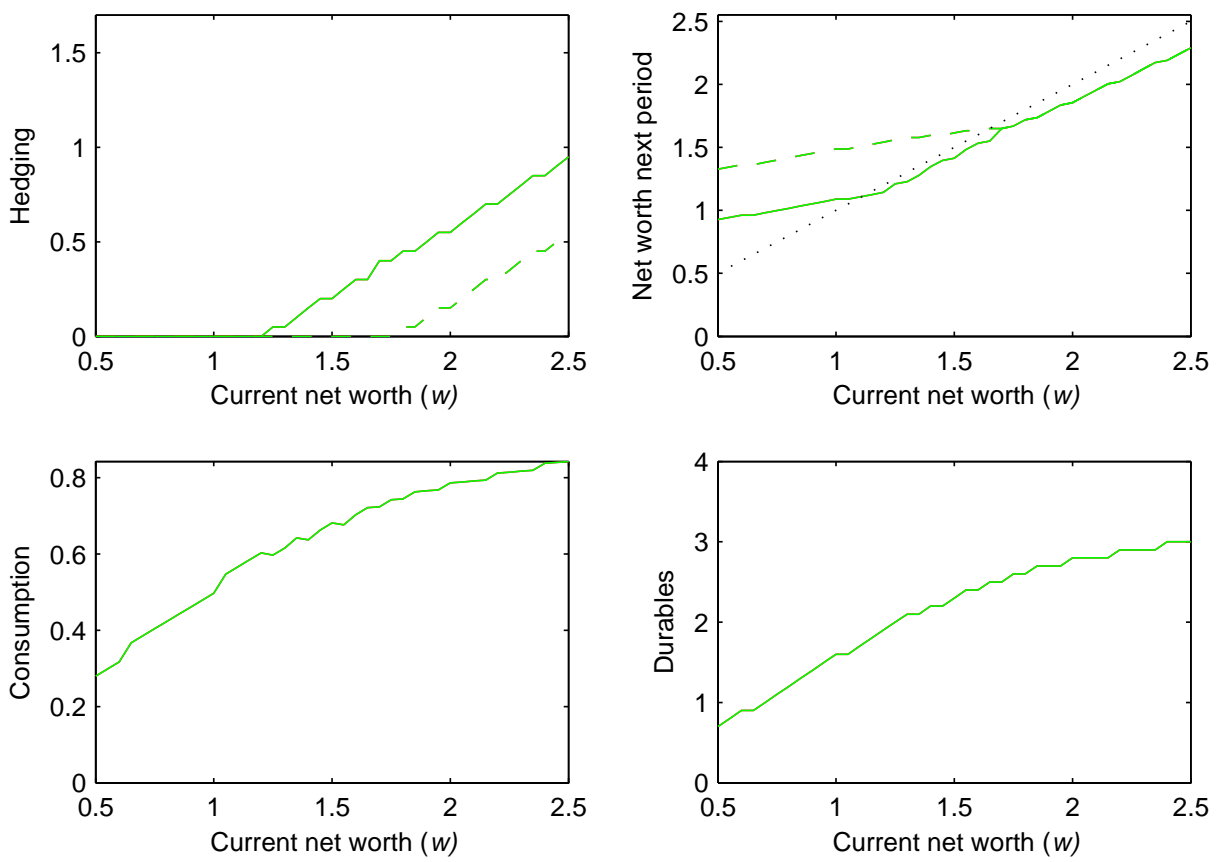

Panel B: Effect of Collateralizability
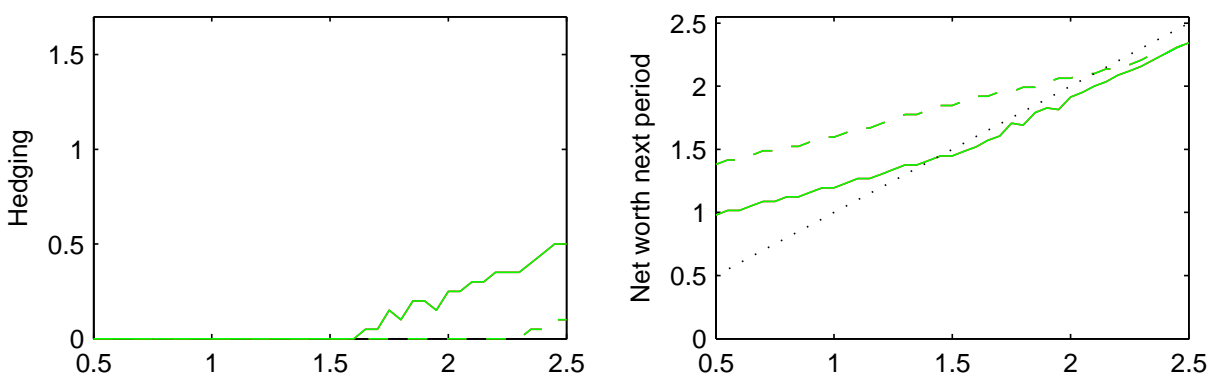

Panel C: Persistent income
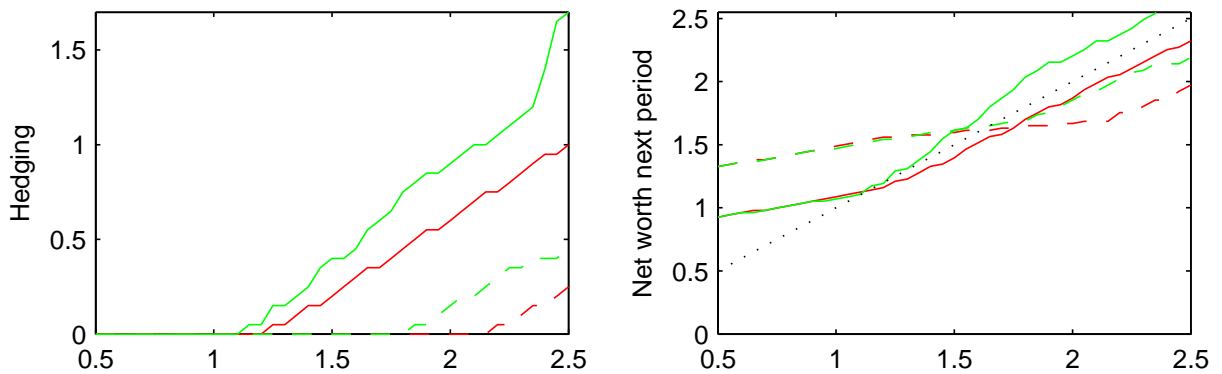


\section{Figure 3: Equilibrium and Effect of Collateral on Insurance}

This figure displays equilibrium household risk management as a function of collateralizability $\theta$. Panel A displays the equilibrium net interest rate $r$ (top left), aggregate hedging $H$ (top right), aggregate durable goods $K$ (bottom left), and the welfare loss (in terms of equivalent income reduction (percent)) (bottom right). Panel B displays the equilibrium distribution of net worth for various levels of $\theta$ (top) and inequality measured by the cross-sectional standard deviation of consumption (bottom left) and net worth (bottom right). Parameters are as in Panel A of Figure 2 except that $g=1, \delta=0.2, y(\underline{s})=0.5$, and $y(\bar{s})=1.5$, implying $\bar{\theta}=0.4736$.

\section{Panel A: Interest Rate, Hedging, Durable Stock, and Welfare Loss}
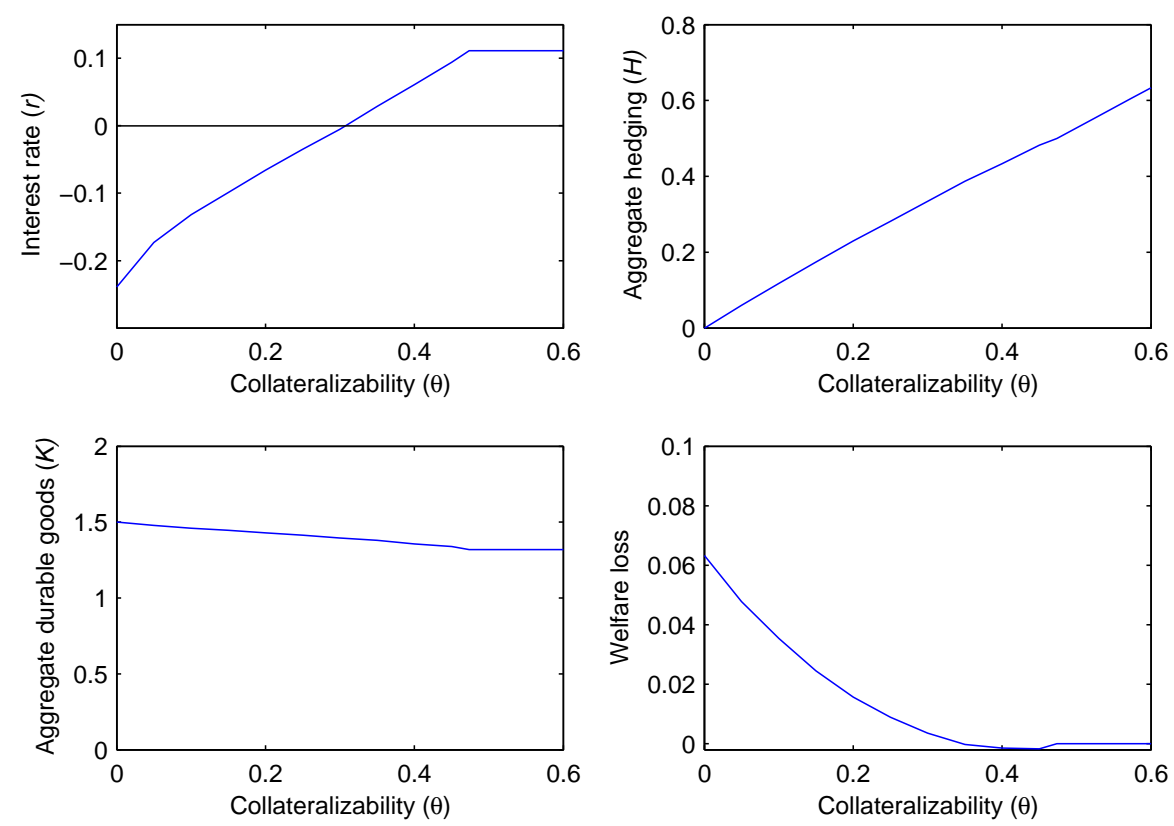

Panel B: Wealth Distribution and Inequality
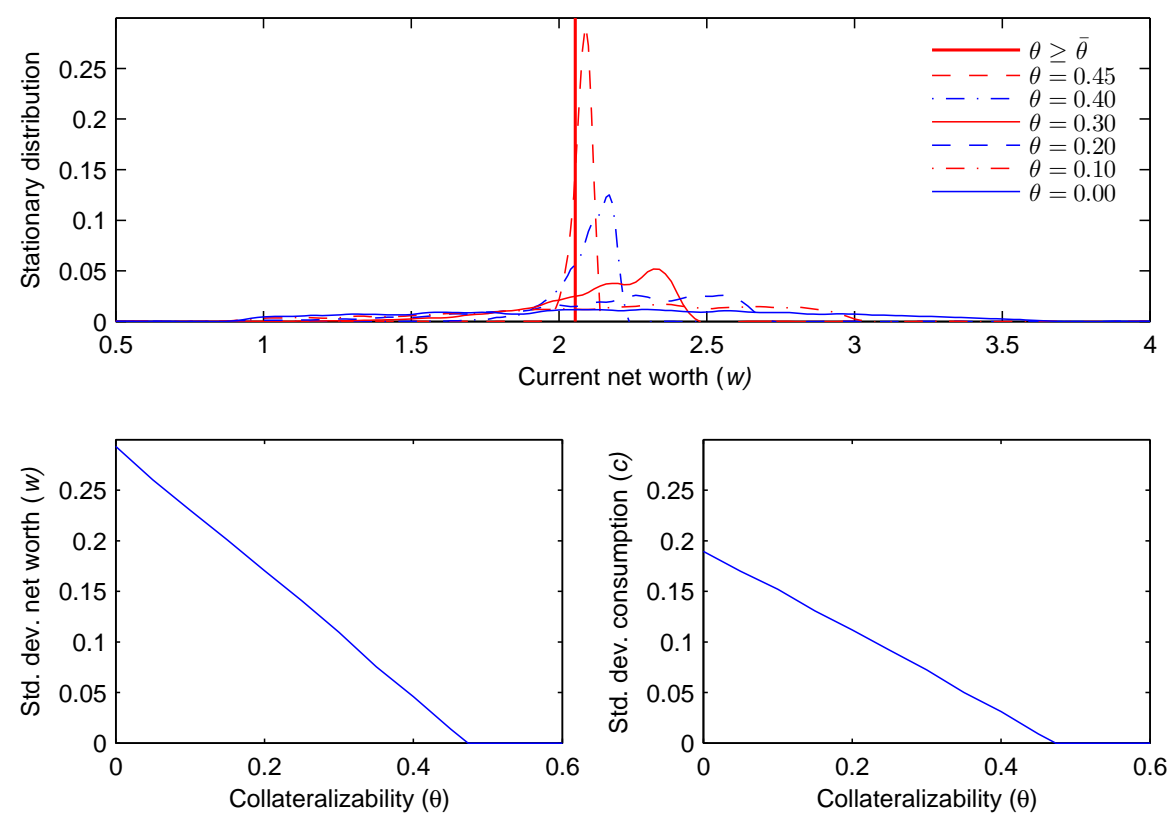


\section{Figure 4: Household Risk Management with Durable Goods Price Risk}

This figure displays household income risk management with durable goods price risk when household income and durable goods prices follow a two state Markov process with independence. The solid (dashed) lines plot the policies for the low (high) state next period. The darker (and red) lines are associated with $\underline{s}$ and the lighter (and green) lines with $\bar{s}$. Top left: hedging $h^{\prime}$; top right: net worth next period $w^{\prime}$ and 45-degree line (dotted); bottom left: consumption $c$; and bottom right: durable goods consumption $k$. Parameters are as in Figure 2 except that $q(\underline{s})=0.95$ and $q(\bar{s})=1.05$, and $\Pi(\underline{s}, \underline{s})=\Pi(\bar{s}, \bar{s})=0.50$.
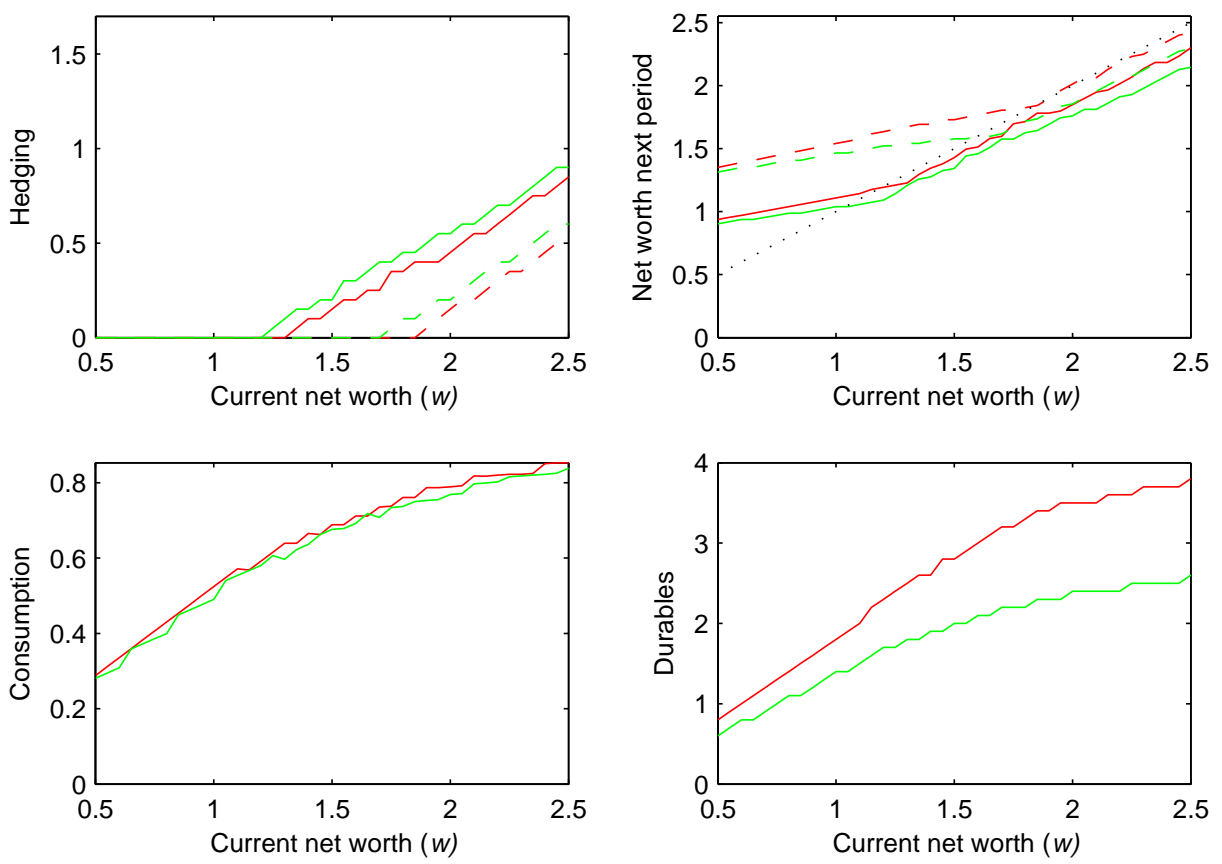


\section{Figure 5: Risk Management, Rent vs. Buy, and Durable Goods Price Risk}

This figure displays household risk management with durable goods price risk when households can choose to rent as well as buy durables and where income and durable goods prices each follow an independent two state Markov process which is independent over time. The solid (dashed) lines plot the policies for the low (high) price state next period (except where noted otherwise). The darker (and red) lines are associated with $\underline{s}$ and the lighter (and green) lines with $\bar{s}$. Top left: hedging $h^{\prime}$; top right: net worth next period $w^{\prime}$ and 45-degree line (dotted); bottom left: consumption $c$; and bottom right: consumption of durable goods, total $k$ (dotted), owned $k_{o}$ (solid), and rented $k_{l}$ (dashed). Parameters are as in Figure 4 except that the monitoring cost $m=0.02$.
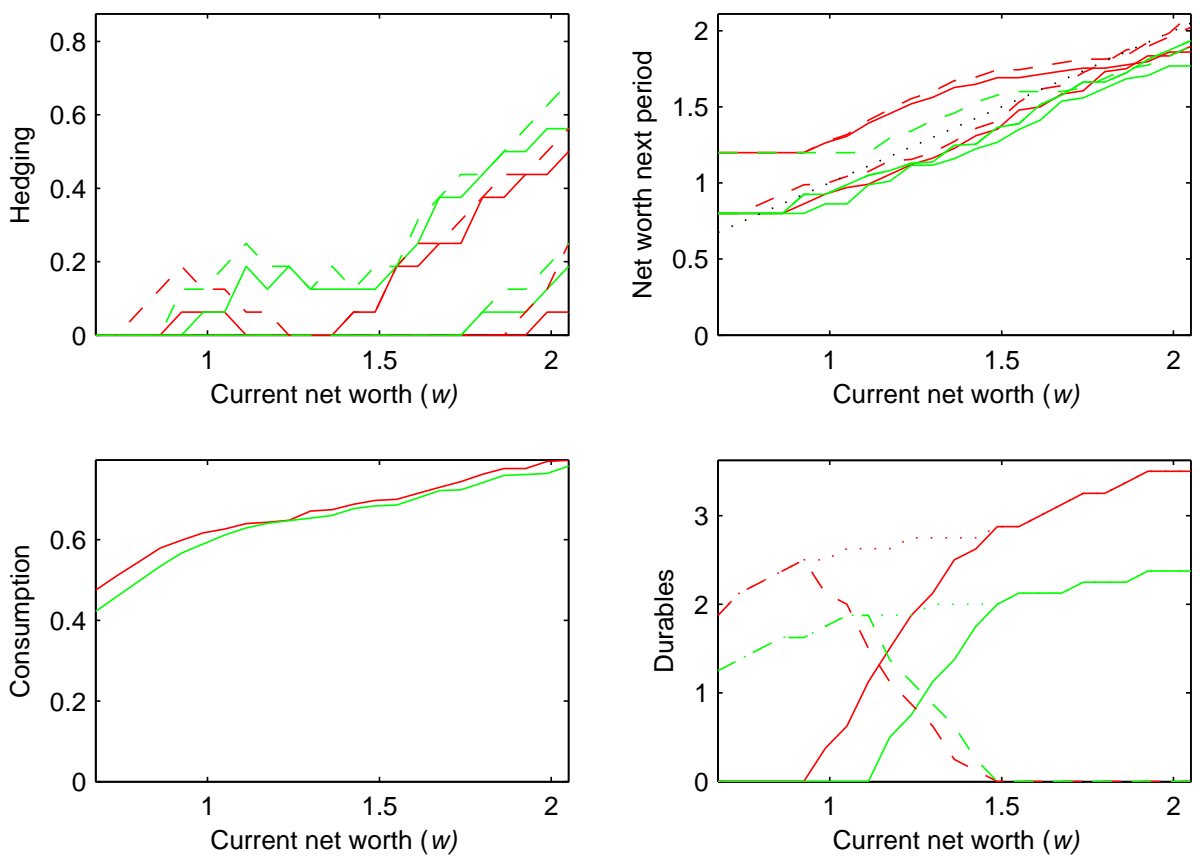


\section{Appendix -- For Online Publication}

\section{Appendix D: Extensions}

In this appendix we compare our results from Section 2 to the savings behavior in the standard buffer stock savings model. We show that buffer stock savings are not monotone increasing in the state $s$ and that convexity of the marginal utility is required to guarantee precautionary behavior of household savings. Moreover, we compare the limiting behavior of our model and the buffer stock savings model as $\beta R \rightarrow 1$.

\section{Appendix D.1: Comparison to Buffer Stock Savings Models}

Consider the standard incomplete markets model of Bewley (1977), Aiyagari (1994), and others. ${ }^{36}$ The household solves the following recursive problem by choosing (non-negative) consumption $c$ and (gross) savings $h$ which do not vary with the state $s^{\prime}$ next period (and associated net worth $w^{\prime}$ ) given the exogenous state $s$ and the net worth $w$ (cum current income),

$$
v(w, s) \equiv \max _{c, h, w^{\prime} \in \mathbb{R}_{+} \times \mathbb{R}^{S+1}} u(c)+\beta E\left[v\left(w^{\prime}, s^{\prime}\right) \mid s\right]
$$

subject to the budget constraints for the current and next period, $\forall s^{\prime} \in S$,

$$
\begin{aligned}
w & \geq c+R^{-1} h, \\
y^{\prime}+h & \geq w^{\prime},
\end{aligned}
$$

and the short-sale constraint

$$
h \geq 0
$$

While this canonical model behaves similarly to ours in some ways, we stress that household savings are not monotone increasing in the Bewley model, in the sense that savings are decreasing in the current state $s$, which means that the household's consumption is lower in some states next period when the current state $s$ is higher.

Proposition D.1 (Household savings in Bewley model not increasing). Assume that $\Pi\left(s, s^{\prime}\right)$ is stochastically monotone. (i) The marginal value of net worth $v_{w}(w, s)$ is decreasing in net worth $w$ and in the state s. (ii) The household's savings $h$ are increasing in $w$ given $s$, but decreasing in s given $w$; therefore, net worth and consumption next period $w^{\prime}$ and $c^{\prime}$ are decreasing in the current state $s$.

Proof of Proposition D.1. Part (i): The proof proceeds analogously to the proof of Part (i) of Proposition 2.

$$
T v(w, s) \equiv \max _{c, h, w^{\prime} \in \mathbb{R}_{+} \times \mathbb{R}^{S+1}} u(c)+\beta E\left[v\left(w^{\prime}, s^{\prime}\right) \mid s\right]
$$

\footnotetext{
${ }^{36}$ See Ljungqvist and Sargent (2012) for an authoritative treatise of savings behavior in incomplete markets models.
} 
subject to equations (D.2) through (D.4). Define the sets $\mathcal{S}$ and $\mathcal{S}^{o}$ as before. We show that $T(\mathcal{S}) \subset \mathcal{S}^{o} \subset \mathcal{S}$ and hence $v \in \mathcal{S}^{o}$ has the required property.

Suppose that $v \in \mathcal{S}$, but that $\exists s_{+}>s$, such that $T v_{w}\left(w, s_{+}\right)>T v_{w}(w, s)$, that is $T v \notin \mathcal{S}^{o}$. Using the envelope condition, $c_{+}<c$ which implies, using the budget constraint (D.2), that $h_{+}>h$ and $w_{+}^{\prime}=y^{\prime}+h_{+}>y^{\prime}+h=w, \forall s^{\prime} \in S$. The Euler equation for savings can be written as

$$
\begin{array}{cl}
T v_{w}(w, s) \geq \beta R E\left[v_{w}^{-}\left(w^{\prime}, s^{\prime}\right) \mid s\right] \geq \beta R E\left[v_{w}^{+}\left(w^{\prime}, s^{\prime}\right) \mid s\right] & \text { if } h=0 \\
T v_{w}(w, s) \in\left[\beta R E\left[v_{w}^{+}\left(w^{\prime}, s^{\prime}\right) \mid s\right], \beta R E\left[v_{w}^{-}\left(w^{\prime}, s^{\prime}\right) \mid s\right]\right] & \text { if } h>0 .
\end{array}
$$

Using (D.5) and the envelope condition, we have

$$
\beta R E\left[v_{w}^{-}\left(w_{+}^{\prime}, s^{\prime}\right) \mid s_{+}\right] \geq T v_{w}\left(w, s_{+}\right)>T v_{w}(w, s) \geq \beta R E\left[v_{w}^{+}\left(w^{\prime}, s^{\prime}\right) \mid s\right] .
$$

However, since $w_{+}^{\prime}>w^{\prime}, \forall s^{\prime} \in S$, and given stochastic monotonicity, we also have that

$$
E\left[v_{w}^{+}\left(w^{\prime}, s^{\prime}\right) \mid s\right] \geq E\left[v_{w}^{+}\left(w^{\prime}, s^{\prime}\right) \mid s_{+}\right]>E\left[v_{w}^{-}\left(w_{+}^{\prime}, s^{\prime}\right) \mid s_{+}\right],
$$

a contradiction. Therefore, $T v \in \mathcal{S}^{o}$.

Part (ii): Since $v \in \mathcal{S}^{o}$ by part (i), it is differentiable and $v_{w}(w, s)$ is decreasing in $s$. Suppose that, given $s, w_{+}>w$ and $h_{+}<h$, then

$$
u_{c}(c)=v_{w}(w, s)=\beta R E\left[v_{w}\left(w^{\prime}, s^{\prime}\right) \mid s\right]<\beta R E\left[v_{w}\left(w_{+}^{\prime}, s^{\prime}\right) \mid s\right] \leq v_{w}\left(w_{+}, s\right)=u_{c}\left(c_{+}\right),
$$

whereas $c_{+}>c$ implies that $u_{c}\left(c_{+}\right)<u_{c}(c)$, a contradiction. Thus, $h$ is increasing in $w$ given $s$.

Let $s_{+}>s$ and suppose that $h_{+}>h$ for given $w$. Then $c_{+}<c$ and $w_{+}^{\prime}>w^{\prime}, \forall s^{\prime} \in S$. Then

$u_{c}(c)<u_{c}\left(c_{+}\right)=v_{w}\left(w, s_{+}\right)=\beta R E\left[v_{w}\left(w_{+}^{\prime}, s^{\prime}\right) \mid s_{+}\right]<\beta R E\left[v_{w}\left(w^{\prime}, s^{\prime}\right) \mid s_{+}\right] \leq \beta R E\left[v_{w}\left(w^{\prime}, s^{\prime}\right) \mid s\right]$

since $v_{w}(w, s)$ is decreasing in $s$ by part (i) and $w^{\prime}$ is increasing in $s^{\prime}$, contradicting (D.5). So for $s_{+}>s, h_{+} \leq h$ and thus $w_{+}^{\prime} \leq w^{\prime}$. Moreover, using the envelope condition, $u_{c}\left(c^{\prime}\right)=v_{w}\left(w^{\prime}, s^{\prime}\right) \leq v_{w}\left(w_{+}^{\prime}, s^{\prime}\right)=u_{c}\left(c_{+}^{\prime}\right)$ and thus $c_{+}^{\prime} \leq c^{\prime}$.

The parallels between our model and the Bewley economy are that since $v_{w}(w, s)$ is decreasing in $w$ and $s$ in both cases, the envelope condition implies that current consumption $c$ is increasing in $w$ and $s$ in both economies as well. Therefore, both risk management expenditures $E\left[R^{-1} h^{\prime} \mid s\right]$ in our model and savings $h$ in the Bewley economy increase in $w$ given $s$ and decrease in $s$ given $w$. The key distinction however is that household risk management $h^{\prime}$ in our model increases in $s$, for all $s^{\prime} \in S$, although as stated before the total risk management expenditures $E\left[R^{-1} h^{\prime} \mid s\right]$ decrease in $s$; in other words, $w^{\prime}$ and $c^{\prime}$ increase in $s$, and household risk management is increasing in $s$ in this sense. In contrast, savings $h$ decrease in $s$ implying that net worth and consumption next 
period $w^{\prime}$ and $c^{\prime}$ decrease in $s$; again, household savings are thus not increasing in $s$ in the Bewley economy.

The critical difference is the following. If the future is brighter, the household in the Bewley economy consumes more and saves less, making it less well off state-bystate next period; in contrast, the household in our economy consumes more and buys more state-contingent claims, which are now cheaper, making it better off state-by-state next period, too. The incompleteness of markets has significant consequences for the qualitative behavior of the economy.

In contrast to the precautionary nature of state-contingent savings in our model (see Proposition 5), in the Bewley model convexity of marginal utility $u_{c}(c)$ is required to guarantee precautionary savings.

Proposition D.2 (Precautionary saving in Bewley model). Assume that $\Pi\left(s, s^{\prime}\right)=\pi\left(s^{\prime}\right)$, $\forall s^{\prime} \in S$. (i) If $u_{c}(c)$ is (weakly) convex in consumption $c$, the marginal value of net worth $v_{w}(w)$ is convex in net worth $w$. (ii) Suppose $\tilde{\pi}\left(s^{\prime}\right)$ is a mean-preserving spread of $\pi\left(s^{\prime}\right)$. If $u_{c}(c)$ is (weakly) convex in $c$, then household's savings $\tilde{h} \geq h$.

Proof of Proposition D.2. Part (i): Suppose $u_{c}(c)$ is (weakly) convex. Take $w_{0}, w_{1}>$ $w_{0}$, and $\varphi \in(0,1)$, and define $w_{\varphi} \equiv(1-\varphi) w_{0}+\varphi w_{1}$ and analogously for other variables. Consider operator $T$ defined analogously to the one in the proof of Proposition D.1. By the same argument, $\mathcal{S}^{o} \subset \mathcal{S}$ and we can restrict our attention to functions in $\mathcal{S}^{o}$. Assume that savings are strictly positive at $w_{0}$ and note that this implies that they are strictly positive at $w_{1}$ and indeed for any $w \geq w_{0}$ as savings are increasing in $w$ by part (ii) of Proposition D.1. From the first order condition for savings we have

$$
T v_{w}\left(w_{0}\right)=u_{c}\left(w_{0}-R^{-1} h_{0}\right)=\beta R E\left[v_{w}\left(y^{\prime}+h_{0}\right)\right]
$$

and analogously for $h_{1}$ at $w_{1}$ and $h\left(w_{\varphi}\right)$ at $w_{\varphi}$. Suppose $v \in \mathcal{S}^{o}$ and $v_{w}(w)$ is convex, $\forall w \in \mathbb{R}_{+}$, but that $T v_{w}(w)$ is not convex, that is,

$$
\begin{aligned}
u_{c}\left(w_{\varphi}-R^{-1} h\left(w_{\varphi}\right)\right) & =T v_{w}\left(w_{\varphi}\right)>(1-\varphi) T v_{w}\left(w_{0}\right)+\varphi T v_{w}\left(w_{1}\right) \\
& =(1-\varphi) u_{c}\left(w_{0}-R^{-1} h_{0}\right)+\varphi u_{c}\left(w_{1}-R^{-1} h_{1}\right) \geq u_{c}\left(w_{\varphi}-R^{-1} h_{\varphi}\right),
\end{aligned}
$$

and, thus, $h\left(w_{\varphi}\right)>h_{\varphi}$. But then, using the fact that $v_{w}(w)$ is convex, we have

$$
(1-\varphi) E\left[v_{w}\left(y^{\prime}+h_{0}\right)\right]+\varphi E\left[v_{w}\left(y^{\prime}+h_{1}\right)\right] \geq E\left[v_{w}\left(y^{\prime}+h_{\varphi}\right)\right]>E\left[v_{w}\left(y^{\prime}+h\left(w_{\varphi}\right)\right)\right]
$$

and combining the two results, $T v_{w}\left(w_{\varphi}\right)>\beta R E\left[v_{w}\left(y^{\prime}+h\left(w_{\varphi}\right)\right)\right]$, a contradiction. When savings are zero at $w_{1}$, then $T v_{w}(w)=u_{c}(w)$ in the relevant range which is convex by assumption. Let $w^{*}=\inf _{w}\{h>0\}$. The above shows that $T v_{w}(w)$ is convex on $\left[0, w^{*}\right]$ and $\left[w^{*}, \infty\right)$. Next we consider the case where $w_{0}<w^{*}<w_{1}$.

Note that for $w \leq w^{*}, T v_{w}(w)=u_{c}(w)$, and for $w>w^{*}, c<w$ as $h>0$ and hence $T v_{w}(w)=u_{c}(c)>u_{c}(w)$. First, consider $\varphi \in(0,1)$ such that $w_{\varphi} \equiv(1-\varphi) w_{0}+\varphi w_{1} \leq w^{*}$; then

$$
(1-\varphi) T v_{w}\left(w_{0}\right)+\varphi T v_{w}\left(w_{1}\right)>(1-\varphi) u_{c}\left(w_{0}\right)+\varphi u_{c}\left(w_{1}\right) \geq u_{c}\left(w_{\varphi}\right)=T v_{w}\left(w_{\varphi}\right) .
$$


If instead $w_{\varphi}>w^{*}$, then define $\varphi^{*}$ and $\hat{\varphi}$ implicitly by $w^{*}=\left(1-\varphi^{*}\right) w_{0}+\varphi^{*} w_{1}$ and $w_{\varphi}=(1-\hat{\varphi}) w^{*}+\hat{\varphi} w_{1}$, which implies that $\varphi=(1-\hat{\varphi}) \varphi^{*}+\hat{\varphi}$; then by the previous argument

$$
\left(1-\varphi^{*}\right) T v_{w}\left(w_{0}\right)+\varphi^{*} T v_{w}\left(w_{1}\right)>T v_{w}\left(w^{*}\right)
$$

and hence

$$
\begin{aligned}
(1-\varphi) T v_{w}\left(w_{0}\right)+\varphi T v_{w}\left(w_{1}\right) & =(1-\hat{\varphi})\left[\left(1-\varphi^{*}\right) T v_{w}\left(w_{0}\right)+\varphi^{*} T v_{w}\left(w_{1}\right)\right]+\hat{\varphi} T v_{w}\left(w_{1}\right) \\
& >(1-\hat{\varphi}) T v\left(w^{*}\right)+\hat{\varphi} T v_{w}\left(w_{1}\right) \geq T v_{w}\left(w_{\varphi}\right),
\end{aligned}
$$

where the last inequality follows from the convexity above $w^{*}$. Therefore, $T v_{w}(w)$ is convex with strict convexity at $w^{*}$.

We already know that $v \in \mathcal{S}^{o}$ and for any $\hat{v} \in \mathcal{S}^{o}, T^{n} \hat{v} \rightarrow v$. But by above if we start with $\hat{v}$ such that $\hat{v}_{w}(w, s)$ is convex, then $T^{n} \hat{v}$ is convex; moreover, $T^{n} \hat{v}_{w}(w, s)=u_{c}(\hat{c})$ and the policy function converges, and hence so does the marginal value of net worth. Thus, $v_{w}(w, s)$ is convex, too.

Part (ii): Define $\overline{\mathcal{S}}$ and $\overline{\mathcal{S}}^{o}$ as in the proof of Proposition 5. Define the operator $T$ as in the proof of Proposition D.1 and define the operator $\tilde{T}$ associated with $\tilde{\pi}\left(s^{\prime}\right)$ analogously. Proceeding along the lines of the proof of part (i) of Proposition D.1, one can show that $T(\overline{\mathcal{S}}) \subset \overline{\mathcal{S}}^{o} \subset \overline{\mathcal{S}}$ and analogously for $\tilde{T}$.

Pick $\hat{v} \in \overline{\mathcal{S}}^{o}$ such that $\hat{v}_{w}(w)$ is convex. We show that if $\tilde{T}^{n} \hat{v}_{w}(w) \geq T^{n} \hat{v}_{w}(w)$, then $\tilde{T}^{n+1} \hat{v}_{w}(w) \geq T^{n+1} \hat{v}_{w}(w)$. Suppose that $\tilde{T}^{n} \hat{v}_{w}(w) \geq T^{n} \hat{v}_{w}(w)$, but that $\tilde{h}<h$, and hence $\tilde{c}>c$ and $\tilde{w}^{\prime}<w^{\prime}$. Using the first order condition for savings, we have

$$
u_{c}(c)=E\left[\beta R T^{n} v_{w}\left(y^{\prime}+h\right)\right] \leq \tilde{E}\left[\beta R T^{n} v_{w}\left(\tilde{y}^{\prime}+h\right)\right]<\tilde{E}\left[\beta R \tilde{T}^{n} v_{w}\left(\tilde{w}^{\prime}\right)\right] \leq u_{c}(\tilde{c}),
$$

and thus $c>\tilde{c}$, a contradiction. Thus, $\tilde{h} \geq h, \tilde{c} \leq c$, and $\tilde{T}^{n+1} \hat{v}_{w}(w) \geq T^{n+1} \hat{v}_{w}(w)$.

Since $T^{n} \hat{v} \rightarrow v$ and $T^{n} \hat{v}_{w}(w, s)=u_{c}(c)$ (and analogously for $\tilde{T} \hat{v}$ ), and the policy functions converge, the value functions $v$ and $\tilde{v}$ satisfy the property, too.

While this result is well-understood (see Leland (1968), Sandmo (1970), Sibley (1975), and Kimball (1990)), we provide a simple and to the best of our knowledge novel proof using a similar recursive approach to the one in the proof of Proposition 2. Again, we emphasize that risk aversion is sufficient for state-contingent savings to be precautionary in our model, in contrast to savings in incomplete markets models which require further assumptions about preferences, in particular prudence, to guarantee precautionary behavior. Note that the presence of borrowing constraints strengthens the precautionary demand for saving by inducing local convexity in the marginal utility of net worth (see Deaton (1991)), but additional assumptions about preferences are required to guarantee precautionary behavior globally.

Figure D.1 illustrates the effect of an increase in risk (that is, a mean-preserving spread) on hedging in our model and on saving in the incomplete markets model when the marginal utility is convex. The top left panel shows that in our model the expenditure 
on state-contingent savings is precautionary (see Proposition 5). The bottom left panel shows that, when $u_{c}(c)$ is convex, saving is precautionary in the Bewley economy (see Proposition D.2). The example has an independent income process with three states. Specifically, $y\left(s^{\prime}\right) \in\{y-\sigma, y, y+\sigma\}$ with probabilities $\pi\left(s^{\prime}\right)=\pi_{\sigma}, 1-2 \pi_{\sigma}$, and $\pi_{\sigma}$ respectively. We study an increase in risk in the sense of a mean-preserving spread by considering values of $\pi_{\sigma}$ equal to 0 (in which case the economy is deterministic), 0.2 , and 0.5 (which is the example studied in Figure 1).

Notice that the deterministic limit of our economy and the Bewley economy coincide and hence the solid (black) line denoting "hedging" expenditure $R^{-1} h^{\prime}$ in our model in the top left panel is identical to the solid (black) line denoting saving $R^{-1} h$ in the Bewley economy in the bottom left panel. In a deterministic economy, there is no "hedging" or saving in the steady state, but for higher (and transitory) levels of net worth "hedging" or saving is clearly positive as households dissave slowly.

In our model, hedging expenditures are increasing in risk (see the top left panel), but the behavior of hedging for each state $h\left(s^{\prime}\right)$ is not monotone in risk. Indeed, one can prove that $\inf _{w}\left\{h\left(\underline{s}^{\prime}\right)>0\right\}$ is the same for all values of $\pi_{\sigma}$ and that in a neighborhood above that threshold $h\left(\underline{s}^{\prime}\right)$ is decreasing in $\pi_{\sigma}$. But the top right panel shows that this pattern reverses for higher levels of net worth. In contrast, in the example $h\left(\bar{s}^{\prime}\right)$ is monotone increasing in $\pi_{\sigma}$. In comparison, in the Bewley economy with convex marginal utility, an increase in risk increases saving (as the bottom left panel shows), that is, households save more for a given level of wealth than they would in the deterministic economy.

\section{Appendix D.2: Risk Management when Households are Eventu- ally Unconstrained}

Consider the limit of the economy in Section 2 where $\beta R=1$, which means that households are eventually unconstrained. ${ }^{37}$ We show that the economy displays full insurance under the stationary distribution in the limit and that household net worth is nevertheless bounded in the limit. These results are related to results for the classic class of income fluctuations problems studied among others by Yaari (1976), Schechtman (1976), Schechtman and Escudero (1977), Bewley (1977, 1980), Aiyagari (1994), and especially Chamberlain and Wilson (2000), in which households solve a consumption savings problem with noncontingent debt and borrowing constraints, that is, have access to incomplete markets

\footnotetext{
${ }^{37}$ Aguiar, Amador, and Gopinath (2009) discuss the effect of impatience on the long run behavior of models with limited commitment.
} 
only. ${ }^{38}$ Our results are similar in that there is complete consumption insurance in the limit, but they are rather different in that net worth is bounded in the limit whereas it grows without bound in these related papers. Thus, our model features substantially less asset accumulation than the canonical model with incomplete markets.

We emphasize that for net worth levels below the upper bound of net worth under the stationary distribution $w_{b n d}(s), \forall s \in S$ (see the proof of Proposition 4 for an exact definition), household risk management is incomplete and increasing in current net worth even when $\beta R=1$, although such levels of net worth are transient. The main result of our paper hence obtains even in this case, albeit only in the transition.

When income is independent over time and $\beta R=1$, we know from equation (7) and the envelope condition that $v_{w}(w)=v_{w}\left(w^{\prime}\right)+\lambda^{\prime}$ and therefore $v_{w}(w)$ is non-increasing and $w$ is non-decreasing. ${ }^{39}$ Denoting the upper bound of net worth under the stationary distribution by $\bar{w}$, we hence have $v_{w}(\bar{w}) \geq v_{w}\left(w^{\prime}\right)$, but by strict concavity $v_{w}(\bar{w}) \leq v_{w}\left(w^{\prime}\right)$, and thus $\bar{w}=w^{\prime}, \forall s^{\prime} \in S$, that is, $\bar{w}$ is absorbing. Note that for $w<\bar{y}, \lambda\left(\bar{s}^{\prime}\right)>0$ and $w\left(\bar{s}^{\prime}\right)=\bar{y}$. Moreover, suppose $\exists s^{\prime} \in S$, such that $w^{\prime}>\bar{y}$, then $v_{w}(\bar{y})>v_{w}\left(w^{\prime}\right)$ and $\lambda^{\prime}>0$, that is, $w^{\prime}=y^{\prime} \leq \bar{y}$, a contradiction. Therefore, $w^{\prime}=\bar{y}$, for all $s^{\prime} \in S$. Thus, the stationary net worth distribution collapses to unit mass at $\bar{w}=\bar{y}$.

Proposition D.3 states that the full insurance result is general, that is, does not require independence of the income process. Moreover, as $\beta R$ goes to 1 , the stationary distribution converges to the stationary distribution given $\beta R=1$ and, when the income process is independent, the stationary distribution for higher $\beta$ first-order stochastically dominates the distribution for lower $\beta$.

Proposition D.3 (Full insurance under the stationary distribution in the limit). (i) When $\beta R=1$, the household engages in full insurance under the stationary distribution. (ii) Let $p^{*}(\beta)$ be the stationary distribution of net worth for given $\beta$. As $\beta \nearrow R^{-1}$, $p^{*}(\beta) \rightarrow p^{*}\left(R^{-1}\right)$; moreover, when $\Pi\left(s, s^{\prime}\right)=\pi\left(s^{\prime}\right), \forall s, s^{\prime} \in S$, if $\beta_{+}>\beta$, then $p^{*}\left(\beta_{+}\right)$ $\operatorname{FOSD} p^{*}(\beta)$.

Proof of Proposition D.3. Part (i): From equation (7) and the envelope condition that $v_{w}(w, s)=v_{w}\left(w^{\prime}, s^{\prime}\right)+\lambda^{\prime}$ and therefore $v_{w}(w, s)$ is non-increasing. Consider the marginal value of net worth at the upper bound of the stationary distribution for some state $s, v_{w}(\bar{w}(s), s)$; suppose there exists some state, say, w.l.o.g., next period, such that $v_{w}(\bar{w}(s), s)>v_{w}\left(w^{\prime}, s^{\prime}\right)$. But $v_{w}\left(w^{\prime}, s^{\prime}\right) \geq v_{w}\left(w^{\prime \prime}, s^{\prime \prime}\right), \forall s^{\prime \prime} \in S$, including $s^{\prime \prime}=s$. But then, by concavity, $v_{w}(\bar{w}(s), s) \leq v_{w}\left(w^{\prime \prime}, s\right)$, a contradiction. Thus, $v_{w}(w, s)=v_{w}\left(w^{\prime}, s^{\prime}\right)$, $\forall(w, s),\left(w^{\prime}, s^{\prime}\right)$ in the support of the stationary distribution.

\footnotetext{
${ }^{38}$ In a calibrated life-cycle model with incomplete markets, Fuster and Willen (2011) study the trade-off between insuring consumption across states and intertemporal smoothing quantitatively.

${ }^{39}$ This result is reminiscent of the downward rigidity of wage contracts in Harris and Holmström (1982).
} 
Part (ii): We first prove that as $\beta \nearrow R^{-1}, p^{*}(\beta) \rightarrow p^{*}\left(R^{-1}\right)$. From the proof of Proposition 4 and Theorem 11.4 in Stokey and Lucas with Prescott (1989), we know that

$$
\left\|p_{0} P(\beta)^{k}-p^{*}(\beta)\right\|_{\Delta} \leq(1-\varepsilon)^{k}\left\|p_{0}-p^{*}(\beta)\right\|_{\Delta} \leq(1-\varepsilon)^{k} 2,
$$

where $p_{0}$ and $p^{*}(\beta)$ are defined in the proof of Proposition 4 and $\|\cdot\|_{\Delta}$ denotes the total variation norm, and we use the fact that the total variation norm is bounded by 2 . Note that $\varepsilon=\varepsilon_{(\bar{y}, \bar{s})}$ does not depend on $\beta$.

Let $\delta_{n}>0, \delta_{n} \searrow 0$. Given $\delta_{n}$, there exists $k_{n}$ such that $\left\|p_{0} P(\beta)^{k_{n}}-p^{*}(\beta)\right\|_{\Delta}<\delta_{n} / 2$, $\forall \beta$. Further, pick $\beta_{n}$ such that $\forall \beta>\beta_{n}$,

$v_{w}^{\beta}(\bar{y}, \bar{s})=(\beta R)^{l} v_{w}^{\beta}\left(w_{l}^{\beta}(s), s\right), w_{l}^{\beta}(s) \geq y(s)$, and $\left|w_{l}^{\beta}(s)-w^{*}(s)\right|<\delta_{n}, 1 \leq l \leq k_{n}, \forall s \neq \bar{s}$,

where $v_{w}^{R^{-1}}(\bar{y}, \bar{s})=v_{w}^{R^{-1}}\left(w^{*}(s), s\right), \forall s \neq \bar{s}$. Note that by continuity of the optimal policy in $\beta$ we can ensure that there is such a $\beta_{n}$. Essentially, for all $\beta>\beta_{n}$, the household hedges all states (except the highest one) for the first $k_{n}$ periods.

Define $H_{n}(\beta)=\left\{z \in Z^{*}(\beta) \mid p_{0} P(\beta)^{k_{n}}(z)>0\right\}, R_{n}(\beta)=\left\{z \in Z^{*}(\beta) \mid p_{0} P(\beta)^{k_{n}}(z)=\right.$ $0\}=Z^{*}(\beta) \backslash H_{n}(\beta)$, and $H_{n}(\beta, s)=\left\{z \in Z^{*}(\beta) \mid z=\left(w_{l}^{\beta}(s), s\right), 1 \leq l \leq k_{n}\right\}, \forall s \neq \bar{s}$, and $H_{n}(\beta, \bar{s})=\{(\bar{y}, \bar{s})\}$. By construction, we have $p_{0} P(\beta)^{k_{n}}\left(H_{n}(\beta, s)\right)=p_{0} P\left(R^{-1}\right)^{k_{n}}\left(\left\{\left(w^{*}(s), s\right)\right\}\right)$ and $p_{0} P(\beta)^{k_{n}}\left(H_{n}(\beta)\right)=p_{0} P\left(R^{-1}\right)^{k_{n}}\left(Z^{*}\left(R^{-1}\right)\right)=1$. For $\beta>\beta_{n}$,

$$
\begin{aligned}
& \left|p^{*}(\beta)\left(H_{n}(\beta, s)\right)-p^{*}\left(R^{-1}\right)\left(\left\{\left(w^{*}(s), s\right)\right\}\right)\right|<\left|p^{*}(\beta)\left(H_{n}(\beta, s)\right)-p_{0} P\left(R^{-1}\right)^{k_{n}}\left(\left\{\left(w^{*}(s), s\right)\right\}\right)\right| \\
& +\left|p_{0} P\left(R^{-1}\right)^{k_{n}}\left(\left\{\left(w^{*}(s), s\right)\right\}\right)-p^{*}\left(R^{-1}\right)\left(\left\{\left(w^{*}(s), s\right)\right\}\right)\right| \\
& =\left|p^{*}(\beta)\left(H_{n}(\beta, s)\right)-p_{0} P(\beta)^{k_{n}}\left(H_{n}(\beta, s)\right)\right| \\
& +\left|p_{0} P\left(R^{-1}\right)^{k_{n}}\left(\left\{\left(w^{*}(s), s\right)\right\}\right)-p^{*}\left(R^{-1}\right)\left(\left\{\left(w^{*}(s), s\right)\right\}\right)\right|<\delta_{n} / 2+\delta_{n} / 2=\delta_{n},
\end{aligned}
$$

which follows from the convergence in the total variation norm given any $\beta$. Moreover, $H_{n}(\beta, s) \rightarrow\left\{\left(w^{*}(s), s\right)\right\}, \forall s \neq \bar{s}$, and $p^{*}(\beta)\left(R_{n}(\beta)\right) \rightarrow 0$ and $p^{*}(\beta)\left(H_{n}(\beta)\right) \rightarrow 1$.

We now prove that when $\Pi\left(s, s^{\prime}\right)=\pi\left(s^{\prime}\right), \forall s, s^{\prime} \in S$, if $\beta_{+}>\beta$, then $p^{*}\left(\beta_{+}\right)$FOSD $p^{*}(\beta)$. We follow a proof strategy similar to the one used in Part (i) of Proposition 5 . Define the operator $T$ as in the proof of Proposition 2. Let $\beta_{+}>\beta$ and denote variables associate with $\beta_{+}$with a subscript + . As before, $T(\overline{\mathcal{S}}) \subset \overline{\mathcal{S}}^{o} \subset \overline{\mathcal{S}}$ and analogously for $T_{+}$.

Pick $\hat{v} \in \overline{\mathcal{S}}^{o}$. We show that if $T_{+}^{n} \hat{v}_{w}(w, s) \geq T^{n} \hat{v}_{w}(w, s)$, then $T_{+}^{n+1} \hat{v}_{w}(w, s) \geq$ $T^{n+1} \hat{v}_{w}(w, s)$. Suppose $T_{+}^{n} \hat{v}_{w}(w, s) \geq T^{n} \hat{v}_{w}(w, s)$, but that $T_{+}^{n+1} \hat{v}_{w}(w, s)<T^{n+1} \hat{v}_{w}(w, s)$, and hence by the envelope condition $u_{c}\left(c_{+}\right)<u_{c}(c)$, implying that $c_{+}>c$ and $E\left[h_{+}^{\prime} \mid s\right]<$ $E\left[h^{\prime} \mid s\right]$. If so, there must exist a state $s^{\prime}$ for which $0 \leq h_{+}\left(s^{\prime}\right)<h\left(s^{\prime}\right)$ and $w_{+}\left(s^{\prime}\right)<w\left(s^{\prime}\right)$, but then

$u_{c}\left(c_{+}\right)<u_{c}(c)=\beta R T^{n} v_{w}\left(w\left(s^{\prime}\right), s^{\prime}\right) \leq \beta R T^{n} v_{w}\left(w_{+}\left(s^{\prime}\right), s^{\prime}\right)<\beta_{+} R T_{+}^{n} v_{w}\left(w_{+}\left(s^{\prime}\right), s^{\prime}\right) \leq u_{c}\left(c_{+}\right)$,

a contradiction. Hence, $T_{+}^{n+1} \hat{v}_{w}(w, s) \geq T^{n+1} \hat{v}_{w}(w, s), c_{+} \leq c$, and $E\left[h_{+}^{\prime} \mid s\right] \geq E\left[h^{\prime} \mid s\right]$.

Since $T^{n} \hat{v} \rightarrow v$ and $T^{n} \hat{v}_{w}(w, s)=u_{c}(c)$ (and analogously for $T_{+} \hat{v}$ ), and the policy functions converge, the value functions $v$ and $v_{+}$satisfy the property, too.

Note that if $\Pi\left(s, s^{\prime}\right)=\pi\left(s^{\prime}\right), \forall s, s^{\prime} \in S$, then net worth in the hedged states $w_{h}$ is constant and $E\left[h_{+}^{\prime}\right] \geq E\left[h^{\prime}\right]$ implies $w_{h+} \geq w_{h}$. In this case we can follow the proof of 
Part (i) of Proposition 4 and start at $(\bar{y}, \bar{s})$, a recurrent state, with the distribution

$$
p_{0}= \begin{cases}1 & \text { if } z=(\bar{y}, \bar{s}) \\ 0 & \text { if } z \neq(\bar{y}, \bar{s}), z \in Z^{*}(\beta) .\end{cases}
$$

Let $P(\beta)$ denote the transition matrix on the induced state space $z=(w, s) \in Z^{*}(\beta)$. Then $p_{0} P\left(\beta_{+}\right)^{k}$ FOSD $p_{0} P(\beta)^{k}$ and hence $p^{*}\left(\beta_{+}\right)$FOSD $p^{*}(\beta)$.

In the case of a symmetric two state Markov chain for income, we can solve for the stationary distribution of net worth in closed form. Specifically, say $S=\left\{s_{L}, s_{H}\right\}$ with $s_{L}<s_{H}$, and $\Pi\left(s_{H}, s_{H}\right)=\Pi\left(s_{L}, s_{L}\right) \equiv p$. We use subscripts $L$ and $H$ where convenient. Using the fact that the stationary distribution of $y$ is $(1 / 2,1 / 2)$ and that $w_{H}=y_{H}$ since the household does not hedge the highest state next period given stochastic monotonicity (see Proposition 3), $w_{L}=y_{L}+h_{L}, c_{H}=w_{H}-(1-p) R^{-1} h_{L}, c_{L}=w_{L}-p R^{-1} h_{L}$, and $c_{H}=c_{L}$, that is, full insurance, we obtain

$h_{L}=\frac{R}{R-\rho}\left(y_{H}-y_{L}\right), \quad w_{L}-w_{H}=\frac{\rho}{R-\rho}\left(y_{H}-y_{L}\right), \quad c_{H}=c_{L} \equiv c=E[y]+\frac{1}{2} \frac{r}{R-\rho}\left(y_{H}-y_{L}\right)$

where $\rho=2 p-1 \geq 0$ and $r \equiv R-1$. When income is independent over time, $p=1 / 2$ and $\rho=0$, we have $h_{L}=y_{H}-y_{L}, w_{H}=w_{L}=y_{H}$, and $c=E[y]+r / R\left(y_{H}-E[y]\right)$.

Note that $w_{L} \geq w_{H}$ and that the difference $w_{L}-w_{H}$ is increasing in the persistence $\rho$. So net worth as we defined it is higher in the low state than in the high state. To see why this is, denote the present value of income (ex current income), that is, human capital, by $P V_{s}$, and note that

$$
\begin{aligned}
P V_{H} & =R^{-1}\left(p\left(y_{H}+P V_{H}\right)+(1-p)\left(y_{L}+P V_{L}\right)\right) \\
P V_{L} & =R^{-1}\left((1-p)\left(y_{H}+P V_{H}\right)+p\left(y_{L}+P V_{L}\right)\right)
\end{aligned}
$$

which implies that $P V_{H}-P V_{L}=w_{L}-w_{H}$ or $w_{H}+P V_{H}=w_{L}+P V_{L}$, that is, total wealth, (financial) net worth plus human capital, is constant across states. When the household has low current income, his (financial) net worth is high to compensate for the reduction in present value of future labor income. When income is independent over time, the present value of future labor income is constant across states and so is the household's (financial) net worth.

To sum up, when $\beta R=1$, households are eventually unconstrained and fully insured, but their net worth remains finite, in contrast to the models with incomplete markets in which households accumulate infinite buffer stocks to smooth consumption in the limit. ${ }^{40}$

\footnotetext{
${ }^{40}$ That said, assuming $\beta R<1$, Castañeda, Díaz-Giménez, and Ríos-Rull (2003) and the subsequent literature are able to match the wealth accumulation in calibrated versions of the incomplete markets model.
} 


\section{Figure D.1: Risk and Precautionary Behavior of Hedging and Saving}

This figure displays the effect of an increase in risk on the precautionary behavior of household income risk management in our model (top two panels) and of saving in a Bewley (1977) economy with convex $u_{c}(c)$. Household income follows an independent three state Markov process with $y\left(s^{\prime}\right) \in\{y-\sigma, y, y+\sigma\}$ and $\pi\left(s^{\prime}\right)=\pi_{\sigma}, 1-2 \pi_{\sigma}$, and $\pi_{\sigma}$, respectively, with $y=1, \sigma=0.2$, and $\pi_{\sigma}$ taking the values 0 (solid (black) - deterministic case), 0.2 (dash-dotted (green)), and 0.5 (dashed (red) - two state case as in Figure 1). For our model, the top left panel displays hedging expenditures $E\left[R^{-1} h^{\prime}\right]$ and the top right panel hedging for each state next period $h\left(s^{\prime}\right)$ as a function of net worth for various values of $\pi_{\sigma}$. For the Bewley (1977) economy, the bottom left panel displays saving $h$ as a function of net worth for various values of $\pi_{\sigma}$. The other parameter values are as in Figure 1 .
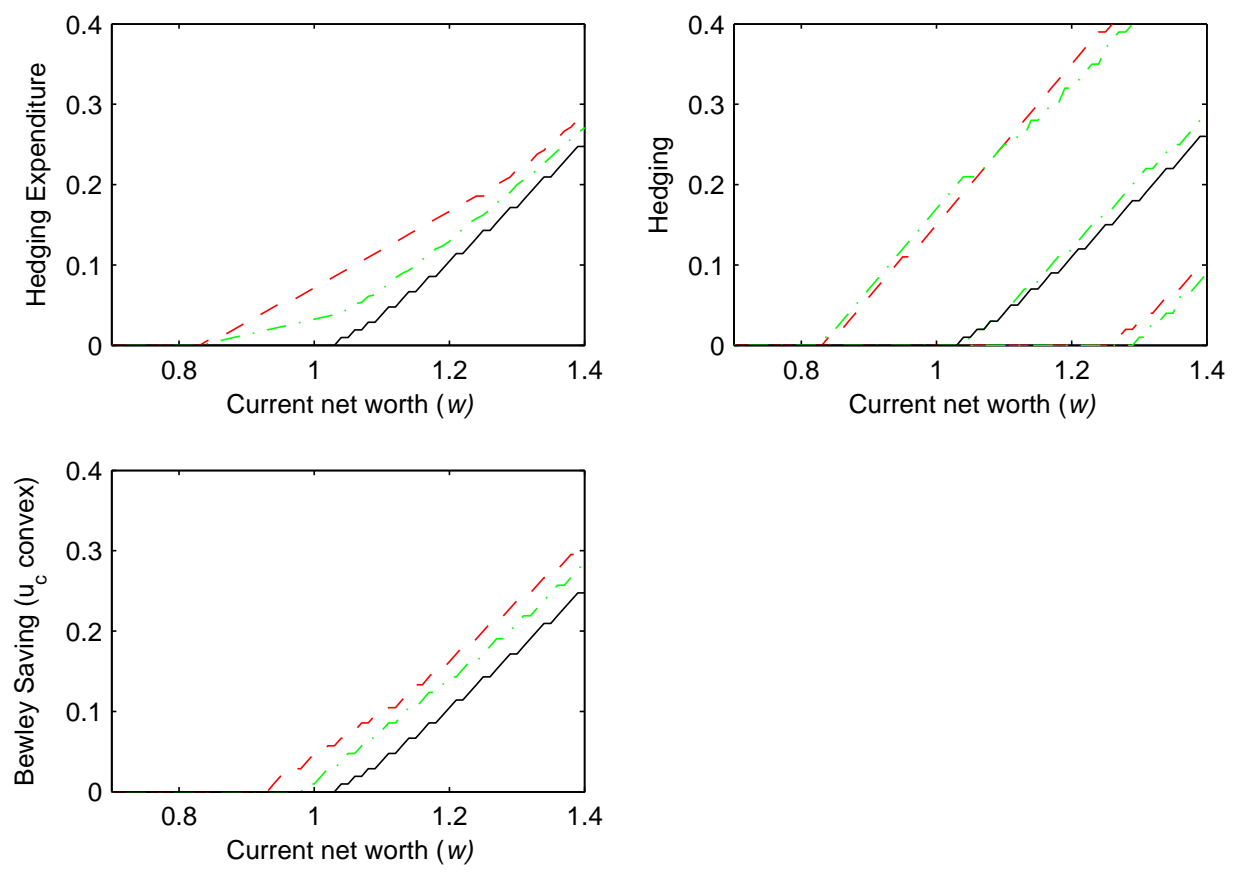